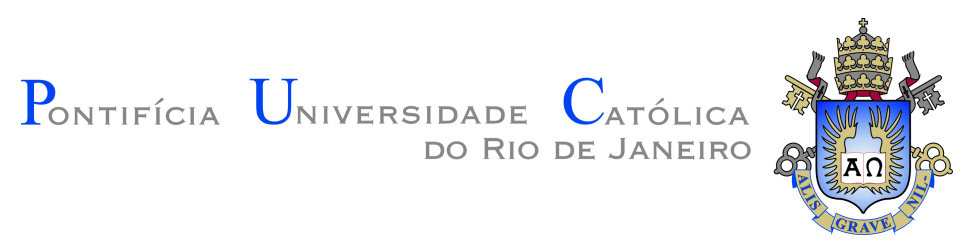

Livia Gouvea Gomes

Essays on Labor Markets

Tese de Doutorado

Thesis presented to the Programa de Pós-graduação em Economia of Puc Rio in partial fulfillment of the requirements for the degree of Doutor em Economia.

Advisor : Prof. Gustavo Gonzaga

Co-advisor: Prof. Juliano Assunção

Rio de Janeiro

April 2019 


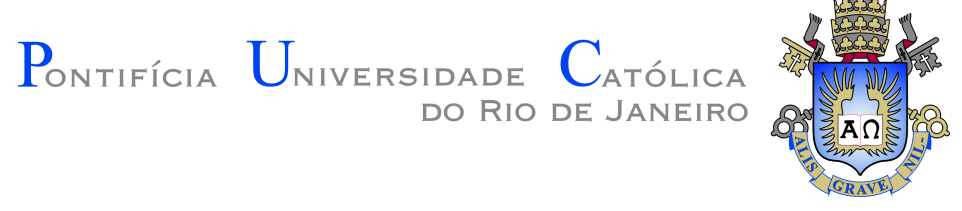

Livia Gouvea Gomes

\title{
Essays on Labor Markets
}

Thesis presented to the Programa de Pós-graduação em Economia of Puc Rio in partial fulfillment of the requirements for the degree of Doutor em Economia. Approved by the undersigned Examination Committee.

\author{
Prof. Gustavo Gonzaga \\ Advisor \\ Departamento de Economia - Puc Rio \\ Prof. Juliano Assunção \\ Co-advisor \\ Departamento de Economia - Puc Rio \\ Dr. Arthur Amorim Bragança \\ Departamento de Economia - PUC-Rio
}

Dr. Carlos Henrique Leite Corseuil

Instituto de Pesquisa Econômica Aplicada - IPEA

Prof. Claudio Abramovay Ferraz do Amaral

Departamento de Economia - PUC-Rio

Prof. Francisco Junqueira Moreira da Costa

Fundação Getúlio Vargas - FGV

Rio de Janeiro, April the 21st, 2019 
All rights reserved.

\section{Livia Gouvea Gomes}

Livia Gouvêa Gomes graduated in Economics from PUC-Rio in 2008. She received his Master's degree in Economics from PUC-Rio in 2011.

Bibliographic data

Gouvea, Livia

Essays on Labor Markets / Livia Gouvea Gomes; advisor: Gustavo Gonzaga; co-advisor: Juliano Assunção. - Rio de janeiro: Puc Rio, Departamento de Economia, 2019.

v., 109 f: il. color. ; $30 \mathrm{~cm}$

Tese (doutorado) - Pontifícia Universidade Católica do Rio de Janeiro, Departamento de Economia.

Inclui bibliografia

1. Economia - Teses - Teses. 2. Mercado de Trabalho Teses. 3. Proteção ao Emprego;. 4. Custos de Demissão;. 5. Rotatividade;. 6. Grande Investimento;. 7. Realocação do Trabalho;. 8. Demanda por Trabalho. I. Gonzaga, Gustavo. II. Assunção, Juliano. III. Pontifícia Universidade Católica do Rio de Janeiro. Departamento de Economia. IV. Título.

CDD: 330 


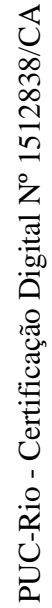

To my family. 


\section{Acknowledgments}

To my advisors Gustavo Gonzaga and Juliano Assunção, for encouraging me from the early years of undergraduate, and for the generous guidance during my Ph.D. years;

To the members of the Examination Committee, for their extremely valuable contributions;

To CNPq and CAPES Foundation Program, since this study was financed in part by the Coordenação de Aperfeiçoamento Pessoal de Nível Superior - Brasil (CAPES) - Código de Financiamento 001, and CNPq;

To my great friends Aline Biz, Maina Celidonio, Marina Palma and Vivian Malta, for all their help, advice and companionship. To my friends at World Bank, Bujana Perolli, Pedro Olinto, Tiago Negreira, and Vivian Amorin, for all stimulus in the final months;

To Anna Lucia, for teaching me so much about myself. To Paula Pedro, for being a true sister, for always being there when I needed support;

To my parents, Luzinete and Delcio, who always encouraged me in my plans, and have always prioritized my and my sister's education. To my sister Fernanda, my brother-in-law Turan, and my nephews Pedro and Rafael, at all times filling my life with joy;

To Mario Caillaux, for his love and companionship. For teaching me to see life from other perspectives than econometric models. To our canine son Bart, an affectionate partner during this years, who knew this work like no one else, and even ate some of its preliminary versions. Shortly after the defense, he considered his job done in this world, and left us with amazing memories and so much saudade. 


\section{Abstract}

Gouvea, Livia; Gonzaga, Gustavo (Advisor); Assunção, Juliano (Co-Advisor). Essays on Labor Markets. Rio de Janeiro, 2019. 109p. Tese de doutorado - Departamento de Economia, Pontifícia Universidade Católica do Rio de Janeiro.

This thesis consists of three essays on labor markets. The first chapter estimates the effect of the change in the Advance Notice Law in 2011 in Brazil. The new law made unjustified (without cause) dismissals more expensive for firms, and the cost gradually increased with tenure. Advance notice is part of the framework of employment protection legislation and is intended to preserve job contracts that, although undesirable in the short term, would be viable in the long term. However, results point to an increase in layoffs in the most affected firms and a higher turnover environment. These results are especially unfavorable considering the already high turnover rate in Brazil. I argue with a theoretical model that the design of the new law is consistent with the results because it increased not only the cost of dismissal but also the expected cost of continuity of employment. The second chapter evaluates the effects of the expansion of the ethanol mills in Mato Grosso do Sul (MS), from labor reallocation perspective. Tracking workers over the years, the analysis indicated mechanisms that enabled labor adjustment to the new labor demands generated by this large investment. I explore the reallocation across sectors, occupations, and regions. The third chapter estimates the impact of the modernization of agriculture (from the innovations of the 1970s) in Central Brazil, considering the effects on the labor force and investment decisions in education. The analysis shows that this event affected labor demand in the region, generating gains for the adult population. In this way, incentives have also changed for young people to make choices between working, with immediate job gains, and investing in human capital, and thus expect potentially higher gains in the future.

\section{Keywords}

Employment Protection; Firing Costs; Turnover; Large Investment; Labor Reallocation; Labor Demand 


\section{Resumo}

Gouvea, Livia; Gonzaga, Gustavo; Assunção, Juliano. Ensaios sobre Mercado de Trabalho. Rio de Janeiro, 2019. 109p. Tese de Doutorado - Departamento de Economia, Pontifícia Universidade Católica do Rio de Janeiro.

Esta tese é composta de três capítulos que analisam aspectos do mercado de trabalho. O primeiro capítulo estima o efeito da mudança na Lei do Aviso Prévio em 2011 no Brasil. A nova lei tornou as demissões sem justa causa mais caras para as firmas, e o aumento do custo se deu de maneira crescente no tempo de serviço do empregado. O aviso prévio é parte do arcabouço da legislação de proteção ao emprego, e tem intenção preservar vínculos que, embora não desejados no curto prazo, seriam viáveis no longo prazo. No entanto, os resultados apontam para o aumento das demissões nas firmas mais afetadas e um ambiente de maior rotatividade. Tais resultados são especialmente desfavoráveis considerando o ambiente já de elevada rotatividade no Brasil. Argumentamos com um modelo teórico que o desenho da nova lei é consistente com os resultados, na medida em que se elevou não apenas o custo de demissão, mas também o custo esperado da continuidade do vínculo empregatício. O segundo capítulo avalia os efeitos da expansão das usinas de etanol no Mato Grosso do Sul (MS), pela perspectiva de realocação do trabalho. Seguindo os trabalhadores ao longo dos períodos, encontramos mecanismos que permitiram o ajuste da mão de obra às novas demandas por trabalho geradas por este grande investimento. Exploramos as realocações entre setores, ocupações e regiões. O terceiro capítulo estima impactos da modernização da agricultura (a partir de inovações da década de 1970) no Brasil Central, considerando os efeitos na força de trabalho e nas decisões de investimento em educação. Mostramos que este evento afetou a demanda por trabalho na região, gerando ganhos para a população adulta como um todo. Dessa forma, os incentivos para os mais jovens nas escolhas entre trabalhar (com ganhos imediatos do emprego) e investir em capital humano (e esperar ganhos potencialmente mais altos no futuro) também mudaram.

\section{Palavras-chave}

Proteção ao Emprego; Custos de Demissão; Rotatividade; Grande Investimento; Realocação do Trabalho; Demanda por Trabalho 


\section{Table of contents}

1 When Firing Costs Increase Backfire: The Effects of Extending Advance Notice in Brazil $\quad 12$

$\begin{array}{ll}1.1 & \text { Introduction } \\ 1.2 & 12\end{array}$

$\begin{array}{ll}1.2 \text { Background of Advance Notice } & 15\end{array}$

$\begin{array}{ll}\text { 1.2.1 Advance Notice: a mechanism to protect employment } & 15\end{array}$

1.2.2 Labor Market Context and EPL in Brazil 18

1.2.3 The New Advance Notice in Brazil: a tenure-dependent Firing Cost 19

$\begin{array}{ll}1.3 \text { Theory and Mechanism of EPL } & 11\end{array}$

$\begin{array}{ll}\text { 1.3.1 Main Equations } & 22\end{array}$

1.3.2 Solving the model 23

1.4 Empirical Strategy 26

$\begin{array}{lll}\text { 1.4.1 The Cost of compliance } & 27\end{array}$

$\begin{array}{ll}1.4 .2 \text { Identification } & 28\end{array}$

$\begin{array}{lll}1.5 & \text { Data } & 29\end{array}$

$\begin{array}{lll}1.6 & \text { Results } & 30\end{array}$

1.6.1 Main Results 32

1.6.2 Other Types of Separations 33

1.6.3 Heterogeneous Groups 35

1.6.4 Impact on Firms 37

$\begin{array}{lll}1.7 & \text { Conclusions } & 37\end{array}$

1.8 Appendix 1: Tables 40

1.9 Appendix 2 - Heterogeneous Groups 44

1.10 Appendix 3 - Full Model 50

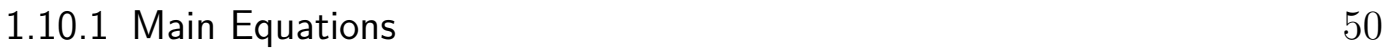

$\begin{array}{ll}1.10 .2 \text { Solving the model } & 51\end{array}$

2 Labor Reallocation in Local Economies Following Large Investments in Ethanol Mills $\quad \mathbf{5 5}$

2.1 Introduction $\quad 55$

2.2 Ethanol Mills Expansion to MT 59

2.2.1 Institutional and Geographic Context 59

$\begin{array}{ll}\text { 2.2.2 Labor Markets Context } & 61\end{array}$

2.3 Empirical Strategy 63

$\begin{array}{lll}2.4 & \text { Data } & 65\end{array}$

$\begin{array}{lll}2.5 & \text { Results } & 67\end{array}$

2.5.1 Characterizing the Shock in Labor Demand 67

2.5.2 Geographical Reallocation 68

2.5.3 Geographical Reallocation and Profile of Migrants 69

$\begin{array}{lll}2.5 .4 & \text { Reallocation across Occupations } & 71\end{array}$

$\begin{array}{lll}2.5 .5 & \text { Reallocation across Sectors } & 72\end{array}$

$\begin{array}{lll}2.6 & \text { Final Considerations } & 73\end{array}$

$\begin{array}{lll}2.7 & \text { Tables } & 75\end{array}$ 
3 Modernization of Agriculture in Central Brazil and Impacts on Human Capital Investment $\quad \mathbf{8 2}$

$\begin{array}{lll}3.1 & \text { Introduction } & 82\end{array}$

3.2 Regional and Historical Context 85

3.3 The Workforce of Central Brazil 86

$\begin{array}{ll}\text { 3.3.1 The nature of child labor } & 88\end{array}$

$\begin{array}{lll}3.4 & \text { Identification Strategy } & 91\end{array}$

3.5 Data 93

3.5.1 Data on Soybean Potential 93

3.5.2 Data on Socioeconomic Outcomes 94

$\begin{array}{lll}3.6 & \text { Results } & 96\end{array}$

$\begin{array}{ll}\text { 3.6.1 Effects on child labor market } & 97\end{array}$

$\begin{array}{ll}\text { 3.6.2 Effects on labor market - Adults } & 101\end{array}$

$\begin{array}{lll}3.7 & \text { Final Considerations } & 102\end{array}$

4 Bibliography $\quad 104$ 


\section{List of figures}

Figure 1.1 Employment Protection for Regular Contracts 17

Figure 1.2 Length of the Advance Notice Period in Countries 18

Figure 1.3 Change in the Law of Advance Notice: Timeline 20

Figure 1.4 Days of Advance Notice versus Tenure: Before and After the Change in Law $\quad 21$

Figure 1.5 Histogram Firm's Cost of Compliance 28

Figure 1.6 Main Results 33

Figure 1.7 Other Types of Separations 35

Figure 1.8 Main Results - net of potential fake lay-off 36

$\begin{array}{lll}\text { Figure 1.9 Exit Rate of Firms } & 38\end{array}$

Figure 2.1 Sugar and Ethanol Mills in MS State - Timeline 60

Figure 2.2 Proportion of FFV in the total of cars produced in Brazil 61

Figure 2.3 Proportion of Sectors in the MS Economy 62

Figure 2.4 Proportion of Sectors in the Brazilian Economy 63

Figure 2.5 Industry Presence in MS 64

Figure 2.6 Migrations Flows to MS 69

Figure 2.7 Migrations Flows from Brazil to MS 71

Figure 2.8 Migrations Flows from Brazil to MS - sub sample: skilled workers 71

Figure 2.9 Flows to Higher Skill Occupations 72

Figure 2.10 Retention in Sectors 73

Figure 3.1 Descriptive Statistics: Adult Population 87

Figure 3.2 Descriptive Statistics: Children Population 90 


\section{List of tables}

$\begin{array}{lll}\text { Table 1.1 Summary Statistics } & 31\end{array}$

Table 1.2 Main Results $\quad 40$

Table 1.3 Other Types of Separation 41

Table 1.4 Main Results - net of potential fake lay-off 42

Table 1.5 Impact on Firms' Exit Rate 43

Table 1.6 Groups of Tenure 44

Table 1.7 Groups of Wage (minimum wages of 2010) 45

Table 1.8 Groups of Education 46

Table 1.9 Groups of Skill $\quad 47$

Table 1.10 Groups of Sector $\quad 48$

Table 1.11 Groups of Firm Size 49

$\begin{array}{lll}\text { Table 2.1 General Results } & 75\end{array}$

$\begin{array}{lll}\text { Table 2.2 Migration } & 76\end{array}$

Table 2.3 Flow to MS, by culture of origin - All Workers 77

Table 2.4 Flow to MS, by culture of origin - Skilled Workers 78

Table 2.5 Flows to higher skill occupations $\quad 79$

Table 2.6 Sector Flows $\quad 80$

Table 2.7 Treated and Untreated Municipalities - Mean Comparison 81

Table 3.1 Descriptive Statistics: Comparison of annual averages in municipalities, in the highest and lowest decile of soybean potential 95

Table 3.2 Descriptive Statistics: comparison of annual averages in municipalities 96

Table 3.3 Effects on variables of schooling and labor market Children in the rural area (Probit Model) 99

Table 3.4 Effects on variables of schooling and labor market Children in the rural area (Probit Model) - cont.

Table 3.5 Effects on variables of schooling and labor market - Adults in the workforce, between 20 and 50 years old and living in the rural area 


\section{When Firing Costs Increase Backfire: The Effects of Extend- ing Advance Notice in Brazil}

\section{1 \\ Introduction}

Employment Protection Legislation (EPL) is a set of mandatory rules that aims to prevent an employment contract from being terminated by arbitrary cause. Several countries use EPL intending to improve job security. Typically, it establishes a cost, or barrier, private for the firm, and seeks the internalization of some part of the social cost of turnover. EPL seeks to preserve job contracts that, although not desirable in the short term, would be viable in the long term. A benefit from job retention would be the incentive to invest in human capital, which increases productivity (Malcomson (1999)).

Firing costs are a widely used type of EPL, and the advance notice is in this framework. When an employer decides to fire a worker without just cause, she has to provide the worker with a formal written notification stipulated in the law, which is called advance notice. The purpose of this period is to provide the employee with some time to search for a job, thus avoiding unemployment. The productivity of the notified worker is potentially low (since the firm has chosen to dismiss her) and tends to fall substantially with the notification (Heckman and Pagés (2004)). For this reason, firms typically pay the employee the wage correspondent to the period between the notification and the end of the employment contract, without requiring the employee to work during the advance notice period. In this sense, it represents a monetary transfer from the firm to the employee. The rule receives criticism from the firms, but the workers desire it. It is up to policy maker to choose an adequate level, and there is an intense discussion about the actual effects of EPL and firing costs.

This study finds empirical evidence that a tenure-dependent structure for firing costs may encourage firing, the opposite of what EPL intends. Using the change of the Advance Notice Law in Brazil in 2011, I analyze the impact of the tenure-dependent firing costs in a difference-in-differences approach. The first difference is to compare the period before and after the change in law, and the second difference explores the heterogeneity of firms' exposure to the 
cost increases. The change in Advance Notice Law not only increases a fixed firing cost but also creates a tenure-dependent firing cost: additional 3 days for each year of service provided in the same firm, up to a maximum of 60 days, totaling up to 90 days. As the additional cost has a tenure-dependent pattern, there is dispersion on how firms perceive the new rule, and the profile of each firm's workforce determines this dispersion. The new law impacts more strongly firms with a workforce profile more concentrated on high-tenure and high-wage workers than firms with labor force concentrated on low-tenure and low-wage workers.

Although the change in legislation aims to guarantee more rights to the dismissed worker, the main results indicate that changing the advance notice law encouraged dismissals. First, the results of a theoretical model show mechanisms by which this distortion can occur. In the context of tenuredependent firing costs, the firm's best response may be to fire in advance, in order to avoid higher firing costs in the future. Next, the empirical analysis, which considers the heterogeneity of the exposure of the firms to the new law, shows results compatible with the incentives seen in the model. Thus, legislation that attempted to protect employment had precisely the opposite effects: that of increasing layoffs. The empirical results show an increase in hiring as well, which is also compatible with the result of the theoretical model. Since new hires have no advance notice cost for some period, the new workers are interesting substitutes for those fired because of the new law. Summing up, incentives are in the direction of increasing turnover. The results persist for samples that ignore potential fake lay-off. Finally, there is also empirical evidence that the new law has caused an increase in the exit rate of firms.

As a sensitive issue to workers and firms, the effects of the EPL have been the subject of theoretical and empirical studies, as well as debated in the public policy arena. The seminal papers elaborate theoretical models, finding no effects of firing costs on the level of employment (Lazear (1990)), in the presence of flexible wages. However, with wage bargain, the incumbent worker is favored to the incoming worker (Bentolila and Bertola (1990)). Empirical articles also explore the theme. Much of the initial evidence came from crosscountry studies, with time series. These studies have limitations since the EPL adopted by the country is sometimes endogenous to its labor market conditions. For example, a country that has a higher rate of layoffs may choose a more rigid EPL than a country with a lower rate. In that case, an environment with more firings would be the cause, not the consequence of the EPL.

This work is more closely associated with the most recent literature, that explores variations in the EPL within countries, using discontinuities at the 
level of firms, individuals and sectors, to deal with endogeneity. There is an extensive literature on labor markets to evaluate these effects on employment, unemployment, and turnover. This literature sometimes considers heterogeneous effects between different types of employees (by tenure, wage, gender, for example) and composition issues (for example, the use of temporary contracts, more precarious, may increase). There is evidence that EPL can protect workers. Marinescu (2009) analyzes the impact of increasing job protection for workers with low tenure in the United Kingdom. She finds that the firing hazard for these workers decreased, and firms are making more considerable efforts in recruiting. However, there is also evidence that higher firing costs can affect the ability to reallocate jobs, reducing both hiring and firing. Kugler and Pica (2008) find that an increase in firing costs in Italy decreased both hiring and firing for workers in firms affected, with a negligible impact on net employment. Besides, they find a reduction in firms' entry rates and no effect on exit rates. Kugler (1999) examines the impact of the reduction of firing costs in Colombia, finding that exit hazard rates into and out of unemployment increased. Kugler and Saint-Paul (2004) show that increasing firing costs in the US made firms more likely to hire employed workers (less likely to be lemons).

In another direction, some studies show that increases in firing costs may not mean protection for workers. Hijzen, Mondauto, and Scarpetta (2013) show that more restricted EPL increases worker reallocation in Italy, suggesting that it reduces rather than increase worker security on average. This effect happens because firms facing more stringent EPL make greater use of temporary workers. That is, there are heterogeneous effects, when it protects workers with regular contracts, but promotes more significant use of contracts in more precarious conditions: temporary contracts. In the line of research that tries to understand how EPL affects different groups, Leonardi and Pica (2013) find that a slight average wage reduction induced by increasing in EPL in Italy hides heterogeneous effects. The negative impact is stronger for young blue collars workers, low-wage workers, workers in low-employment regions and workers who change of firm during the reform period.

There is also literature dealing with differences in local enforcement. Autor (2003) assesses the contribution of 'unjust firing' doctrine to temporary employment in the US. Courts in states adopted exceptions to the common law doctrine of employment at will, which limited employers' discretion to terminate a job contract and exposed them to litigation. Empirical strategy explores the timing in each state adopts these exceptions. Fraisse, Kramarz, and Prost (2014) use variations in local conditions of the activity of the labor courts to assess the effect of firing costs on the French labor market. Gianfreda 
and Vallanti (2017) exploit the variation in the length of labor trial across Italian judicial districts. Boeri and Jimeno (2005) assess the effects of EPL on firing probabilities and the equilibrium size distribution of firms, exploiting variation in enforcement.

Firing costs (and EPL in general) can lead to some distortions in the labor market. Since they reduce the expected profit from an employment contract, higher firing costs may discourage new hires (Cahuc, Carcillo, and Zylberberg (2014) and Bertola (1991)). There are also potential distortions associated with the segmentation between contract types or employees profiles: those covered by protection tend to benefit, and those not covered face more precarious employment conditions. Firing costs can also limit firms' reallocation and adjustment channels in the face of new demands and new technologies, and lead to potential inefficiencies (Blanchard and Katz (1997)).

This study also finds adverse effects of a stricter EPL. However, this case is peculiar in which, even the workers who would be covered by the protection, suffer negative consequences. The design of the new notice law creates nonobvious impacts. A change of legislation that makes the firing cost increase in the tenure creates an ambiguity: while it makes the firing of a worker more expensive, it makes the continuity of this contract even more expensive, since the firing cost in subsequent years will be even higher. It is not clear that the New Advance Notice Law generates incentives for the maintenance of employment contracts. On the contrary, the results point to an increase in firing, hiring and, consequently, turnover.

The rest of this work is organized as follows. Section 1.2 gives some institutional background on advance notice and explain its general motivation and application in Brazil. Section 1.3 explains the mechanism of advance notice and the expected impact of the reform in firms ${ }^{1}$. Section 1.4 discusses the empirical strategy, and section 1.5 presents the data sources used in this study. Section 1.6 presents the main results and comments potential heterogeneous results $^{2}$. Section 1.7 presents conclusions.

\section{2 \\ Background of Advance Notice}

\subsection{1}

\section{Advance Notice: a mechanism to protect employment}

When an employer decides to fire a worker without just cause, she has to provide the worker with a formal written notification stipulated in the law,

\footnotetext{
${ }^{1}$ Section 1.10 - Appendix shows a more detailed version for the model.
}

${ }^{2}$ Complete tables are in section 1.8 and 1.9 
which is called advance notice ${ }^{3}$. The purpose of this period is to provide the employee with some time to search for a job, thus avoiding unemployment ${ }^{4}$. Firms typically pay the employee the wage correspondent to the period between the notification and the end of the employment contract, without requiring the employee to actually work during the advance notice period. In this sense, advance notice is a type of firing monetary cost for the firm measured by the number of advance notice wages the firm pays the employee. This approach makes sense because the productivity of the notified worker is potentially low (since the firm has chosen to dismiss her) and tends to fall substantially with the notification (Heckman and Pagés (2004)). Therefore, the greater the advance notice required, the higher the firing cost.

Firing costs as advance notice are a widely used type of employment protection legislation (EPL). To increase employment stability, the EPL makes the decision of firing more difficult or costly to the firm. It typically establishes a monetary cost or barriers for the firm, that seeks the internalization of some part of the social cost of turnover, and prevents an employment contract from being terminated by arbitrary firing. The idea is not to completely prevent termination of a contract, but to preserve those that may become profitable again in the long run, although not desirable in the short term. With job retention, there is also an incentive to invest in human capital (Malcomson (1999)).

The OECD Index - Indicators of Employment Protection measures the level of employment protection in 45 countries, with zero representing a very flexible labor legislation and six meaning a stricter legislation. This index considers the length of the advance notice period, the length of the trial period and the possibility of reinstatement of workers following unfair dismissals, for example. Brazil appears in 14th place in the last available data (2012) with an index of 1.84, somewhat more rigid than before the change of the advance notice law (when it was in 12th place, with an index equal to 1.75), but still presenting a more flexible labor market than the average of the countries (Figure 1.1).

Considering the categories related to the advance notice, however, Brazil shows some aspects of greater rigidity. Three indices are measuring the length of the advance notice: for employees at nine-months tenure, at four-years tenure and at twenty-years tenure. For each category, the country receives a score

\footnotetext{
${ }^{3}$ Employees sometimes also need to provide advance notice when they quit. This will not be relevant in our paper.

${ }^{4}$ There may be moral hazard in this process, and the employee can use all of the advance notice time because the firm can not monitorate job search. Thus, although the severance pay may be optimal, the delay in termination of the contract does not (Pissarides (2010)
} 
Figure 1.1: Employment Protection for Regular Contracts

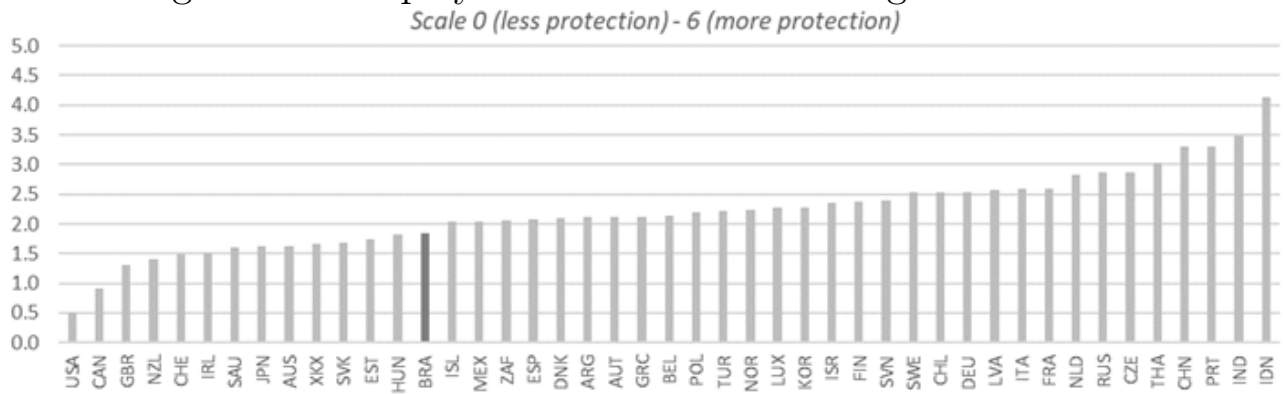

Note: OECD Indicators of Employment Protection, Index 2012. The OECD indicator of employment protection legislation is a synthetic indicator of the strictness of regulation on dismissals and the use of temporary contracts, and is available on http://www.oecd.org/employment.

between 0 and six, in which 0 reflects a less protected environment and six reflects a more protected. It is not possible to know precisely the position of Brazil among the 45 countries, as there are several countries with the same score. However, we can have an approximate idea of Brazil's position in each category. Figure 1.2 shows, for each tenure, the distribution of countries in the six categories, and the indication of the note that Brazil receives in 2012 (after the change of law). For low tenures (at nine months) Brazil is more flexible than the average of the countries, but for medium and high tenure the legislation is more rigid. For tenures at four years, Brazil receives a grade 3, before grade 2 in 2011 and earlier. For tenure at 20 years, Brazil has a grade 2, before grade 1 in 2011 and earlier. At nine-month tenure, the index has not changed.

There are three relevant aspects. First, change in advance notice legislation has generated more rigidity for layoffs of higher tenure employees. Second, the current level is more restrictive than the average for countries. Finally, although employees with higher tenure have more protection than employees with low tenure in several countries, Brazil's relative positions suggest greater heterogeneity in the treatment of workers than in other countries.

In the methodological description of the index, it is possible to see details of the advance notice legislation in the countries surveyed. It is common in some countries that workers with higher tenure are more protected, with longer duration on advance notice. However, there are typically a few thresholds over the years, when the worker earns more rights. The design of the new Brazilian legislation, in which advance notice is entirely tenure-dependent, increasing every year, is very peculiar and will be discussed in the next subsection. 
Figure 1.2: Length of the Advance Notice Period in Countries

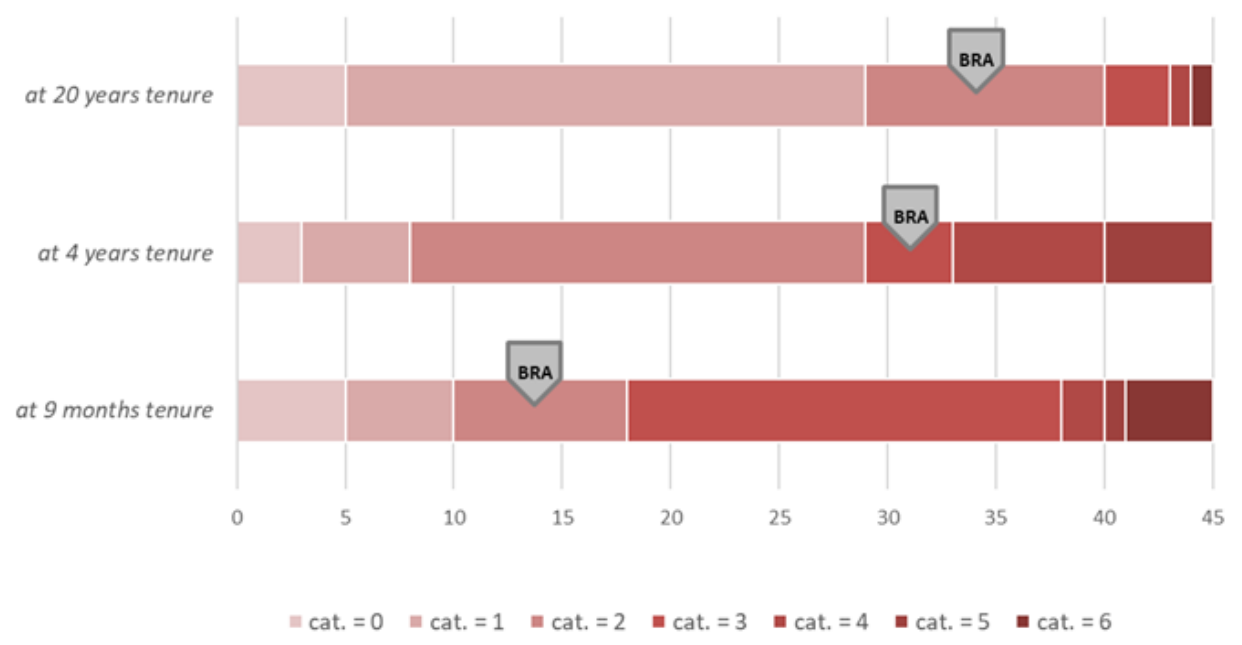

Note: OECD Indicators of Employment Protection, Index 2012. Category equal to 0 means a less protected labor market, and category equal to six means a more protected. http://www.oecd.org/employment.

\subsection{2}

\section{Labor Market Context and EPL in Brazil}

The Brazilian labor market is characterized by low duration job contracts and very high job turnover (Corseuil, Ribeiro, et al. (2002), Menezes-Filho and Fernandes (2004), Pinto (2015)). These aspects may generate disincentives for investment in human capital of workers, with adverse effects on productivity (Corseuil and Servo (2006)). In this context, Brazil has several EPL, and the evaluation of its effectiveness is of great importance.

Private firms in Brazil are allowed to fire employees without justification ${ }^{5}$, if they pay some monetary compensations. Such compensations, however, may represent important constraints for firms. The magnitude and design of compensation for dismissals have particularities.

The labor legislation in Brazil has important mechanisms to protect employment. The rules, however, do not appear to be sufficient to reduce layoffs and turnover and increase the average tenure of workers. In fact, several authors argue that the design of some employment protection programs creates perverse incentives that encourage turnover .

Previous studies have warned that the design of FGTS induces dismissal because getting fired is the primary way to access FGTS funds (Macedo (1985), Amadeo and Camargo (1996), Gonzaga (1998), Barros, Corseuil, and Foguel (2000), Gonzaga (2003)). The fund's profitability, which is managed

\footnotetext{
${ }^{5}$ There are some exceptions, in workers can enjoy momentary stability. These exceptions apply to workers returning from medical leave (caused by work-related accidents) and pregnant workers or workers who have given birth within the last five months. Elected unions representatives also enjoy stability.
} 
by the government, is generally below market rates. Therefore it would be more profitable for the worker to have access to values and to invest it more efficiently. Also, much of the fine paid by the employer goes directly to the employee, which makes a false termination agreement feasible ${ }^{6}$. All these characteristics generate perverse incentives and create turnover (Gonzaga (2003)).

Also, the design of the new law of advance notice in Brazil possibly is another source of distortions. Advance notice in Brazil was instituted in 1943 in CLT, as thirty days of work (or equivalent in wage and benefits). In 2011, advance notice increases by 3 days for each year of service provided in the same firm, up to a maximum of 60 days, totaling up to 90 days. Firms can avoid firing costs for the first three months of the employment contract, the so called probationary period. The advance notice is the focus of this work, and the next subsection will give more details, exploring this discontinuity of the law in 2011.

\subsection{3}

\section{The New Advance Notice in Brazil: a tenure-dependent Firing Cost}

CLT instituted the Advance Notice in Brazil on May 1, 1943 (see timeline in Figure 1.3). Employees with one year or more of service in a particular firm have thirty days' work of advance notice if the firm decides to fire without just cause. Therefore, when the firm decides to fire an employee without just cause, it must notify her 30 days before. Once notified, the worker has reduced her working day by $25 \%$ (daily or weekly) and use this time to search another job. An alternative used by the firm is to pay the wage for that period and dismiss the worker immediately (Barros, Corseuil, and Foguel (2000) e Gonzaga (2003)).

The 1988 Constitution introduced the concept of proportionality in advance notice, without defining how it would be applied. Several initiatives have attempted to establish criteria for proportionality.

Only on October 11, 2011, the New Advance Notice Law was amended, with the precise definition of proportionality. With the change of law, advance notice increases three days for each year of service provided in the same firm, up to a maximum of 60 days, totaling up to 90 days. Figure 1.4 shows days of advance notice, by tenure, before and after the change of the law. The change was different for workers and consequently for firms. The change affects costs

${ }^{6}$ The fake lay-off consists of the firm firing the employee (who so has access to the FGTS), and be informally reimbursed the fine paid for the dismissal. After a certain period, the same firm hires the same worker. 
Figure 1.3: Change in the Law of Advance Notice: Timeline

\begin{tabular}{|c|c|c|}
\hline 1943 & - Advance Notice Law (Labor Law Consolidation - CLT) & - 30 days \\
\hline \multirow[t]{2}{*}{1988} & - Constitution of 1988 & $\begin{array}{l}\text { - Proportional to the time of } \\
\text { service. Minimum of } 30 \text { days. }\end{array}$ \\
\hline & (several bills trying to regulariz & tionality) \\
\hline 2011 & - Law 12.506 & $\begin{array}{l}\text { - New Avance Notice Law. } \\
\text { Regulates proportionality. } \\
\text { Additional } 3 \text { days for each year } \\
\text { of work in the same firm. }\end{array}$ \\
\hline
\end{tabular}

only for firms, that is, if a worker quits, she will not incur in the additional cost $^{7}$.

It is common for EPL to protect workers differently, according to specific characteristics, to minimize some of their distortions. A probationary period, in which there are no firing costs, would give the employer time to know the employee better, and to learn about the quality of the match (Marinescu (2009) shows the effects of changes in the probationary period). EPL policies conditional on tenure are common in several countries. Some countries stipulate different advance notice policies according to different ranges of tenure. The change in the advance notice legislation in Brazil, by contrast, did not change the probationary period nor established different thresholds. It designed a protection linear in tenure, and the net effect is ambiguous.

The longer the job contract, the higher the additional protection worker will receive. On the one hand, this is a system that makes sense when we think that it punishes less dismissals of individuals with little tenure, which match quality the firm is still learning. Analogously, it punishes more severely dismissals of those workers who have already been in the firm for a long time and possibly contribute considerably to the firm's profits (otherwise they would have already been fired earlier). The older worker tends to be the one who has the most difficulty in relocating to the labor market, since much of her stock of human capital is specific to the activities in the firm, and therefore would need protection.

On the other hand, while it makes the firing of a worker more expensive, it makes the continuity of her contract even more expensive, since the firing

${ }^{7}$ There was uncertainty at the time of the law, about whether the employee should also provide advance notice to the firm. There were also doubts on whether the law was retroactive to those fired up to 24 months before the passage of the law. Later, the government denied these two possibilities. 
Figure 1.4: Days of Advance Notice versus Tenure: Before and After the Change in Law

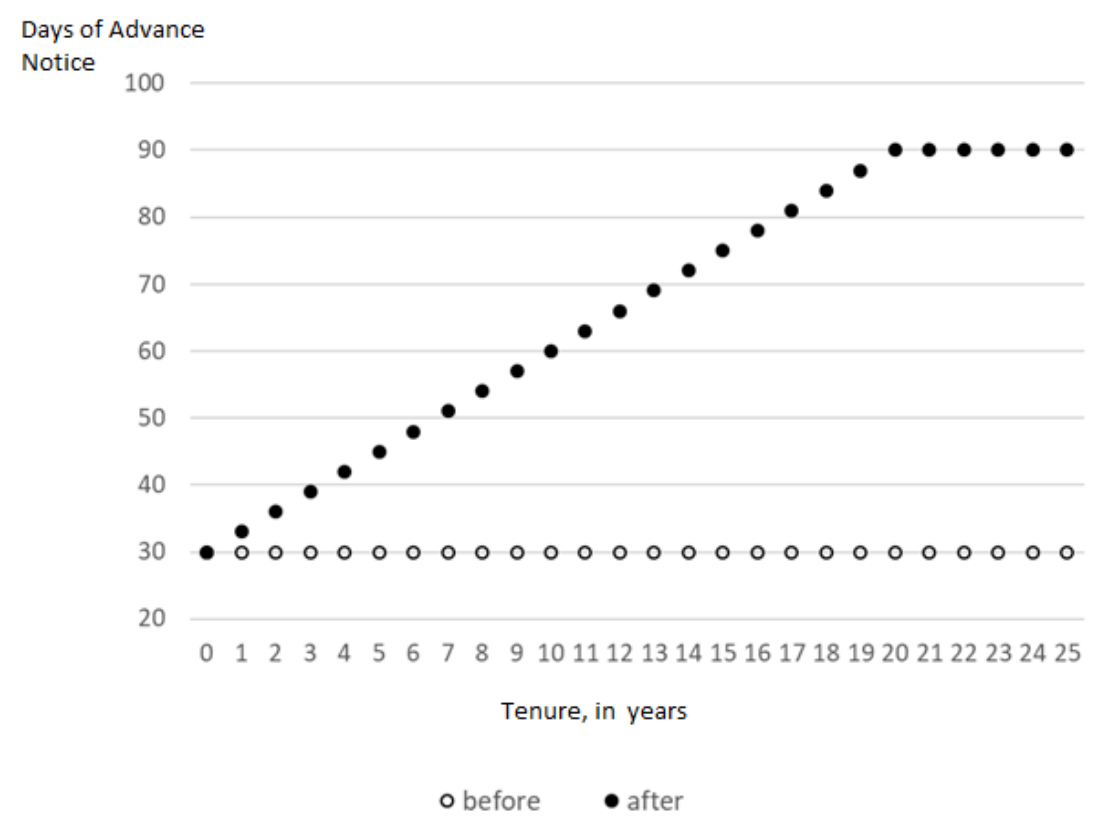

cost in next year will be higher, and each year the cost will increase more and more. For this reason, the new legislation may be an incentive to fire on the current moment in order to avoid rising costs in the future. It is not clear if the New Advance Notice Law generates incentives for the maintenance of employment contracts, as intended. On the contrary, it carries an adverse incentive: to fire the employee before she becomes more expensive.

\section{3}

\section{Theory and Mechanism of EPL}

Firing costs, such as advance notice, are typical instruments of EPL. The objective is to make more difficult or expensive to fire a worker. Its purpose is to protect the termination of an employment contract that is not desirable in the short term, but which may be feasible in the long run. In theory, the mechanism operates reducing reservation productivity of the worker. Reservation productivity is the minimum value of productivity in which a work contract is profitable for the firm. Below this value, the firm fires the worker.

Matching models typically find a negative relationship between firing costs and reservation productivity. That is, the higher the firing cost, the fewer firms fire. However, in general, they consider a fixed value for those costs. In the new Brazilian Advance Notice Law, firing costs became increasing in the tenure of the worker. In this circumstance, the impacts of an increment in firing 
costs are ambiguous. On one hand it is more expensive to fire an employee but, on the other hand, it is also more expensive to keep this employee and take the risk of eventually firing her in the future. So, it is possible that the net effect of a tenure-dependent firing cost in reservation productivity is positive.

The model below illustrates this trade-off and is useful to analyze the impacts of the new advance notice law. The model is based on Cahuc, Carcillo, and Zylberberg (2014), and is structured as follows: $\varepsilon$ is the individual productivity, with support $\left(-\infty, \varepsilon_{u}\right]$, and cumulative distribution function $G($.$) .$ As in Cahuc, Carcillo, and Zylberberg (2014), productivity $\varepsilon$ varies according to a Poisson process, with parameter $\lambda$. This means that productivity changes with a probability $\lambda d t$ over an interval of time $d t$. Shocks are idiosyncratic, affecting each job independently. The next subsections present a short version of the model, and Appendix 1.10 present the full model.

\subsection{1}

\section{Main Equations}

The expected profit from a filled job at stationary equilibrium is:

$$
\Pi_{e}(\varepsilon)=\frac{1}{r+\lambda}\left[\varepsilon-w+\lambda \Pi_{\lambda}\left(\varepsilon^{\prime}\right)\right]
$$

In equation $1-1, \Pi_{\lambda}\left(\varepsilon^{\prime}\right)$ is the expected profit when a productivity change occurs (changing from $\varepsilon$ to $\varepsilon^{\prime}$ ), $w$ is the wage and $r$ is the discount rate. When a shock in productivity occurs, there are two possible consequences: the new productivity remains at a level that is still advantageous for the firm to retain the employee, or the new productivity goes to a level in which is more profitable to fire the employee. Consider reservation productivity $\left(\varepsilon_{d}\right)$ as a productivity value below which it is more profitable for the firm to fire the employee. So, when a shock in productivity occurs, there are two possible scenarios: if the new productivity $\varepsilon^{\prime}$ is such that $\varepsilon^{\prime}<\varepsilon_{d}$, the firm fires the worker and incurs in firing costs; if $\varepsilon^{\prime}>\varepsilon_{d}$ firm keeps the worker on the job, and the expected profit amounts to $\Pi_{\lambda}\left(\varepsilon^{\prime}\right)$. The average expected profit $\Pi_{e}\left(\varepsilon^{\prime}\right)$ if a productivity shock occurs is:

$$
\Pi_{\lambda}\left(\varepsilon^{\prime}\right)=\int_{-\infty}^{\varepsilon_{d}}-E[F]+\Pi_{\nu} d G(\varepsilon)+\int_{\varepsilon_{d}}^{\varepsilon_{u}} \Pi_{e}\left(\varepsilon^{\prime}\right) d G(\varepsilon)
$$

In equation 1-2, $E[F]$ is the expected firing cost that the firm incurs. The firm just knows the current firing cost for a employee, but in the event of a future shock it only has an expectation of this value, $E[F]$.

\section{Reservation productivity}


We define reservation productivity $\left(\varepsilon_{d}\right)$ as the level of productivity below which it is more profitable for a firm to fire the worker than to continue with the employment contract. In each period, a firm fires if:

$$
\Pi_{e}(\varepsilon)<-F+\Pi_{\nu}
$$

$\Pi_{\nu}$ is the value of the vacant job. With free entry, $\Pi_{\nu}=0$. There is $\varepsilon_{d}$ such $\Pi_{e}\left(\varepsilon_{d}\right)=-F$. Using equation 1-1 and considering a particular productivity value as $\varepsilon=\varepsilon_{d}$ :

$$
\Pi_{e}\left(\varepsilon_{d}\right)=\frac{1}{r+\lambda}\left[\varepsilon_{d}-w+\lambda \Pi_{\lambda}\left(\varepsilon^{\prime}\right)\right]=-F
$$

and

$$
\varepsilon_{d}=w-(r+\lambda) F-\lambda \Pi_{\lambda}\left(\varepsilon^{\prime}\right)
$$

\section{Firing costs}

This model differs from the baseline (Cahuc, Carcillo, and Zylberberg (2014)) in the structure of firing costs. While models typically use a fixed firing cost, as a lump sum, our model explores an additional tenure-dependent firing cost.

- Baseline model (fixed firing costs): $F=\bar{f} \rightarrow E[F]=\bar{f}$

- Our model (tenure-dependent firing costs): $F=\bar{f}+f T \rightarrow E[F]=$ $\bar{f}+f E[T]$, and $T$ represents the duration of the employment contract (tenure).

\subsection{2}

\section{Solving the model}

Using equation 1-4, we can show after some algebra:

$$
\Pi_{e}\left(\varepsilon^{\prime}\right)=\frac{\varepsilon^{\prime}-\varepsilon_{d}^{\prime}}{r+\lambda}-E[F]=\frac{\varepsilon^{\prime}-\varepsilon_{d}^{\prime}}{r+\lambda}-(\bar{f}+f E[T])
$$

The tenure is known in the current period, however, in the event of a future shock (like in equation 1-6), the future tenure is not defined, but an expected value, $E[T]=\bar{T}+E[\Delta T] . E[\Delta T]$ is closely related to the duration of the productivity shock. Starting from a productivity $\varepsilon$, the expected time for a productivity shock (that changes $\varepsilon$ to $\varepsilon^{\prime}$ ) is the same incremental time in the tenure, $E[\Delta T]$. Assuming that productivity $\varepsilon$ follows a Poisson process, and knowing its distribution, it is easy to find $E[\Delta T]$ :

$$
E[\Delta T]=\int_{0}^{\infty} \tau \lambda e^{-\lambda \tau} d \tau=\frac{1}{\lambda}
$$


The ratio $\frac{1}{\lambda}$ is time independent, representing the average shock duration. $\frac{1}{\lambda}$ is the time necessary to wait for a change in productivity and, in the same way, $\frac{1}{\lambda}$ is the value the tenure is expected to increase, until this shock.

Using equation 1-7, equation 1-6 becomes:

$$
\Pi_{e}\left(\varepsilon^{\prime}\right)=\frac{\varepsilon^{\prime}-\varepsilon_{d}^{\prime}}{r+\lambda}-\left(\bar{f}+f \bar{T}+f \frac{1}{\lambda}\right)
$$

Equation 1-8 helps to define the expected profit when a productivity change occurs $\left(\Pi_{\lambda}\left(\varepsilon^{\prime}\right)\right)$ in equation 1-2:

$$
\Pi_{\lambda}\left(\varepsilon^{\prime}\right)=-\left(\bar{f}+f T+\frac{f}{\lambda}\right)+\frac{1}{r+\lambda} \int_{\varepsilon_{d}}^{\varepsilon_{u}}\left(\varepsilon^{\prime}-\varepsilon_{d}^{\prime}\right) d G(\varepsilon)
$$

Equation 1-9 and equation 1-5 define the reservation productivity $\left(\varepsilon_{d}\right)$ :

$$
\varepsilon_{d}=w-r \bar{f}+f(1-r \bar{T})-\frac{\lambda}{r+\lambda} \int_{\varepsilon_{d}}^{\varepsilon_{u}}\left[\varepsilon^{\prime}-\varepsilon_{d}^{\prime}\right] d G(\varepsilon)
$$

If $f=0$, equation 1-10 would become the same as the fixed-cost baseline model in Cahuc, Carcillo, and Zylberberg $(2014)^{8}$.

\section{Firing Costs and Reservation Productivity}

This model allows two kinds of firing costs: fixed firing costs $(\bar{f})$ and tenure-dependent firing costs $(f)$. Adjusts in each of them have different impacts on reservation productivity.

- Fixed firing costs: $\frac{\partial \varepsilon_{d}}{\partial f}=-r<0$

- Tenure-dependent firing costs: $\frac{\partial \varepsilon_{d}}{\partial f}=1-r \bar{T}$.

In the absence of tenure-dependent firing costs $(f=0$, as in the baseline model), equation 1-10 shows that reservation productivity is lower than wage. It means that for values of productivity close to reservation productivity, the firm may suffer a loss in the current period. Two reasons justify this decision: if the firm fires, it incurs in firing costs $\bar{f}$, if it doesn't fire, it is possible that in the future it will be compensated for this current loss through an increase in worker productivity (which comes from $\lambda \Pi_{\lambda}\left(\varepsilon^{\prime}\right)$ ). This result is a phenomenon

\footnotetext{
${ }^{8}$ It is important to note that the reserve productivity $\varepsilon_{d}$, in equilibrium, is a function of the current tenure $\bar{T}$, that is, a known and determined value.
} 
known as labor hoarding: the (fixed) firing costs incentive firm to keep workers during slowdowns, anticipating future profits when recovery occurs.

A tenure-dependent firing costs $(f)$ decrease the size of labor hoarding, and can even eliminate it. The intuition behind it is that tenure-dependent firing costs represent a potential cost in waiting for recovery because if it does not happen, the future firing cost will be higher. In other words, not only the firing cost increased, but also the cost of retaining the worker did.

A firm fires an employee when a shock changes her productivity ${ }^{9}$, which happens at a rate $\lambda$, and the new productivity value is below reservation productivity $\left(\varepsilon^{\prime}<\varepsilon_{d}\right)$, which happens with probability $G\left(\varepsilon^{\prime}\right)$. Therefore, a filled job is destroyed at a rate $q=\lambda G\left(\varepsilon^{\prime}\right)$. Differentiating equation 1-10 with respect to firing costs $f$ and $\bar{f}$, implications on job destruction are:

- Fixed firing costs: $\frac{\partial q}{\partial f}=\frac{\partial \lambda G\left(\varepsilon_{d}\right)}{\partial \bar{f}}<0$

- tenure-dependent firing costs: $\frac{\partial q}{\partial f}=\frac{\partial \lambda G\left(\varepsilon_{d}\right)}{\partial f}>0$, if $1>r \bar{T}$

Hence, while an increase in fixed firing costs lowers the reservation productivity and consequently lowers firing, an increase in tenure-dependent firing costs may increase the reservation productivity and consequently may increase firing. An increase in the tenure-dependent firing costs only protects workers with very high tenure.

\section{Labor Market Tightness}

Different patterns of firing costs can generate different impacts not only on firing but also on hiring. Considering $h$ as costs arising from the search for a worker, the value of a vacant job is:

$$
r \Pi_{v}=-h+m(\theta)\left[\Pi_{e}\left(\varepsilon_{u}\right)-\Pi_{v}\right]
$$

As standard in the literature, consider the measure of labor market tightness $\theta$ as the ratio between the number of vacant jobs $(V)$ and the number of unemployed people $(U) \cdot m(\theta)$ is the probability of filling a vacant job per unit of time ${ }^{10}$. When the free entry condition is satisfied $\left(\Pi_{v}=0\right)$, this relation entails $\Pi_{e}\left(\varepsilon_{u}\right)=\frac{h}{m(\theta)} 11$. Setting $\varepsilon=\varepsilon_{u}$ in equation 1-8 defines the labor market tightness $\theta$.

\footnotetext{
${ }^{9} \mathrm{It}$ is the only source of variation in incentives.

${ }^{10}$ from matching models, $m(\theta)=\frac{M(V, U)}{V}, V$ is the number of vacant jobs, $U$ is the number of unemployed people, and $M(V, U)$ is a matching function that represents the instantaneous flow of hires at a given date. $M(V, U)$ is assumed to be strictly increasing with respect to each of its arguments.

${ }^{11}$ The lifespan of a filled job always starts at the maximum value $\varepsilon_{u}$, as in Cahuc, Carcillo, and Zylberberg (2014)
} 
Considering that tenure $\bar{T}=0$ for a just hired worker, and the existence of a probationary period when firing costs doesn't apply $(f=\bar{f}=0)$, firing costs does not affect the expected profit for a new job $\Pi_{e}\left(\varepsilon_{u}\right)$. Firing costs do not affect $\theta\left(\frac{\partial \theta}{\partial f}=0\right)$, neither the exit rate of unemployment $\theta m(\theta)\left(\frac{\partial \theta m(\theta)}{\partial f}=0\right)$. It implies that the number of vacant jobs $V$ does not change with $\bar{f}$.

Considering $n$ the growth rate of the labor force, standard matching models determine that in equilibrium the unemployment rate is:

$$
u=\frac{q+n}{\theta m(\theta)+q+n}
$$

In equation 1-12, $u=\frac{U}{N}, U$ is the number of unemployed people and $N$ is the number of people in the labor force. As firing costs affect only $q\left(\frac{\partial q}{\partial f}>0\right)$, so $\frac{\partial u}{\partial f}>0$. Because $U$ increases and $V$ does not change with $f$, the instantaneous flow of hires $M(V, U)$ increases with $f$. Summing up, in an opposite way to the results of fixed firing costs, the tenure-dependent cost pattern combined with a probationary period causes increasing of both firing and hiring.

\section{4}

\section{Empirical Strategy}

The New Advance Notice Law in Brazil in 2011 has increased employment protection. Firing costs increased, and assumed a tenure-dependent structure. I analyze the impact of this change in firing, hiring, and turnover, in a differencein-differences approach. The first difference is temporal and considers the periods before and after the new law of 2011. The second difference explores the heterogeneity of firms' exposure to cost increases. As the additional cost has a tenure-dependent pattern, there is dispersion on how firms perceive the new rule.

The profile of each firm's workforce determines this dispersion. After the change of law, a firm that considers firing a low-wage and a low-tenure employee does not have a substantial incentive to change. However, if the firm considers the firing of a high-tenure and high-wage worker, the additional cost is more relevant. Thus, the new law impacts more strongly firms with a workforce profile more concentrated on high-tenure and high-wage workers than firms with labor force concentrated on low-tenure and low-wage workers. Considering that the new law is from 2011, the profile of the firm's workforce at the beginning of this year will be a measure of the firm's cost of compliance with the new law, $C C_{f}$.

Equation 1-13 summarizes our identification strategy, that combines $C C_{f}$ with years dummies. The idea is to analyze the change of the firms' choices, 
before and after the new law, considering their degree of exposure to the new rules.

$$
Y_{f t}=X_{f t}^{\prime} \alpha+\rho * Z_{f}+\sum_{\tau=2006}^{2013}\left(\rho_{\tau} * I_{\tau}\right)+\sum_{\tau=2006}^{2013}\left[\beta_{\tau}\left(C C_{f} * I_{\tau}\right)\right]+\epsilon_{f t}
$$

Equation 1-13 is at firm level, where $f$ indexes firms and $t$ each year. $Y_{f t}$ it the outcome of interest (firing, hiring, turnover, firm exit) and $C C_{f}$ is the treatment (the level of the cost of compliance, that is, the degree of firm exposure to the new rules). $I_{\tau}$ represents year fixed effects and $Z_{f}$ represents firm fixed effect. $X_{f t}$ is a vector of firm characteristics that change over the years (age of the firm, for example).

$\beta_{\tau}$ 's are the coefficients of interest, representing the additional tenuredependent costs impact. This strategy results in a $\beta_{\tau}$ coefficient for each year, i.e., the impact of having a higher compliance cost on the variable of interest in each different year, between 2006 and 2013. As the change occurs in 2011, if it has an impact, one would expect that $\left|\beta_{\tau}\right|>0$, for $\tau \geq 2011$.

\subsection{1 \\ The Cost of compliance}

The cost of compliance is a measure of the firm's exposure to the new cost structure of the advance notice. $C C_{f}$ is the amount that the firm would pay (in wages $^{12}$ ) if it had to fire all its employees, considering the new rule, less what it would pay considering the old rule. In other words, it is the calculation of the additional value the firm would pay if it had to fire its workforce. This value is seen in relative terms to the firm's payroll, and considers the workforce's characteristics at the beginning of 2011, before the change in the law. Equation 1-14 show the cost of compliance, $C C_{f}$.

$$
C C_{f}=\frac{\text { change in potential total cost with advance notice }}{\text { payroll }}
$$

First, the additional cost per worker is increasing in tenure. Thus, a worker with one year tenure has an increase of 3 days of notice, a growth of $10 \%$ over the original cost (30 days). A worker with 20 years of tenure will have an increase of 60 days of advance notice, which represents a $200 \%$ increase. Therefore, firms with more employees with high tenure will have a higher cost of compliance. Besides, the cost of the advance notice is in terms

\footnotetext{
${ }^{12}$ After the advance notice of firing, productivity typically declines substantially, and advance notice can also mean a firing cost (Heckman and Pagés (2004)).
} 
of wage ${ }^{13}$. Thus, for the same tenure, a higher paid employee will represent a higher additional cost to a firm than a lower paid employee. Figure 1.5 shows $C C_{f}$ as a continuous variable, that varies across firms, reflecting variation in the composition of the workforce.

Figure 1.5: Histogram Firm's Cost of Compliance

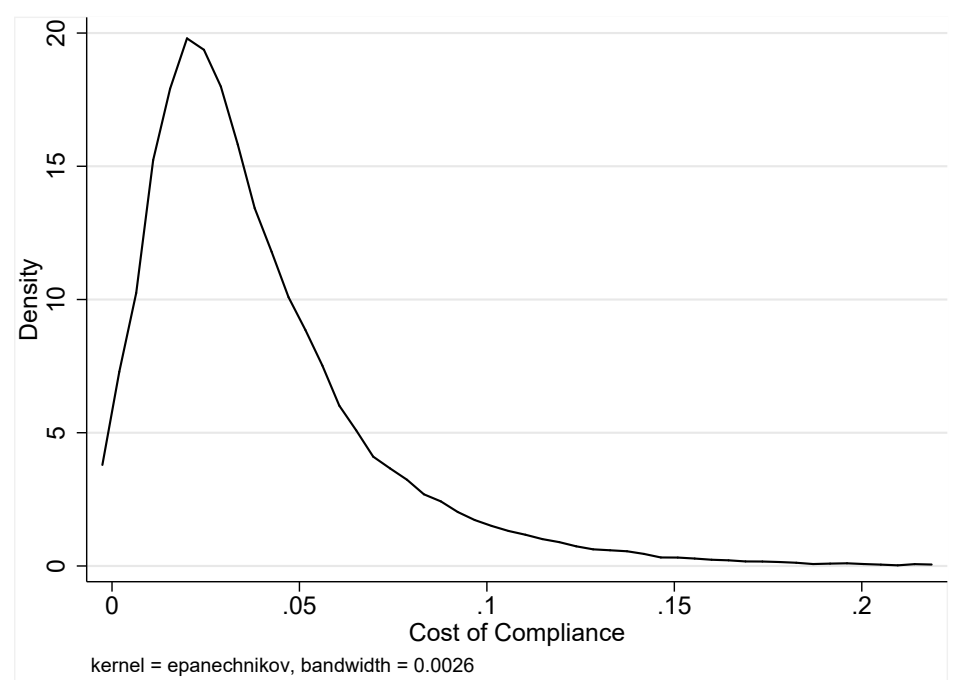

Note: Cost of Compliance, considering workforce of firms in early 2011. Source: RAIS.

\section{4 .2 \\ Identification}

Some factors can influence the variables of interest and the variable of treatment, $C C_{f}$. Some sectors, like construction for instance, typically practice a much larger level of turnover than other sectors. This pattern can affect the $C C_{f}$, which will be lower since the workers in this sector have on average lower tenure. Firm fixed effects control for this kind of issue. Time fixed effects control for common temporal trends, as well.

Some characteristics that affect the outcomes, however, are in the error term, and by hypothesis do not affect the $C C_{f}$. For example, a shock in the demand of a particular firm can cause reallocation in its workforce. This shock would cause firing and hiring $\left(Y_{f t}\right)$, but it is not correlated with $C C_{f}$. First, because $C C_{f}$ results from the firm's profile in early 2011, and it is not correlated with subsequent shocks beyond the change of law. However, there is a possibility that $C C_{f}$ may be correlated with previous shocks, and this would compromise identification. To test this hypothesis, equation 1-13 evaluates

\footnotetext{
${ }^{13}$ The additional advance notice cost will also include charges for additional service time (FGTS, 13th proportional and vacation proportional). additional advance notice cost = $\frac{\text { additional advance notice days }}{30.4} *$ wage $*[1+0.08+0.08 * 50 \%+1 / 12+1 / 12 *(1+1 / 3)]$. Or simplifying additional advance notice cost $=\frac{\text { additional advance notice days }}{30.4} *$ wage $*[1.314]$
} 
$\beta_{\tau}$, for $\tau<2011$. As results in section 1.6 will show, in general $\beta_{\tau}=0$ or not significant for $\tau<2011$, which guarantees identification. This discussion justifies the use of the potential firing cost in $C C_{f}$, considering all employees and not just actually fired workers (in 2010, before the change in the law, for example). In this second case, there could be a correlation between the error and the treatment variable.

Finally, there is no reverse causality, since the construction of variable $C C_{f}$ considers the profile of the firm before the change of the new law, which firms did not anticipate. In other words, $C C_{f}$ is not a variable that the firm chose in order to adjust to the costs of the new law, because it uses the structure of the workforce before the change.

To a better interpretation of the results, $C C_{f}$ is divided by ten. Each $\beta_{\tau}$ is the effect of the firm having $C C_{f}=10 \%$ (and being more exposed to cost increase) in comparison with the same firm having $C C_{f}=0 \%$ (and being less exposed to cost increase). This range is compatible with the firm going from the first to the last decile of the $C C_{f}$ distribution (as Figure 1.5 shows).

\section{5 \\ Data}

This study uses data from the Relação Anual de Informações Sociais (RAIS). RAIS is a restricted-access matched employee-firm administrative dataset, with information that the Brazilian Ministry of Labor and Employment requests to firms annually. RAIS has information of all formally employed workers in Brazil, and includes detailed information on the employee (social security number, gender, education), on the employer (tax number, sector of activity, establishment size, geographical location), and on the employment relationship (wage, tenure, hiring date, layoff date and reason, etc). This study uses data from RAIS for the period from 2005 - 2013, considering employment contracts from private firms and workers in the CLT rules (not temporary workers). The sample does not consider employment contracts from the public sector, from agriculture and livestock sector and workers with an average wage equal to zero or missing. After these filters, variables are aggregated at the firm level ${ }^{14}$ such as firm age ${ }^{15}$, sector of activity, the average tenure of workers, firm size (in terms of the number of employees). Firm age and firm size are controls in $X_{f t}$ because they change over time and thus are not in fixed effect. All firms in Brazil with active contracts in 2010 and 2011 are considered.

\footnotetext{
${ }^{14} \mathrm{~A}$ firm may have more than one establishment. The criterion for the construction of the base is: if the establishments are within the same municipality, they represent only one firm. If there is an establishment in another municipality, it represents another firm.

${ }^{15} \mathrm{An}$ approximation, which considers the first time the firm appears at the base.
} 
We use a sample of $10 \%$ of these firms, so that the work is computationally feasible. The panel tracks these firms over time.

Data are at the firm level, and the main variables of interest are firing, hiring and turnover. Firing is all contracts termination without justified cause, by request of the firm, throughout the year, divided by the number of employees of the firm at the beginning of this year. Hiring is all new contracts of the firm throughout the year, divided by the number of employees of the firm at the beginning of this year. Turnover is the sum of these two variables. We drop firms with less than three employees because adjustments in their workforce are very noisy. Except in the analysis on the exit rate of firms, only firms that are active throughout analysis are on the sample.

Table 1.1 shows summary statistics for 2010 and 2012, before and after the New Advance Notice Law. Firms were 5.2 years old on average in 2010, and 7.2 years old in 2012. The difference is precisely two years because we are dealing with the same set of firms throughout the period. The composition is concentrated in services and commerce (more than 80\% in 2010 and 2012), with only about $17.5 \%$ of firms being in the industry sector. The average tenure of workers is 2.2 years in 2012, 0.5 years higher than in 2010. Also, the composition of tenure ranges shows an increase in average tenure. More than $70 \%$ of workers earn up to two minimum wages. In 2012, the number of employees earning two minimum wages or more increases. The composition of the level of education of the employees also shows some improvement between the two years, but considering the occupations, the proportion of high skill is stable in about $60 \%$ over the years. While the level of education reflects a measure of individual formal instruction, the skill variable groups each worker in terms of activity engaged in the specific occupation in the firm. The workers with high skill are those who perform more sophisticated activities, while those with low skill have routine activities. In the period, turnover is high, at around 1.6 in 2010 and 1.2 in 2012. These numbers mean that on average a firm that started 2010 with ten employees hired eleven other employees during the year, and fire five employees during the year. In 2012, on average, a firm that started the year with ten employees hired seven workers and fired five workers during the year.

\section{6 \\ Results}

The new Advance Notice Law introduced in Brazil in 2011 meant an increase in firing costs. This paper identifies its impact by calculating the exposure of each firm to the new rules. This section presents the main results 
Table 1.1: Summary Statistics

\begin{tabular}{|c|c|c|c|c|}
\hline & \multicolumn{2}{|c|}{ Mean } & \multirow[t]{2}{*}{ diff } & \multirow[t]{2}{*}{ se } \\
\hline & Before (2010) & After (2012) & & \\
\hline Age (firm) & 5.21 & 7.21 & -2.00 & 0.01 \\
\hline Tenure & 1.81 & 2.23 & -0.42 & 0.01 \\
\hline Firm size (number of workers) & 35.45 & 38.20 & -2.75 & 1.11 \\
\hline Industry $(\%)$ & $17.5 \%$ & $17.5 \%$ & 0.00 & 0.00 \\
\hline Service $(\%)$ & $35.9 \%$ & $36.2 \%$ & 0.00 & 0.00 \\
\hline Commerce $(\%)$ & $46.6 \%$ & $46.3 \%$ & 0.00 & 0.00 \\
\hline \multicolumn{5}{|l|}{ Composition } \\
\hline$[0 \mathrm{y}, 1 \mathrm{y})$ & $46.8 \%$ & $44.0 \%$ & 0.03 & 0.00 \\
\hline$[1 \mathrm{y}, 2 \mathrm{y})$ & $20.0 \%$ & $21.0 \%$ & -0.01 & 0.00 \\
\hline$[2 \mathrm{y}, 5 \mathrm{y})$ & $20.4 \%$ & $21.7 \%$ & -0.01 & 0.00 \\
\hline$[5 y$, inf $)$ & $12.3 \%$ & $15.0 \%$ & -0.03 & 0.00 \\
\hline \multicolumn{5}{|l|}{ Wage (minimum wage) } \\
\hline$(0,2 \mathrm{mw})$ & $75.1 \%$ & $73.5 \%$ & 0.02 & 0.00 \\
\hline$[2 \mathrm{mw}$, inf $)$ & $24.9 \%$ & $26.5 \%$ & -0.02 & 0.00 \\
\hline \multicolumn{5}{|l|}{ Educational Level } \\
\hline Less than High School & $40.1 \%$ & $36.5 \%$ & 0.04 & 0.00 \\
\hline High School or more & $59.9 \%$ & $63.5 \%$ & -0.04 & 0.00 \\
\hline \multicolumn{5}{|l|}{ Skill } \\
\hline High Skill & $60.2 \%$ & $60.3 \%$ & -0.00 & 0.00 \\
\hline Low Skill & $37.3 \%$ & $36.6 \%$ & 0.01 & 0.00 \\
\hline Missing & $2.5 \%$ & $3.1 \%$ & -0.01 & 0.00 \\
\hline Turnover & 1.59 & 1.23 & 0.37 & 0.04 \\
\hline$\%$ Hirings & 1.08 & 0.75 & 0.33 & 0.03 \\
\hline$\%$ Firings & 0.51 & 0.48 & 0.04 & 0.01 \\
\hline Observations & 181,456 & & & \\
\hline
\end{tabular}

in figures, and the more detailed results are tables in Appendices 1.8 and 1.9. In the figures, the graphs show the estimated coefficients for the years 2006 to 2013 , with a confidence interval of $95 \%$. On each chart, there is a dotted line that indicates the periods before and after the change of notice law. If there are effects of the new law on the variables of interest, the coefficients should present different pattern from the year 2011. The variables related to firing, hiring, and turnover are proportions of the stock of workers at the beginning of the period. Each $\beta_{\tau}$ is the effect of the firm having $C C_{f}=10 \%$ (and being more 
exposed to cost increase) in comparison with the same firm having $C C_{f}=0 \%$ (and being less exposed to cost increase). This range is compatible with the firm going from the first to the last decile of the $C C_{f}$ distribution.

\subsection{1}

\section{Main Results}

Figure 1.6 shows that more exposed firms reacted to the shock firing more and hiring more, and so turnover increases too. Although firing costs aim to protect employment, the opposite happens in this case, in which the new cost is tenure-dependent. This effect is compatible with the predictions of the model in section 1.3. The mechanism is that firing cost increases, but costs to retain a worker also increases. Results indicate that the second channel is stronger than the first. So, the firm chooses to fire and replace the worker, before she becomes too expensive to fire.

To quantify the impact in $2011\left(\beta_{2011}\right)$, if a firm starts the year with ten employees, five are fired throughout the year in the baseline scenario. The effect of the law for the firms most affected (which are in the last decile of distribution) is to fire additionally three employees, totaling eight workers fired over the year. A typical firm hires six employees more than in the baseline scenario (in which it would hire nine workers). In terms of turnover, a firm that starts the year with ten employees would hire and fire fourteen employees over the year in the baseline scenarios, and the most affected firms would hire and fire ten more employees. Figure 1.6 shows that in general $\beta_{\tau}=0$ or non significant for $\tau<2011$, which means that $C C_{f}$ is not correlated with other variables in the error term. One exception is $\beta_{2011}$ for layoffs, which is positive and significant. However, the magnitude change is quite noticeable as of 2011.

The increments in firing and hiring are compatible with the need for replacement. Additional firing cost for an entrant work is zero and remains low for some time, so replacement is a strategy that makes sense for firms. Effects on hiring are larger than effects on hiring. Heterogeneous productivity among these workers can explain these results. If the fired worker is more productive, the firm needs to replace her with more than one new contract.

Results are persistent over time, suggesting that what happens is not a one-off adjustment, but a permanent change in the management of the labor force. In other words, the firm chooses to operate with a higher level of turnover. The persistent pattern can be noticed, for example, in the turnover panel in Figure X. Before the law change, firms most exposed to the new costs had the same pattern of least exposed firms. After the change of law, more exposed firms has ten additional employees hired or fired 2011, seven in 2012 
and seven in 2013 (for every ten employees who start the year working in the firm).

A tenure-dependent advance notice seems fair because it aims to protect more an employee that, being in the firm for a long time, possibly contributed more for firm performance over the years. This employee is also the one that has more difficult to find another job, because of her age and the fact that probably a lot of the human capital accumulated was specific for work in this firm. It makes sense that the law aims to protect more this employee, but the rule design does not work on this purpose.

The new law lowers the incentives to keep a long-working relationship since it carries a stimulus that is the opposite to the original intention: to fire the employee before she becomes too expensive to fire.

Figure 1.6: Main Results
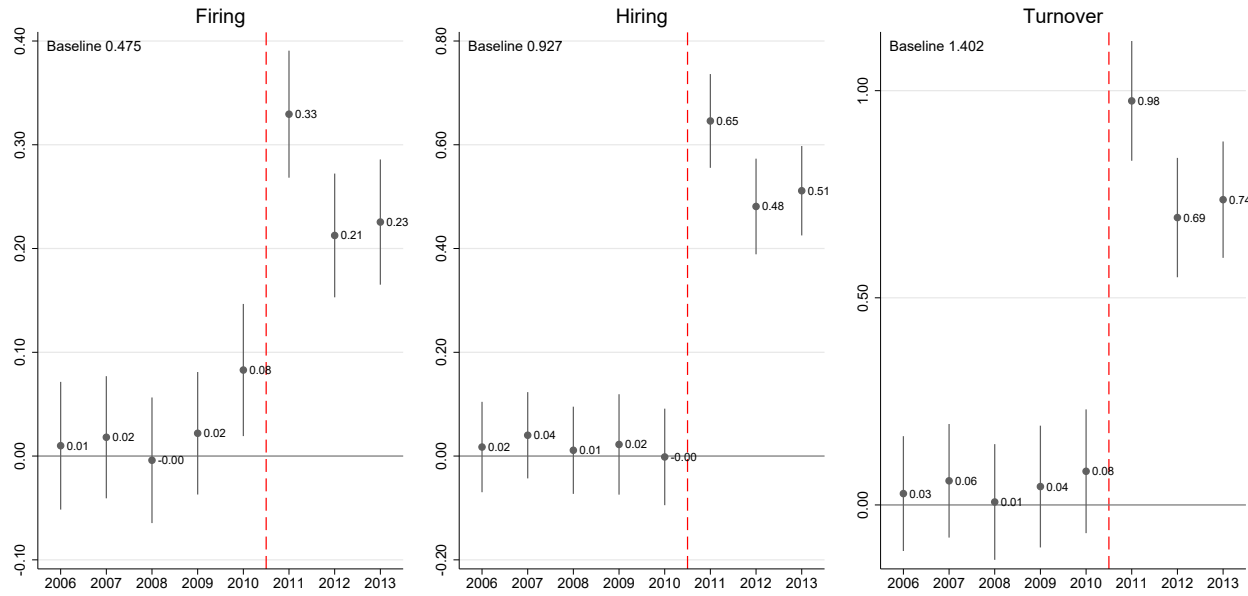

Note: Each $\beta_{\tau}$ is the effect for the firm more exposed to cost increase $\left(C C_{f}=10 \%\right)$, in comparison with the same firm if it was less exposed to cost increase $\left(C C_{f}=0 \%\right)$. Estimated coefficients for the years 2006 to 2013, with a confidence interval of $95 \%$. The dotted line indicates the periods before and after the change of notice law. Firing: all contracts termination without justified cause, by request of the firm, throughout the year, divided by the number of employees of the firm at the beginning of this year. Hiring: all new contracts of the firm throughout the year, divided by the number of employees of the firm at the beginning of this year. Turnover is the sum of these two variables. Source: RAIS.

\section{6 .2}

\section{Other Types of Separations}

The results of the previous subsection motivate the investigation of other kinds of job termination. The first panel in Figure 1.7 presents the effects of the new advance notice law in quits (when the employee requests the contract termination). The results show that the law also had a positive impact on 
quits. To quantify the impact in $2011\left(\beta_{2011}\right)$, two employees quit in a typical firm (with ten employees). The effect in the next years is smaller in magnitude, but still significant. It may seem unclear the incentive for workers to quit more often in firms more affected by the new legislation, but it makes sense that more affected firms create a more propitious environment for their employees to quit. The firm can create a more hostile environment for the worker not promoting her, giving lower wage growth or worsening conditions in general. By doing so, the firm creates incentives for the worker to quit, and in this case, it does not have to incur in additional costs of the law.

Still, in the second panel of Figure 1.7, we can see that other types of separations that are neither firing nor quit, such as retirement, not appear to have suffered a significant impact. The coefficients have low magnitude and are non-significant. It would be possible that among this group occurred a phenomenon similar to that seen among workers who quit, but this is not verified.

Some previous studies analyze the incentives in labor legislation in Brazil for employees to collude with the employer to perform a fake lay-off (Pinto (2015), Doornik, Schoenherr, and Skrastins (2017), Carvalho, Corbi, and Narita (2018)). In this case, the firm fires the worker, that remains on the job relationship unofficially. The worker receives labor benefits, and compensate the firm returning the costs it had with the fire. There is a net gain for the worker (mainly related to part of the FGTS and unemployment insurance) in this collusion. In the higher advance notice scenario, the incentive for the firm to make such agreement may increase. The cost with advance notice (and other charges) will be compensated by the worker, as before. Moreover, also, the employment contract will start again, with zero tenure, and so the firm will lower costs if it effectively needs to fire this worker in the future.

The last panel in Figure 1.7 shows that the increase in firing costs from the new advance notice law has increased layoffs that could potentially be false. In this chart, potential fake lay-offs are firings that were followed by re-employment in the same firm within one year ${ }^{16}$. Quantify the impact, $\beta_{2011}$ and $\beta_{2012}$ means that if a firm starts the year with ten employees, two has a potential fake layoff in the baseline scenario. The effect of the law for the firms most affected is the increment of two more potential fake layoffs in 2011, and one more em 2012.

Once we find a positive impact on the potential fake lay-offs (Figure 1.7 ), it is important to recalculate the main results excluding these cases.

\footnotetext{
${ }^{16}$ These are not necessarily fake layoff, but potential cases. Other employee return periods (90 days, 180 days) were tested, with similar results.
} 
Figure 1.7: Other Types of Separations
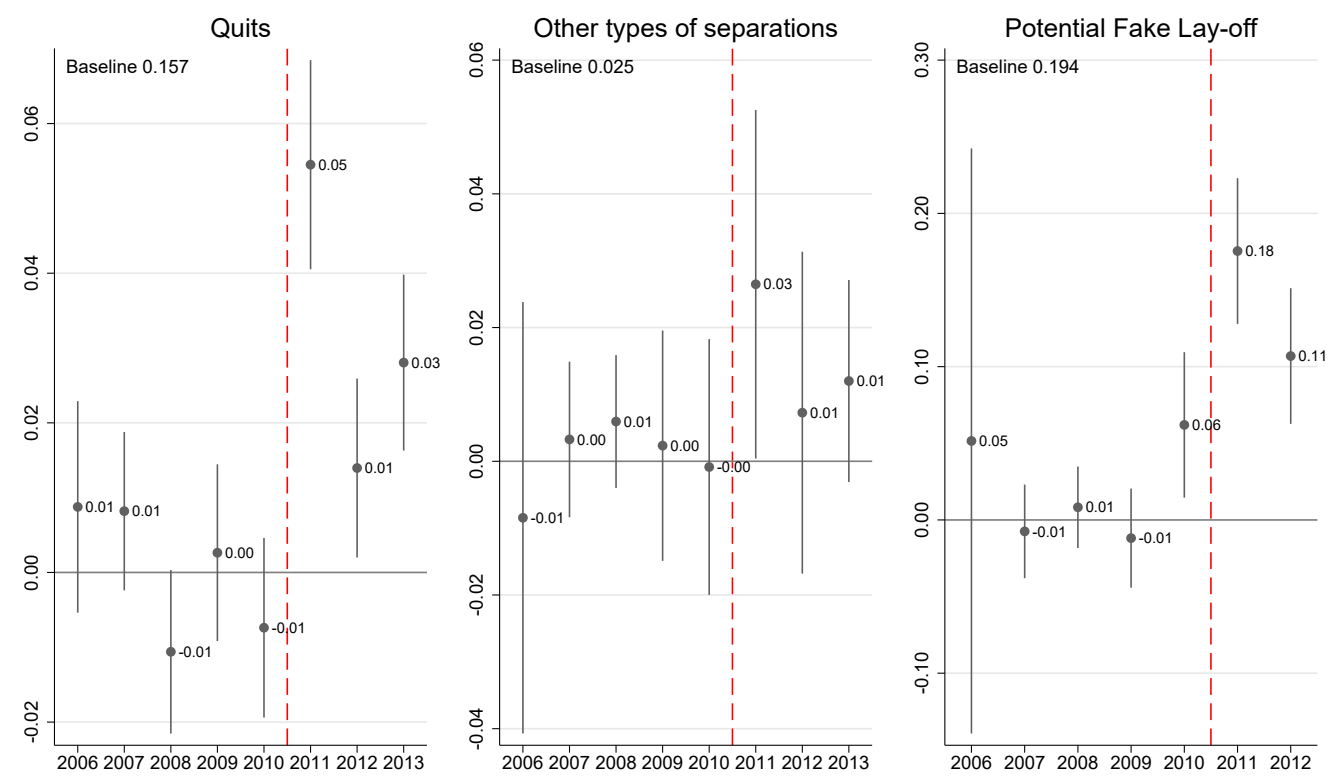

Note: Each $\beta_{\tau}$ is the effect for the firm more exposed to cost increase $\left(C C_{f}=10 \%\right)$, in comparison with the same firm if it was less exposed to cost increase $\left(C C_{f}=0 \%\right)$. Estimated coefficients for the years 2006 to 2013, with a confidence interval of $95 \%$. The dotted line indicates the periods before and after the change of notice law. Quits: all contracts termination, by request of the employee, throughout the year, divided by the number of employees of the firm at the beginning of this year. Other types of separations: all contracts termination except firing or quit, throughout the year, divided by the number of employees of the firm at the beginning of this year. Potential fake layoff: all firings that were followed by re-employment in the same firm within one year, divided by the number of employees of the firm at the beginning of this year. Source: RAIS.

The results of increasing in firing, hiring and turnover remain, as Figure 1.8 shows. Although the magnitudes are somewhat smaller, the coefficients remain significant.

\subsection{3}

\section{Heterogeneous Groups}

Tables in the Appendix (Section 1.9) present the main results (firing, hiring and turnover) for subsamples, in order to seek possible heterogeneity. The results show some heterogeneity for subsamples of firms by size (Table 1.11). The change of the law has little impact on firms with 250 or more employees. It may be related to its ability to react using other instruments, such as pejotizaçã $o^{17}$. Internal policies of large companies are also potential

${ }^{17}$ When firms maintain a relationship with a worker not through an employment contract, but through a contract which defines the worker as a firm as well. When the labor relationship is not established between a firm and a worker, but between two firms, all labor costs cease to exist. This trend has grown in Brazil in recent years, but requires some legal knowledge, 
Figure 1.8: Main Results - net of potential fake lay-off
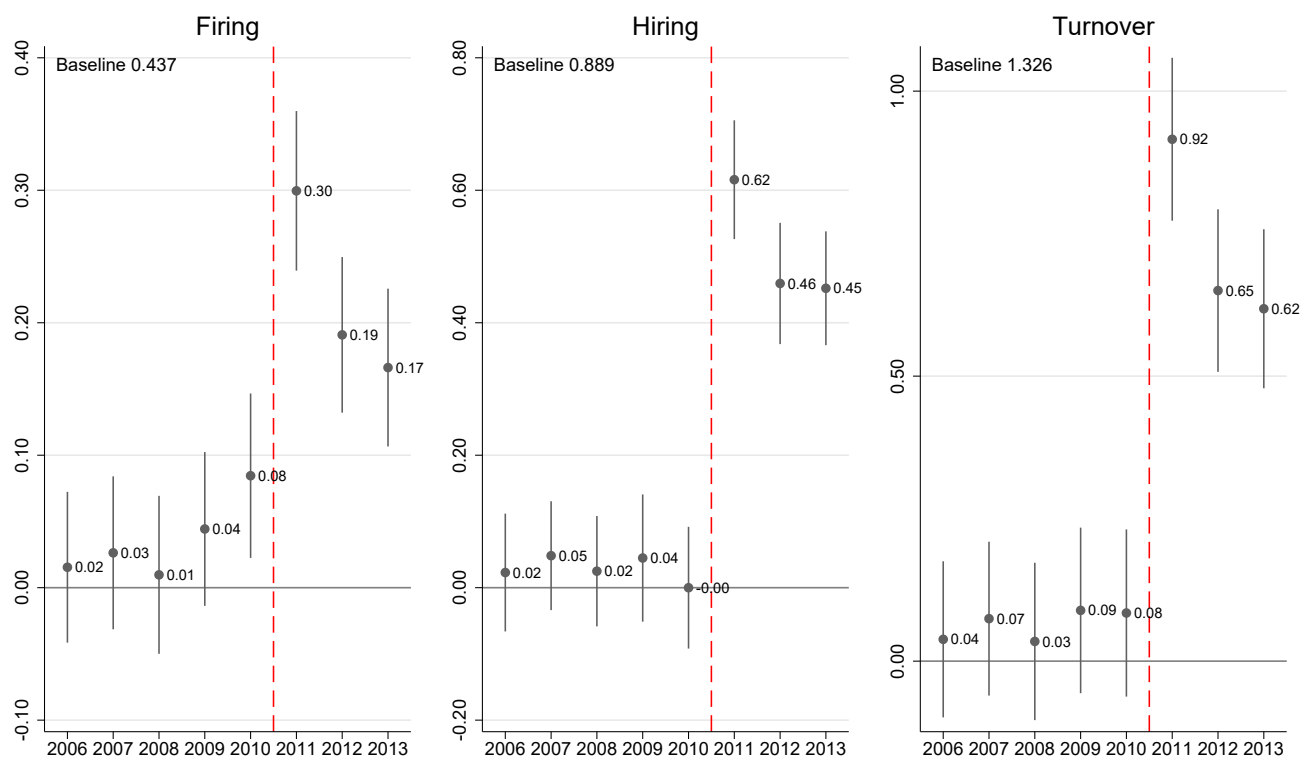

Note: Each $\beta_{\tau}$ is the effect for the firm more exposed to cost increase $\left(C C_{f}=10 \%\right)$, in comparison with the same firm if it was less exposed to cost increase $\left(C C_{f}=0 \%\right)$. Estimated coefficients for the years 2006 to 2013, with a confidence interval of $95 \%$. The dotted line indicates the periods before and after the change of notice law. The variables of interest are the same as in Figure 1.6, but net of the Potential fake layoff in Figure 1.7. Source: RAIS.

explanations for this little impact. It is possible that large firms already treated more generously workers with higher tenure. In that case, the new law may have been irrelevant ${ }^{18}$.

The results for subsamples of firms across the sectors (industry, commerce, and services) show different magnitudes, but similar to the aggregates. In all sectors, the effects are significant and persistent over the years. The impacts of the highest magnitude are those of the service sector, both in terms of firing and in terms of hiring. The second highest impacts are in the industry, and lastly in the commerce.

Another way of looking at possible heterogeneous effects is considering subgroups of workers within firms. The results at subgroups within firms (such as tenure, wage, education, and skill) change only in magnitude. However, the which is more accessible in large firms. RAIS has no information on this type of contract.

${ }^{18}$ It may be unexpected that large firms are more generous spontaneously with workers with higher tenure, even before the change of law. However, interviews with managers of large companies (Schincariol, Embracon National Consortium, ThyssenKrupp Bilstein, Zambon, and Souza Cruz), at Revista Exame (November 2013), showed that some of them stated that their companies were already operating with rules more generous than the new law, making it irrelevant in practice. In this same interview, a manager of these companies shows concern about the number of organizations that could be recycling their workforce (that is, firing the employee before she becomes very expensive, with the new advance notice law), something in line with the results presented in this study. 
larger magnitude for the lower tenure impacts in Table 1.6 goes toward the mechanisms described in the model in Section 1.3. Coefficients have larger magnitudes in groups with lower tenure. It is interesting to note that the coefficient of the highest tenure group ( 5 years tenure or more) has a more considerable magnitude impact only in the exact year of the law change, but later in the following years, this is the group that has the smaller effect. In the disaggregation by tenure, we can note that some coefficients are significant before the change of law, but still, the change in pattern is remarkable. A more exciting way of seeing heterogeneous effects at the worker level, however, seems to be an identification strategy that operates at the level of the individual, a job for future studies.

\subsection{4}

\section{Impact on Firms}

Finally, Figure 1.9 shows how the increase in the firing costs impacts the exit rate of firms. In this case, all the firms that existed at the beginning of the period are in the sample. There is a dummy variable (death), starting with a zero value. If the firm leaves the sample in a specific year, this dummy assumes a value equal to one, and from that point, the value is missing.

Figure 1.9 shows that these firms have started from a higher average of deaths in 2010. However, with a one-year lag from the change of the law, the coefficient becomes higher in magnitude. For every one hundred firms, 1.4 died in the baseline firms in 2010. Firms more exposed to the new law already had a higher exit rate: two more firms exiting, in 2010. In 2011 this difference remained and in 2012 rose to four, and three in 2013. This pattern may indicate that firms most affected by the increase in firing costs were not able to make adjustments in the labor force in the required magnitude. These firms then do not survive and are no longer viable after the change of law.

\section{7}

\section{Conclusions}

The Brazilian labor market is characterized by low duration job contracts and very high job turnover. In October 2011, the government approved the New Advance Notice Law, in thesis giving more protection for workers. The new law not only increased firing costs but also changed the advance notice design: it created a tenure-dependent benefit, that is, advance notices of job terminations that increase with tenure. A tenure-dependent firing cost aims to protect workers with longer job contracts. That seems fair, since this employee possibly contributed more for firm performance over the years, and may have 
Figure 1.9: Exit Rate of Firms

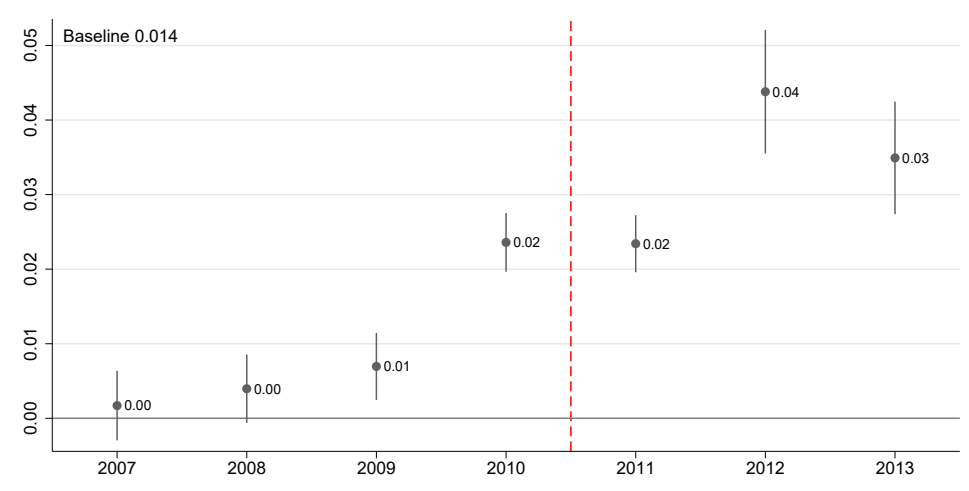

Note: Each $\beta_{\tau}$ is the effect for the firm more exposed to cost increase $\left(C C_{f}=10 \%\right)$, in comparison with the same firm if it was less exposed to cost increase $\left(C C_{f}=0 \%\right)$. Estimated coefficients for the years 2007 to 2013, with a confidence interval of $95 \%$. The dotted line indicates the periods before and after the change of notice law. Exit rate of firms: the proportion of firms that leave the database, in relation to the total number of firms. Source: RAIS.

more difficulties to find another job. However, the results of this study seem to be consistent with the opposite effect.

Conceptually, the change in the law not only implies a higher firing cost but also creates an implicit cost in the maintenance of the employment contract. Thus, the firm faces disincentives to fire, and also disincentives to retain the worker, since to fire will be even more costly in the future. The second channel may be stronger. Adapting a matching model that considers fixed firing costs to a version that considers tenure-dependent firing costs, we show that the mechanism for the new law to potentially increase dismissals is clear.

The empirical analysis reinforces the importance of this mechanism. The results suggest that the new tenure-dependent firing cost structure actually encouraged firms to fire more. A difference-in-differences approach shows that firms mostly affected by the change in the law do fire more, hire more and operate at a higher rate of labor turnover. Results persist when we remove potential fake lay-offs from the estimation.

Large firms exhibit heterogeneous behavior and do not suffer a significant impact from the new law. This result is in line with some anecdotal evidence previously mentioned. The analysis by subgroups of workers shows that all categories have been impacted, with differences only in magnitudes. An empirical strategy with data at the individual level would be a better strategy to identify heterogeneous effects by type of worker. However, exploiting discontinuity at the worker level may not be the useful strategy. For the worker, the discontinuity occurs every year of work in the same firm, when the worker 
receives three additional days of advance notice. The channel by which the employer reacts to legislation may not be in terms of fire before or after the increase in the cost at the worker level. The firm's adjustment appears to be at a more aggregate level, in the sense of not letting its total cost associated with potentially layoffs reach very high values. In other words, the firm does not seem to fire a particular employee before she earns three days of advance notice, but it manages its workforce so that it does not become too costly in a possible dismissal.

Therefore, this work provides evidence that the New Advance Notice Law has not achieved the objective of protecting employment in Brazil. The new design, with a structure dependent on tenure, adds another perverse incentive, among many already studied in Brazilian labor legislation (Gonzaga (2003), Pinto (2015)). The results are especially relevant in a recession scenario when firms can anticipate further layoffs if they expect a slow recovery (Figueiredo and Francis (2018)).

Turnover in Brazil was already at a very high level before The New Advance Notice Law. The findings that the new legislation further increased labor turnover are very worrisome. As argued by many Brazilian economists, a labor market with high turnover generates disincentives for training and investment in human capital, which negatively affect labor productivity. More disturbing is the fact that imposing additional firing cost to firms does not translate into greater employment protection for workers, which reflects an ineffective and ill-designed EPL system. 
Chapter 1. When Firing Costs Increase Backfire: The Effects of Extending Advance Notice in Brazil

\section{8}

\section{Appendix 1: Tables}

Table 1.2: Main Results

\begin{tabular}{lccc}
\hline & $\begin{array}{c}\text { Firing } \\
(1)\end{array}$ & $\begin{array}{c}\text { Hiring } \\
(2)\end{array}$ & $\begin{array}{c}\text { Turnover } \\
(3)\end{array}$ \\
\hline \hline 2006 & 0.010 & 0.017 & 0.027 \\
& $(0.751)$ & $(0.695)$ & $(0.699)$ \\
2007 & 0.018 & 0.040 & 0.058 \\
& $(0.546)$ & $(0.344)$ & $(0.405)$ \\
2008 & -0.004 & 0.011 & 0.007 \\
& $(0.896)$ & $(0.795)$ & $(0.920)$ \\
2009 & 0.022 & 0.022 & 0.044 \\
& $(0.466)$ & $(0.650)$ & $(0.554)$ \\
2010 & $0.083^{*}$ & -0.002 & 0.081 \\
& $(0.011)$ & $(0.972)$ & $(0.286)$ \\
2011 & $0.329^{* * *}$ & $0.646^{* * *}$ & $0.975^{* * *}$ \\
& $(0.000)$ & $(0.000)$ & $(0.000)$ \\
2012 & $0.213^{* * *}$ & $0.481^{* * *}$ & $0.694^{* * *}$ \\
& $(0.000)$ & $(0.000)$ & $(0.000)$ \\
2013 & $0.226^{* * *}$ & $0.511^{* * *}$ & $0.737^{* * *}$ \\
& $(0.000)$ & $(0.000)$ & $(0.000)$ \\
\hline Observations & 405148 & 405148 & 405148 \\
$R^{2}$ & 0.016 & 0.019 & 0.021 \\
\hline$p$-values in parentheses & & \\
Firm FE, Yes, Year FE, Yes, Firm X Year Controls, Yes \\
$*_{p}<0.05, * *$ \\
& $<0.01,{ }^{* * *} p<0.001$ &
\end{tabular}


Table 1.3: Other Types of Separation

\begin{tabular}{|c|c|c|c|}
\hline & $\begin{array}{l}\text { Quits } \\
\text { (1) }\end{array}$ & $\begin{array}{c}\text { Other types } \\
\text { of Separations } \\
(2)\end{array}$ & $\begin{array}{c}\text { Fake Lay-off } \\
\text { (Potential) } \\
(3)\end{array}$ \\
\hline 2006 & $\begin{array}{c}0.009 \\
(0.224)\end{array}$ & $\begin{array}{l}-0.008 \\
(0.608)\end{array}$ & $\begin{array}{c}0.052 \\
(0.597)\end{array}$ \\
\hline 2007 & $\begin{array}{c}0.008 \\
(0.129)\end{array}$ & $\begin{array}{c}0.003 \\
(0.582)\end{array}$ & $\begin{array}{l}-0.007 \\
(0.631)\end{array}$ \\
\hline 2008 & $\begin{array}{l}-0.011 \\
(0.057)\end{array}$ & $\begin{array}{c}0.006 \\
(0.241)\end{array}$ & $\begin{array}{c}0.008 \\
(0.543)\end{array}$ \\
\hline 2009 & $\begin{array}{c}0.003 \\
(0.662)\end{array}$ & $\begin{array}{c}0.002 \\
(0.790)\end{array}$ & $\begin{array}{l}-0.012 \\
(0.472)\end{array}$ \\
\hline 2010 & $\begin{array}{l}-0.007 \\
(0.228)\end{array}$ & $\begin{array}{l}-0.001 \\
(0.930)\end{array}$ & $\begin{array}{c}0.062^{*} \\
(0.010)\end{array}$ \\
\hline 2011 & $\begin{array}{c}0.055^{* * *} \\
(0.000)\end{array}$ & $\begin{array}{l}0.026^{*} \\
(0.046)\end{array}$ & $\begin{array}{c}0.175^{* * *} \\
(0.000)\end{array}$ \\
\hline 2012 & $\begin{array}{l}0.014^{*} \\
(0.022)\end{array}$ & $\begin{array}{c}0.007 \\
(0.554)\end{array}$ & $\begin{array}{c}0.107^{* * *} \\
(0.000)\end{array}$ \\
\hline 2013 & $\begin{array}{c}0.028^{* * *} \\
(0.000)\end{array}$ & $\begin{array}{c}0.012 \\
(0.119)\end{array}$ & $\begin{array}{c}0.000 \\
(.)\end{array}$ \\
\hline $\begin{array}{l}\text { Observations } \\
R^{2}\end{array}$ & $\begin{array}{c}405148 \\
0.026\end{array}$ & $\begin{array}{c}405148 \\
0.001\end{array}$ & $\begin{array}{l}95120 \\
0.005\end{array}$ \\
\hline
\end{tabular}

$p$-values in parentheses

Firm FE, Yes, Year FE, Yes, Firm X Year Controls, Yes

${ }^{*} p<0.05,{ }^{* *} p<0.01,{ }^{* * *} p<0.001$ 
Table 1.4: Main Results - net of potential fake lay-off

\begin{tabular}{lccc}
\hline & $\begin{array}{c}\text { Firing } \\
(1)\end{array}$ & $\begin{array}{c}\text { Hiring } \\
(2)\end{array}$ & $\begin{array}{c}\text { Turnover } \\
(3)\end{array}$ \\
\hline \hline 2006 & 0.015 & 0.023 & 0.038 \\
& $(0.596)$ & $(0.614)$ & $(0.584)$ \\
2007 & 0.026 & 0.048 & 0.075 \\
& $(0.372)$ & $(0.250)$ & $(0.279)$ \\
2008 & 0.010 & 0.025 & 0.035 \\
& $(0.750)$ & $(0.558)$ & $(0.624)$ \\
2009 & 0.044 & 0.045 & 0.089 \\
& $(0.135)$ & $(0.361)$ & $(0.229)$ \\
2010 & $0.085^{* *}$ & -0.000 & 0.084 \\
& $(0.008)$ & $(0.999)$ & $(0.259)$ \\
2011 & $0.300^{* * *}$ & $0.616^{* * *}$ & $0.916^{* * *}$ \\
& $(0.000)$ & $(0.000)$ & $(0.000)$ \\
2012 & $0.191^{* * *}$ & $0.459^{* * *}$ & $0.650^{* * *}$ \\
& $(0.000)$ & $(0.000)$ & $(0.000)$ \\
2013 & $0.166^{* * *}$ & $0.452^{* * *}$ & $0.618^{* * *}$ \\
& $(0.000)$ & $(0.000)$ & $(0.000)$ \\
\hline Observations & 405148 & 405148 & 405148 \\
$R^{2}$ & 0.018 & 0.019 & 0.021 \\
\hline
\end{tabular}

$p$-values in parentheses

Firm FE, Yes, Year FE, Yes, Firm X Year Controls, Yes

${ }^{*} p<0.05,{ }^{* *} p<0.01,{ }^{* * *} p<0.001$ 
Chapter 1. When Firing Costs Increase Backfire: The Effects of Extending Advance Notice in Brazil

Table 1.5: Impact on Firms' Exit Rate

\begin{tabular}{lc}
\hline & Firms' Death \\
& $(1)$ \\
\hline \hline 2007 & $(0.002$ \\
& $0.473)$ \\
& 0.004 \\
2009 & $(0.090)$ \\
& $0.007^{* *}$ \\
2010 & $(0.002)$ \\
& $0.024^{* * *}$ \\
2011 & $(0.000)$ \\
& $0.023^{* * *}$ \\
2012 & $(0.000)$ \\
& $0.044^{* * *}$ \\
2013 & $(0.000)$ \\
& $0.035^{* * *}$ \\
\hline Observations & $(0.000)$ \\
$R^{2}$ & 558960 \\
\hline$p$ vavs & 0.055 \\
\hline
\end{tabular}

$p$-values in parentheses

Firm FE, Yes, Year FE, Yes, Firm X Year Controls, Yes

${ }^{*} p<0.05,{ }^{* *} p<0.01,{ }^{* * *} p<0.001$ 
Chapter 1. When Firing Costs Increase Backfire: The Effects of Extending Advance Notice in Brazil

\section{9}

Appendix 2 - Heterogeneous Groups

Table 1.6: Groups of Tenure

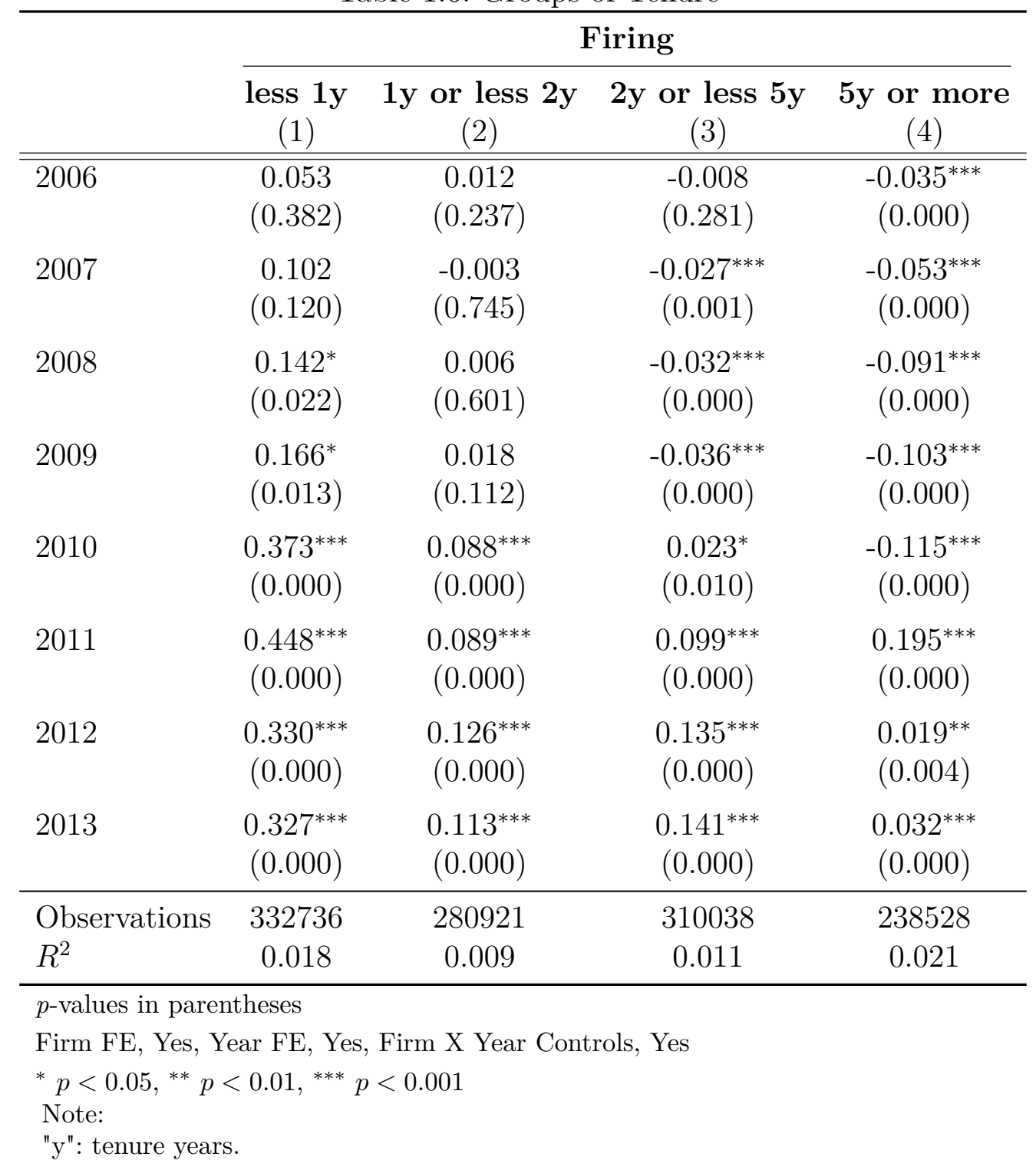




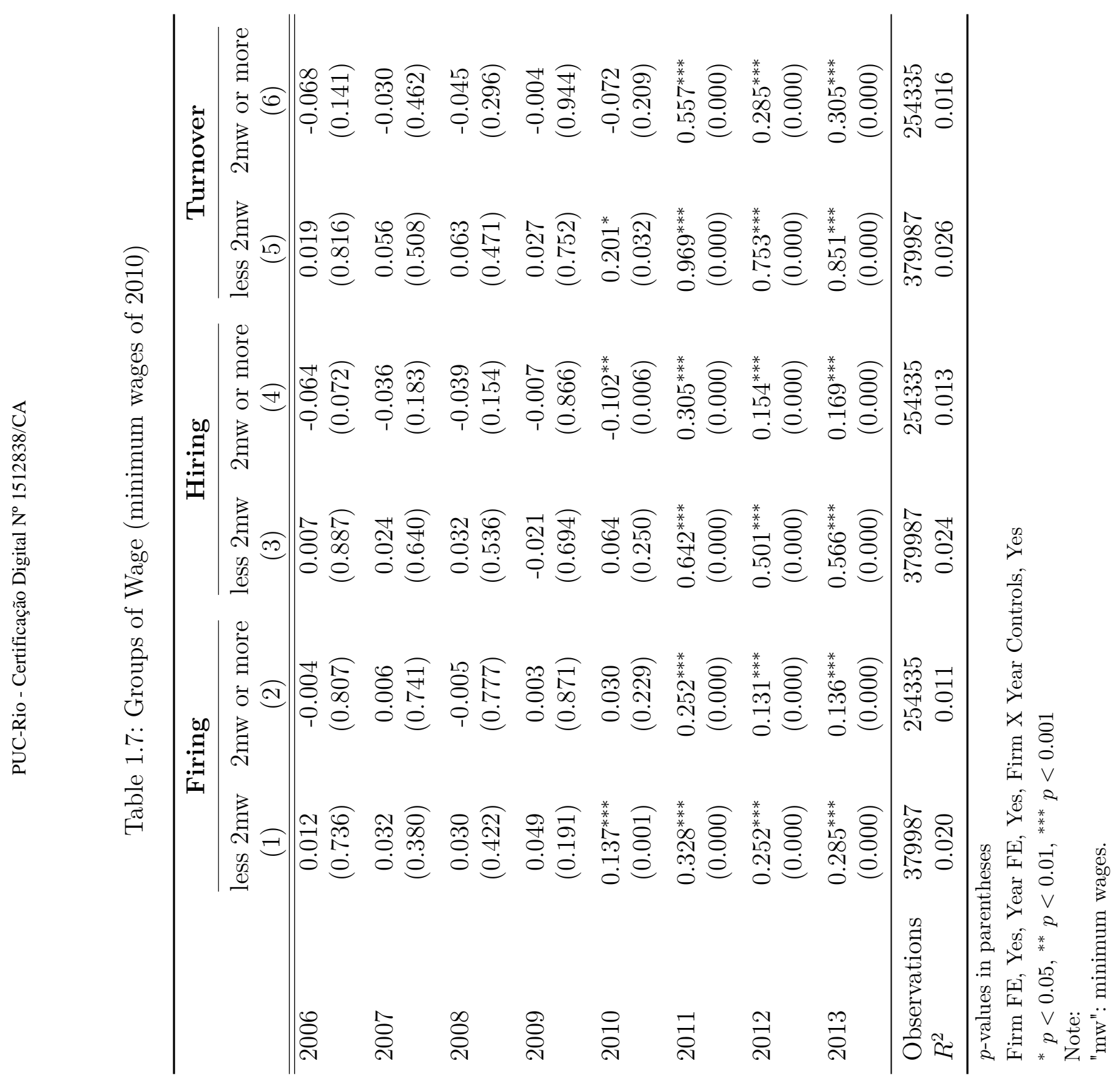




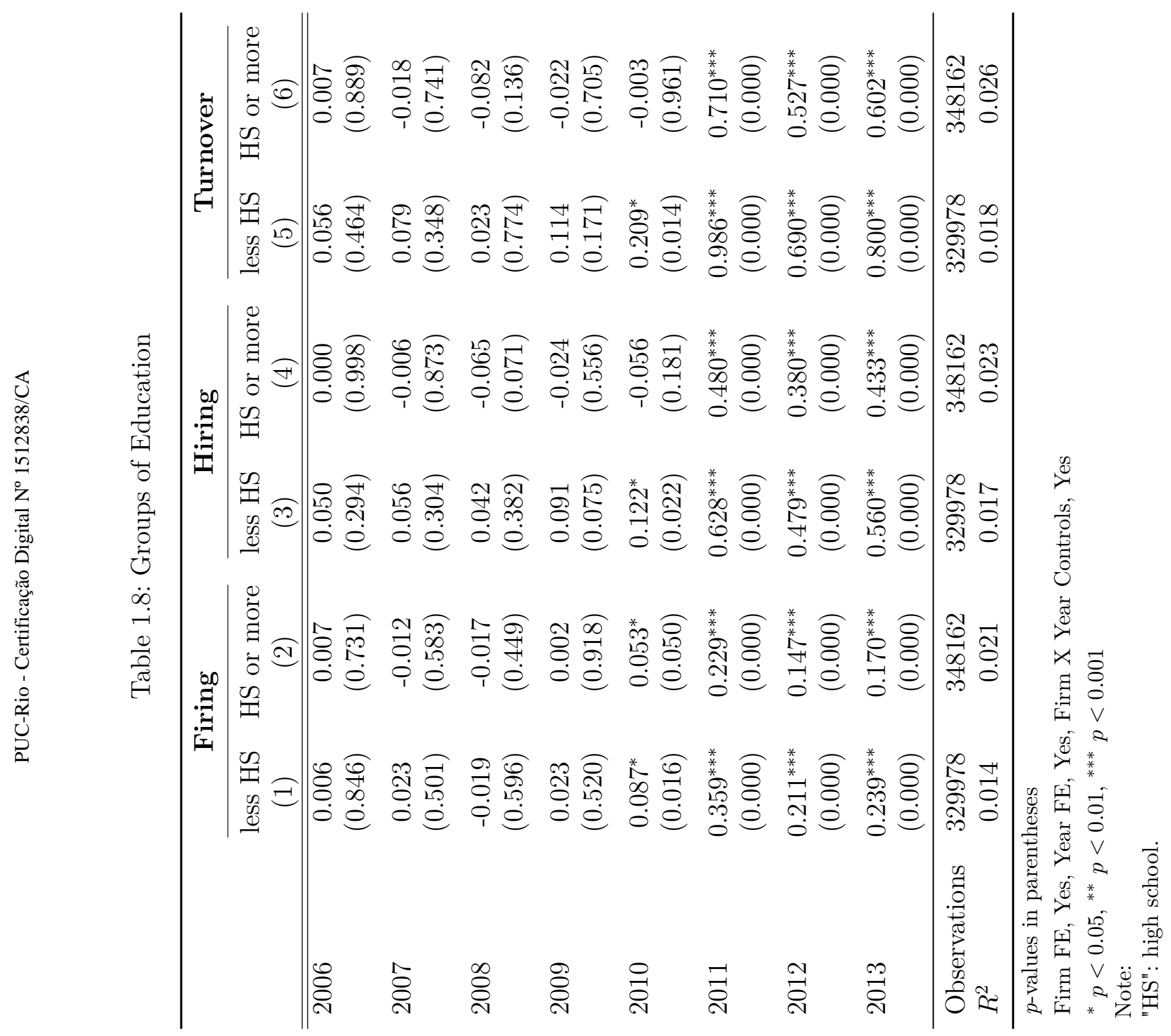




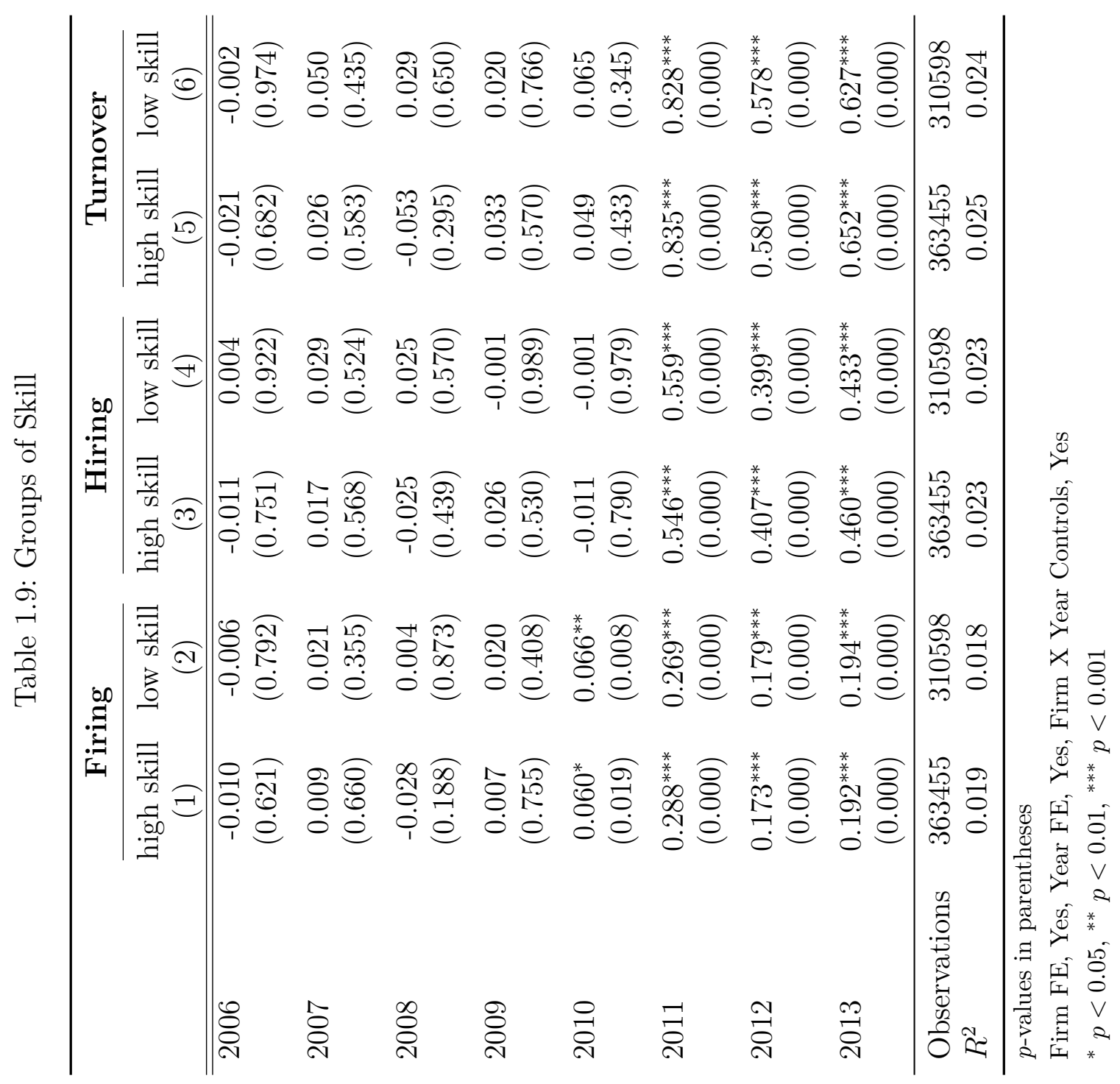




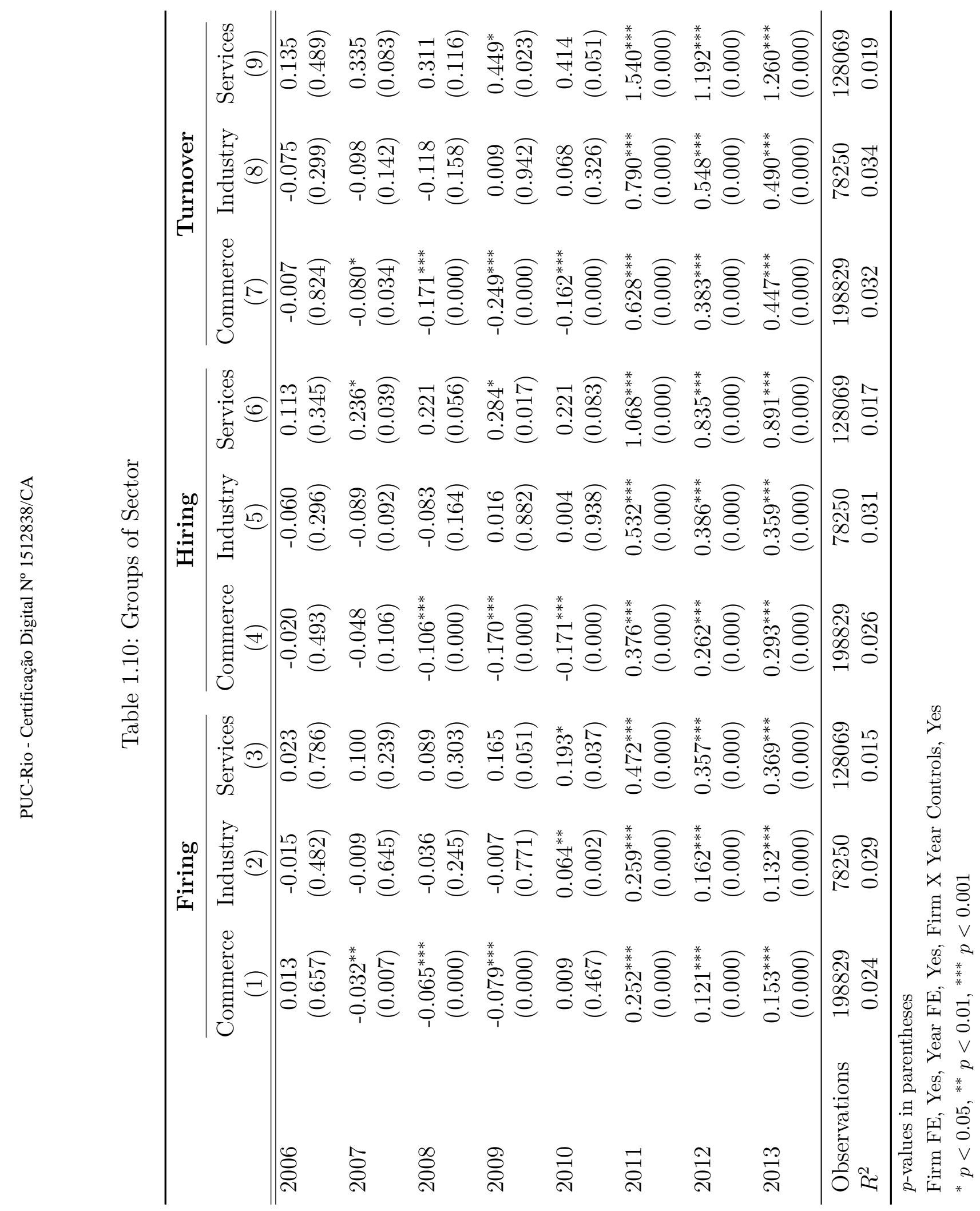




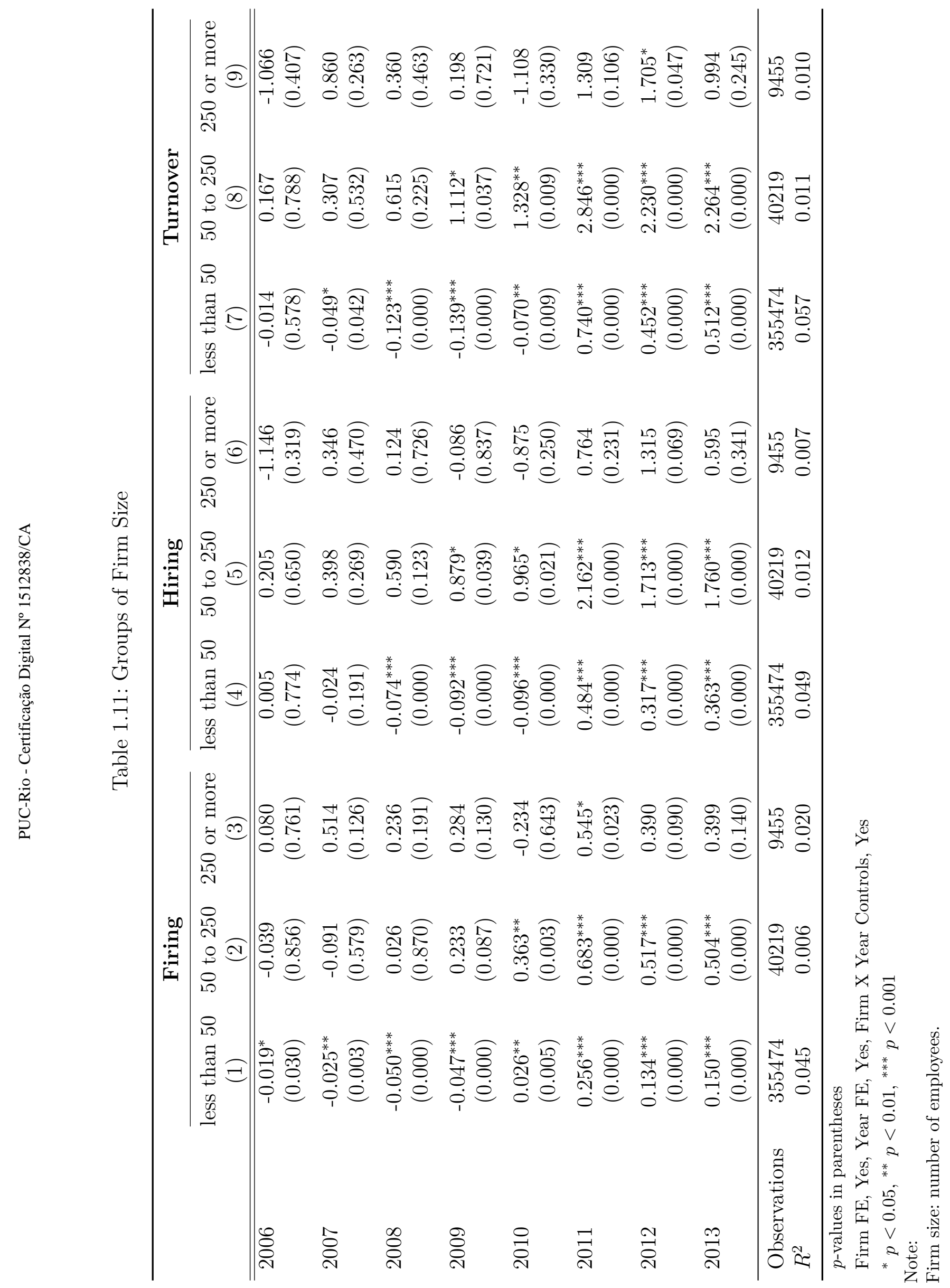


1.10

\section{Appendix 3 - Full Model}

\subsection{1}

\section{Main Equations}

This section provides a more detailed version of the model presented in the paper. The expected profit from a filled job at stationary equilibrium is:

$$
\Pi_{e}(\varepsilon)=\frac{1}{1+r d t}\left[(\varepsilon-w) d t+\lambda d t \Pi_{\lambda}\left(\varepsilon^{\prime}\right)+(1-\lambda d t) \Pi_{e}(\varepsilon)\right]
$$

In equation 1-15, $\Pi_{\lambda}\left(\varepsilon^{\prime}\right)$ is the expected profit when a productivity change occurs (changing from $\varepsilon$ to $\varepsilon^{\prime}$ ). Equation 1-15 can be rewritten as:

$$
\Pi_{e}(\varepsilon)=\frac{1}{r+\lambda}\left[\varepsilon-w+\lambda \Pi_{\lambda}\left(\varepsilon^{\prime}\right)\right]
$$

When a shock in productivity occurs, there are two possible consequences: the new productivity remains at a level that is still advantageous for the firm to retain the employee, or the new productivity goes to a level in which it is more profitable to fire the employee. Consider reservation productivity $\left(\varepsilon_{d}\right)$ as a productivity value below which it is more profitable for the firm to fire the employee. So, when a shock in productivity occurs, there are two possible scenarios: if the new productivity $\varepsilon^{\prime}$ is such that $\varepsilon^{\prime}<\varepsilon_{d}$, the firm fires the worker and incurs in firing costs; if $\varepsilon^{\prime}>\varepsilon_{d}$ the firm keeps the worker on the job, and the expected profit amounts to $\Pi_{\lambda}\left(\varepsilon^{\prime}\right)$. The average expected profit $P i_{e}\left(\varepsilon^{\prime}\right)$ if a productivity shock occurs is:

$$
\Pi_{\lambda}\left(\varepsilon^{\prime}\right)=\int_{-\infty}^{\varepsilon_{d}}-E[F]+\Pi_{\nu} d G(\varepsilon)+\int_{\varepsilon_{d}}^{\varepsilon_{u}} \Pi_{e}\left(\varepsilon^{\prime}\right) d G(\varepsilon)
$$

In equation $1-17, E[F]$ is the expected firing cost that the firm incurs. The firm just knows the current firing cost for a employee, but in the event of a future shock it only has an expectation of this value, $E[F]$.

Reservation productivity We define reservation productivity $\left(\varepsilon_{d}\right)$ as the level of productivity below which it is more profitable for a firm to fire the worker than to continue with the employment contract. In each period, a firm fires if:

$$
\Pi_{e}(\varepsilon)<-F+\Pi_{\nu}
$$

And there is $\varepsilon_{d}$ such: 


$$
\Pi_{e}\left(\varepsilon_{d}\right)=-F+\Pi_{\nu}=-F
$$

$\Pi_{\nu}$ is the value of the vacant job. With free entry, $\Pi_{\nu}=0$.

Using equation 1-19, equation 1-16 and considering a particular productivity value as $\varepsilon=\varepsilon_{d}$ :

$$
\Pi_{e}\left(\varepsilon_{d}\right)=\frac{1}{r+\lambda}\left[\varepsilon_{d}-w+\lambda \Pi_{\lambda}\left(\varepsilon^{\prime}\right)\right]=-F
$$

and

$$
\varepsilon_{d}=w-(r+\lambda) F-\lambda \Pi_{\lambda}\left(\varepsilon^{\prime}\right)
$$

\section{Firing costs}

This model differs from the baseline (Cahuc, Carcillo, and Zylberberg (2014)) in the structure of firing costs. While models typically use a fixed firing cost, as a lump sum, our model explores an additional tenure-dependent firing cost.

- Baseline model (fixed firing costs): $F=\bar{f} \rightarrow E[F]=\bar{f}$

- Our model (tenure-dependent firing costs): $F=\bar{f}+f T \rightarrow E[F]=$ $\bar{f}+f E[T]$, and $T$ represents the duration of the employment contract (tenure).

\subsection{0 .2}

\section{Solving the model}

It helps to note that ${ }^{19}$ :

$$
(r+\lambda)\left[\Pi_{e}(\varepsilon)-\Pi_{e}\left(\varepsilon_{d}\right)\right]=\varepsilon-\varepsilon_{d}
$$

Using equation 1-20 and equation 1-22:

$$
\Pi_{e}(\varepsilon)=\frac{\varepsilon-\varepsilon_{d}}{r+\lambda}-E[F]=\frac{\varepsilon-\varepsilon_{d}}{r+\lambda}-(\bar{f}+f \bar{T})
$$

and

$$
\Pi_{e}\left(\varepsilon^{\prime}\right)=\frac{\varepsilon^{\prime}-\varepsilon_{d}^{\prime}}{r+\lambda}-E[F]=\frac{\varepsilon^{\prime}-\varepsilon_{d}^{\prime}}{r+\lambda}-(\bar{f}+f E[T])
$$

The tenure is known in the current period, in equation $1-23, E[T]=\bar{T}$. However, in the event of a future shock, the future tenure is not defined, but an expected value, $E[T]=\bar{T}+E[\Delta T] . E[\Delta T]$ is closely related to the duration

\footnotetext{
${ }^{19}$ Note that $\lambda \Pi_{\lambda}\left(\varepsilon^{\prime}\right)=\lambda \Pi_{\lambda}\left(\varepsilon_{d}^{\prime}\right)$, because the new productivity is independent of the current productivity. Therefore, for the same period, $\Pi_{\lambda}($.$) assumes the same value, whatever$ the value of $\varepsilon^{\prime}\left(\varepsilon_{d}^{\prime}\right.$ is only a particular case).
} 
of the productivity shock. Starting from a productivity $\varepsilon$, the expected time for a productivity shock (that changes $\varepsilon$ to $\varepsilon^{\prime}$ ) is the same incremental time in the tenure, $E[\Delta T]$. Assuming that productivity $\varepsilon$ follows a Poisson process, and knowing its distribution, it is easy to find $E[\Delta T]$ :

$$
E[\Delta T]=\int_{0}^{\infty} \tau \lambda e^{-\lambda \tau} d \tau=\frac{1}{\lambda}
$$

The ratio $\frac{1}{\lambda}$ is time independent, representing the average shock duration. $\frac{1}{\lambda}$ is the time necessary to wait for a change in productivity and, in the same way, $\frac{1}{\lambda}$ is the value the tenure is expected to increase, until this shock.

Using equation 1-25, equation 1-24 becomes:

$$
\Pi_{e}\left(\varepsilon^{\prime}\right)=\frac{\varepsilon^{\prime}-\varepsilon_{d}^{\prime}}{r+\lambda}-\left(\bar{f}+f \bar{T}+f \frac{1}{\lambda}\right)
$$

Equation 1-26 helps to define the expected profit when a productivity change occurs $\left(\Pi_{\lambda}\left(\varepsilon^{\prime}\right)\right)$ in equation 1-17:

$$
\Pi_{\lambda}\left(\varepsilon^{\prime}\right)=\int_{-\infty}^{\varepsilon_{d}}-\left(\bar{f}+f T+\frac{f}{\lambda}\right) d G(\varepsilon)+\int_{\varepsilon_{d}}^{\varepsilon_{u}}\left(\frac{\varepsilon^{\prime}-\varepsilon_{d}^{\prime}}{r+\lambda}-\left(\bar{f}+f T+\frac{f}{\lambda}\right)\right) d G(\varepsilon)
$$

Or simplifying:

$$
\Pi_{\lambda}\left(\varepsilon^{\prime}\right)=-\left(\bar{f}+f T+\frac{f}{\lambda}\right)+\frac{1}{r+\lambda} \int_{\varepsilon_{d}}^{\varepsilon_{u}}\left(\varepsilon^{\prime}-\varepsilon_{d}^{\prime}\right) d G(\varepsilon)
$$

Equation 1-28 and equation 1-21 define the reservation productivity $\left(\varepsilon_{d}\right)$ :

$$
\varepsilon_{d}=w-r \bar{f}+f(1-r \bar{T})-\frac{\lambda}{r+\lambda} \int_{\varepsilon_{d}}^{\varepsilon_{u}}\left[\varepsilon^{\prime}-\varepsilon_{d}^{\prime}\right] d G(\varepsilon)
$$

If $f=0$, equation 1-29 would become the same as the fixed-cost baseline model in Cahuc, Carcillo, and Zylberberg (2014).

\section{Firing Costs and Reservation Productivity}

This model allows to kinds of firing costs: fixed firing costs $(\bar{f})$ and tenuredependent firing costs $(f)$. Adjusts in each of them have different impacts on reservation productivity.

- Fixed firing costs: $\frac{\partial \varepsilon_{d}}{\partial f}=-r<0$ 
- Tenure-dependent firing costs: $\frac{\partial \varepsilon_{d}}{\partial f}=1-r \bar{T}$.

A firm fires an employee when a shock changes her productivity ${ }^{20}$, which happens at a rate $\lambda$, and the new productivity value is below reservation productivity $\left(\varepsilon^{\prime}<\varepsilon_{d}\right)$, which happens with probability $G\left(\varepsilon^{\prime}\right)$. Therefore, a filled job is destroyed at a rate of $q=\lambda G\left(\varepsilon^{\prime}\right)$. Differentiating equation 1-29 with respect to firing costs $f$ and $\bar{f}$, implications on job destruction are:

- Fixed firing costs: $\frac{\partial q}{\partial f}=\frac{\partial \lambda G\left(\varepsilon_{d}\right)}{\partial f}<0$

- tenure-dependent firing costs: $\frac{\partial q}{\partial f}=\frac{\partial \lambda G\left(\varepsilon_{d}\right)}{\partial f}>0$, if $1>r \bar{T}$

Hence, while an increase in fixed firing costs lowers the reservation productivity and consequently lowers firing, an increase in tenure-dependent firing costs may increase the reservation productivity and consequently increase firing.

\section{Labor Market Tightness}

Different patterns of firing costs can generate different impacts not only on firing but also on hiring. Considering $h$ as costs arising from the search for a worker, the value of a vacant job is:

$$
\Pi_{v}=\frac{1}{1+r d t}\left[-h d t+m(\theta) d t \Pi_{e}\left(\varepsilon_{u}\right)+(1-m(\theta) d t) \Pi_{v}\right]
$$

Equation 1-30 can be rewritten as:

$$
r \Pi_{v}=-h+m(\theta)\left[\Pi_{e}\left(\varepsilon_{u}\right)-\Pi_{v}\right]
$$

As standard in literature, consider the measure of the labor market tightness $\theta$ as the ratio between the number of vacant jobs $(V)$ and the number of unemployed people $(U) \cdot m(\theta)$ is the probability of filling a vacant job per unit of time ${ }^{21}$. When the free entry condition is satisfied $\left(\Pi_{v}=0\right)$, this relation entails $\Pi_{e}\left(\varepsilon_{u}\right)=\frac{h}{m(\theta)} 22$. Setting $\varepsilon=\varepsilon_{u}$ in equation 1-23, we get the expression of $\Pi_{e}\left(\varepsilon_{u}\right)$ :

$$
\Pi_{e}\left(\varepsilon_{u}\right)=\frac{h}{m(\theta)}=\frac{\varepsilon_{u}-\varepsilon_{d}-(r+\lambda)(\bar{f}+f \bar{T})}{r+\lambda}
$$

\footnotetext{
${ }^{20}$ It is the only source of variation in incentives.

${ }^{21}$ From matching models, $m(\theta)=\frac{M(V, U)}{V}, V$ is the number of vacant jobs, $U$ is the number of unemployed people, and $M(V, U)$ is a matching function that represents the instantaneous flow of hires at a given date. $M(V, U)$ is assumed to be strictly increasing with respect to each of its arguments.

${ }^{22}$ The lifespan of a filled job always starts at the maximum value $\varepsilon_{u}$, as in Cahuc, Carcillo, and Zylberberg (2014).
} 
Considering that tenure $\bar{T}=0$ for a just hired worker, and the existence of a probationary period when firing costs doesn't apply ( $f=\bar{f}=0$ ), firing costs does not affect the expected profit for a new job $\Pi_{e}\left(\varepsilon_{u}\right)$. Equation 1-32 defines the labor market tightness $\theta$. Firing costs does not affect $\theta\left(\frac{\partial \theta}{\partial f}=0\right)$, neither the exit rate of unemployment $\theta m(\theta)\left(\frac{\partial \theta m(\theta)}{\partial f}=0\right)$. It implies that the number of vacant jobs $V$ does not change if $\bar{f}$.

Considering $n$ the growth rate of the labor force, standard matching models determine that in equilibrium:

$$
u=\frac{q+n}{\theta m(\theta)+q+n}
$$

In equation 1-33, $u=\frac{U}{N}, U$ is the number of unemployed people and $N$ is the number of people in the labor force. As firing costs affect only $q\left(\frac{\partial q}{\partial f}>0\right)$, so $\frac{\partial u}{\partial f}>0$. Because $U$ increases and $V$ does not change with $f$, the instantaneous flow of hires $M(V, U)$ increases with $f$. Summing up, in an opposite way to the results of fixed firing costs, the tenure-dependent cost pattern combined with a probatory period causes increasing of firing and hiring. 


\section{2 \\ Labor Reallocation in Local Economies Following Large In- vestments in Ethanol Mills}

\section{1 \\ Introduction}

Local policymakers often provide incentives to firms to locate in their region, following a belief that the arrival of new businesses activities produces positive effects on localities. There are relatively few situations in which it is possible to measure the actual impacts of these events, once it is quite challenging to know what would have happened in the local market in the absence of the shock. There is some evidence of positive impacts on aggregate variables such as GDP per capita or employment, for example, but little is known about how these shocks affect individuals and make them reallocate to benefited locations and sectors. As changes in productive structures occur, workers need to reorganize across jobs, locals, occupations or sectors, and an approach that considers the labor reallocation perspective permits to understand the channels that produce aggregate effects in economies.

This study evaluates the effects of a large demand shock on local labor markets, using a labor reallocation perspective. An investment cycle in the construction of new ethanol mills in Mato Grosso do Sul (henceforth, MS) in the 2000s represented a relatively large and economically relevant positive labor demand shock for several small municipalities. MS is a predominantly rural state in the Center-West region of Brazil, and in 2005 (the pre-expansion period) the average GDP among MS municipalities was $\mathrm{R} \$ 304$ million. A single ethanol mill involves a capital amount of about $\mathrm{R} \$ 280$ million (or $\mathrm{U} \$$ 130 million under the terms of 2006).

This study aims to evaluate how individuals have reallocated across localities, sectors and occupations, adjusting the local labor supply to meet these demand shocks. This paper compares trends of locations that receive a large investment (an ethanol mill), with locations that do not. The empirical strategy uses an event study approach, taking into account leads and lags effects. Thus, to identify the effect of the demand shock, the empirical strategy explores the timing of the beginning of the operations of the mills in each 
municipality. The Relação Anual de Informações Sociais (RAIS) is the source of data. RAIS identifies employees and firms, so it is possible to track workers, finding out how they reallocate across sectors, occupations, and regions (migration).

The main results show that the migration of workers to the MS was a substantial source of adjustment, helping the economy to supply the new needs, especially concerning the demand for more skilled labor. The analysis of the municipality of origin profile shows the arrival of potentially specialized workers for the new activities. Results show a higher absorption of workers in the industry, but results on reallocation across sectors are less conclusive.

This paper contributes to three strands of the literature: the literature on the impact of large investments in local economies, the labor reallocation literature, and the literature on the effects of shocks in the energy sector.

A mill is a complex structure and represents a large and exogenous shock in a local economy. Technology innovations and changes in regulations and taxation systems have allowed a significant expansion of ethanol mills in MS in recent years: starting in 2006, the number of mills in MS increased from 8 to 22 (Figure 2.1). Large investments are capable of changing the productive structure of local economies and the demand for factors of production, and there is evidence of positive impact on localities (Greenstone and Moretti (2003)). In order to estimate large investments impacts, some studies usually compare trends between locations more or less exposed to shocks. Blanchard and Katz (1992) and Black, McKinnish, and Sanders (2005) consider a threshold for the participation of the affected sector in the local economy. This paper compares trends of municipalities that receive an ethanol mill, with municipalities that do not.

The analysis of mills' impacts in MS is of the utmost importance considering the developing country context. Aggregated data reveals that the industrial sector experienced a substantial increase in their relative proportion in the MS economy, in the same period of the investment shock. The Brazilian economy as a whole does not present this tendency. The municipalities where the industrial sector grows coincide with the entries of the mills. Assunção, Pietracci, and Souza (2016) study the aggregate effects of this demand shock (the construction of new mills) and find positive effects on several economic outcomes on the affected municipalities. They find that a typical municipality experienced a $30 \%$ increase in GDP, a $10 \%$ increase in population and a $40 \%$ increase in employment in the medium run (three periods after the mill's construction). Employment in the industrial sector (where mills are classified) almost quadruplicated in the same period. Thus, the entry of the 
mills represented a very large positive shock on these local economies.

This paper investigates to what extent migrations (regional reallocation) were useful to meet the new local labor demands generated by the arrival of the ethanol mills. It is possible that the local population of the municipalities would not be able to meet some of the new labor demand. The increase of the population in the municipalities affected by the shock indicates this possibility, and it is relevant to measure how some regions of the country, which had specific human capital for the new activities, contributed to labor supply. Therefore, this paper also contributes to the literature of labor reallocation.

There is a vast literature that analyzes the effects of technological shocks and trade liberalization on labor reallocation. Bustos (2005) analyses trade and capital account liberalization in Argentina in the early 1990s, finding impacts in a reallocation of workers for more skilled occupations. Artuc, Chaudhuri, and McLaren (2010) present a model of dynamic labor adjustment. Using data from the US population, they find an environment of slow adjustment of the economy to trade shocks, with a faster response in wages than in reallocation. Autor, Dorn, Hanson, and Song (2014) also analyzes commercial shocks in the USA, finding that individuals who initially worked in manufacturing industries earn lower cumulative wages and face more chance to be reallocated over sectors and firms. Autor, Dorn, and Hanson (2015) considers types of occupation, finding that labor markets with a specialization in routine task-intensive activities (more exposed to technological shocks) experience occupational polarization within manufacturing and non-manufacturing, without a net employment decline.

Using Brazilian data, Menezes-Filho and Muendler (2011) find that trade liberalization in the 1990s triggers labor reallocation, with an increase in transitions to services, unemployment, and out of the labor force. Their results show that output shifted to more productive firms while labor did not. DixCarneiro and Kovak (2015) study labor market adjustment following trade liberalization in Brazil in the same period, finding reallocation of workers from the formal tradable sector to formal nontradable sector. Non-employment increases in the medium term and non-employed workers reallocate to the informal sector in the long run. Bragança, Assunção, and Ferraz (2015) study the impact of the technological innovations in the agricultural sector implemented in the 1970s in Brazil, finding it affected the demand for skill in agriculture. Aiming to supply this demand, individuals with higher educational attainment were reallocated for this sector, while individuals with lower educational attainment reallocate out of the agricultural sector. This study does not track the workers but finds the results through the evolution of 
sectoral aggregates.

The literature also looks at the relationship between the labor reallocation and the business cycles, evaluating how labor reallocation responds to cycles (Benjamin and Meza (2007) and Saks and Wozniak (2011)) and how they can affect their duration (Chodorow-Reich and Wieland (2016)). Literature also analyzes the reallocation that occurs in the transitions of planned economies (Bound and Holzer (2000)). Environmental regulation also impacts specific sectors and consequently affects the labor market. This effect is more because of the destruction of jobs than the decrease in hiring, and workers need to reallocate (Walker (2011)).

With the growing need for renewable energy sources, the use of ethanol and bio-energy tends to grow in Brazil and the world. It is crucial to understand how ethanol mills affect the labor markets of impacted locations. In this context, the period of large mill entry into the MS (2005 to 2012) is an opportunity to analyze the effects of these large structures on the economies.

Shocks in the energy sector affect economies in different ways. In the context of impacts related to the producing region, there is a vast literature analyzing the effects of price shocks on non-renewable energy sources (oil, coal and natural gas). Much of this literature finds overall positive effects for local economies on boom periods (Allcott and Keniston (2017), Weber (2014), Fetzer (2014), and Michaels (2010)), with potential spillovers to neighboring areas (Feyrer, Mansur, and Sacerdote (2017)) and to other sectors (Marchand (2012)). Some studies show potentially adverse effects on other sectors (Jacobsen and Parker (2014) and Black, McKinnish, and Sanders (2005)). Considering Brazil, there are also studies showing the impacts of investments in renewable energy mills (such as Assunção, Szerman, and Costa (2016) and Assunção, Pietracci, and Souza (2016) previously mentioned)

In the context of a shock in the energy sector, it is also important to understand migratory movements. The available evidence points to population growth and employment, but which mechanisms have made these positive aggregate effects possible? To what extent has internal migration helped this process. What was the typical migrant's profile? For those who migrated, it is investigated whether their municipalities of origin had a tradition in activities that could also be useful for those who would work in mills.

It is essential to consider that the expansion of the mills in the MS affected the way of life of its population as a whole. This study focuses only on the formal labor market. There are indications that the expansion of the milling industry increase conflicts between farmers and natives in some areas 
of the state ${ }^{1}$, which should also be a concern of future policies for the region.

The paper is organized as follows. Section 2.2 provides an overview in theory and background. Section 2.3 discusses the empirical strategy and Section 2.4 presents the data sources used in this study. Section 2.5 presents main results. Section 2.6 concludes.

\section{2 \\ Ethanol Mills Expansion to MT}

\subsection{1}

\section{Institutional and Geographic Context}

As a result of the oil crises in 1973 and 1979, the Brazilian government financed Pro-Alcohol (National Alcohol Program)² between 1975 and 1990, a program of large-scale substitution of vehicular fuels derived from petroleum by ethanol. As a consequence, MS received eight new mills between 1979 and 1982. From 1983, there was a period of stagnation in the construction of new mills until 2005, when many factors boosted the sector again (Figure 2.1).

In particular, technological innovations and regulatory changes made possible a new mill expansion phase, starting in 2005. Between 2005 and 2013, 16 new mills started operations in MS (Figure 2.1). Concerning technological innovations, the production of flexible fuel vehicles (henceforth, FFVs) in Brazil started in May 2003. A FFV is a vehicle with an internal combustion engine designed to run on more than one fuel, usually gasoline blended with ethanol. In 2003 , the FFVs represented only $2.6 \%$ of the total number of cars produced in Brazil, and in only six years, that rate increased to $86.6 \%$ (Figure 2.2). Tax incentives also encouraged FFVs market gain, such as reduction of IPVA (Tax on Motor Vehicle Properties) for these lines. Between the 2009 and 2017 years, the proportion of FFVs in the total number of cars produced in the country was $86.7 \%$ on average. This fast penetration of FFV in the automobile market represented a shock in demand for ethanol, which acted as a stimulus to the new cycle of mills expansion.

Some regulatory changes also stimulated this industry. In Brazil, Law No. 8,723 of 1993, which deals with the emission of pollutants in vehicles, establishes a mandatory percentage of anhydrous ethanol blended with gasoline (at the time, 22\%). This mandatory minimum percentage had changed a few times when laws established a range on which the system can operate. This

\footnotetext{
${ }^{1}$ https://cimi.org.br/wp-content/uploads/2017/11/Relatorio-Violencia-contraindigenas- $\mathrm{MS}_{2} 003-2010 . p d f$

${ }^{2}$ The term "alcohol" was widely used in the past, but was replaced by "ethanol" in recent years to suit the international standard. In 2009, the ANP (National Agency of Petroleum) published a resolution that requires filling stations to update the terms for "ethanol".
} 
Figure 2.1: Sugar and Ethanol Mills in MS State - Timeline

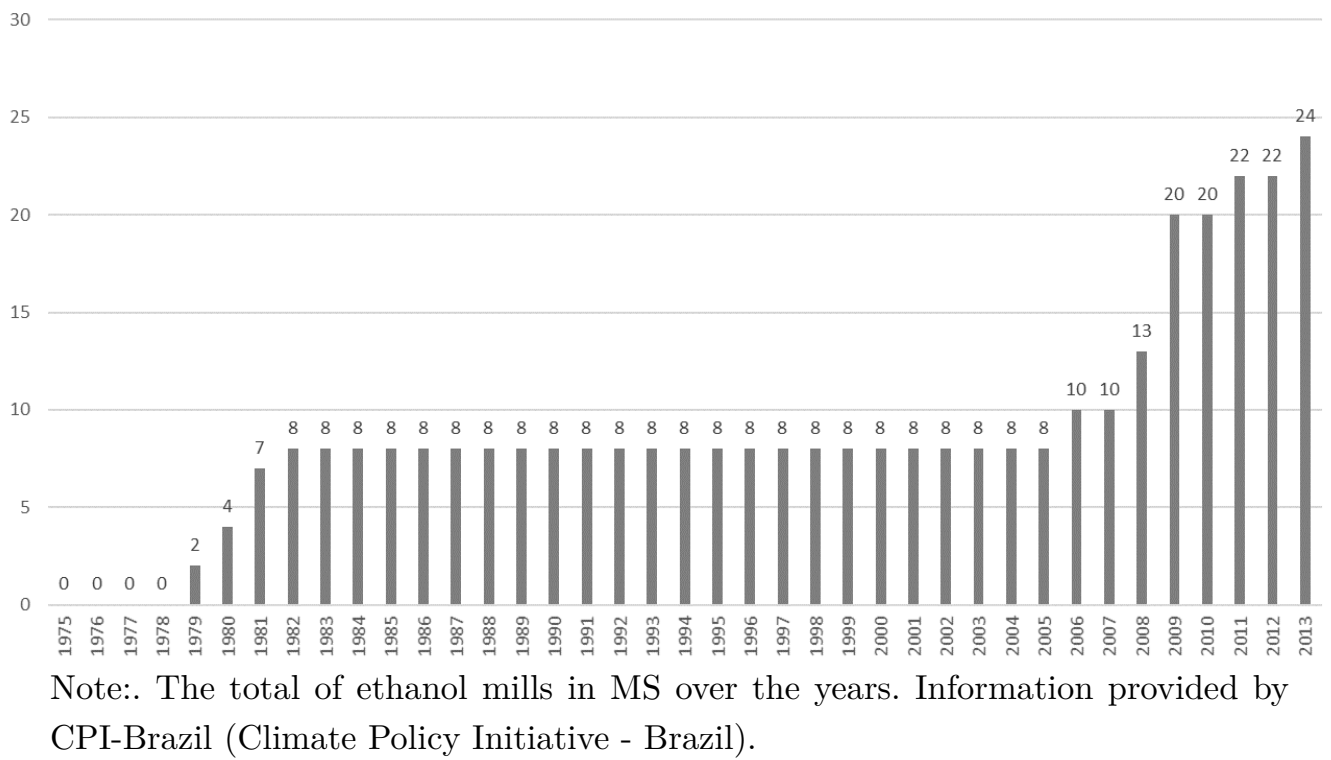

range was $20 \%-24 \%$ in 2001, $18 \%$ - 25\% in 2011 and $18 \%-27.5 \%$ in 2014 . Currently, the stipulated proportion of ethanol is $27 \%$, and there are proposals to increase this percentage in the coming years.

These events boosted both sugar and ethanol production. Initially, São Paulo concentrated this industry, but expansion occurred mainly in the states of Minas Gerais, Goiás, Paraná, and Mato Grosso do Sul (MS). According to Pereira et al. (2007), five factors drive the new mills to MS. First, local tax incentives, with a specific focus on sugarcane industry.Second, environmental licensing was facilitated. The lowest cost of land was also an incentive. By comparison, the land in São Paulo would be 3.4 times more expensive than land in MS. Adequacy of soil (soil, fertility, depth, availability of water, relief) and climate (temperature, rainfall, seasonality) were also stimulating factors. Finally, the state's infrastructure and location, near large consumer centers, attracted new mills for MS. The combination of all these factors made the number of mills to significantly increase in MS, and the state presented the highest percentage growth of the harvested area of sugarcane in the period.

A mill is a complex structure, which requires investments in the order of $\mathrm{R} \$ 280$ million (U\$ 130 million in 2006 figures). This value represents more than $90 \%$ of the GDP of a typical municipality in MS. The construction of a mill and its operation means an enormous economic impact in the municipality. Large investments are capable of changing the productive structure of local economies and the demand for factors of production, such as labor. The analysis of their impacts is of the utmost importance, especially considering the developing country context. 
Figure 2.2: Proportion of FFV in the total of cars produced in Brazil

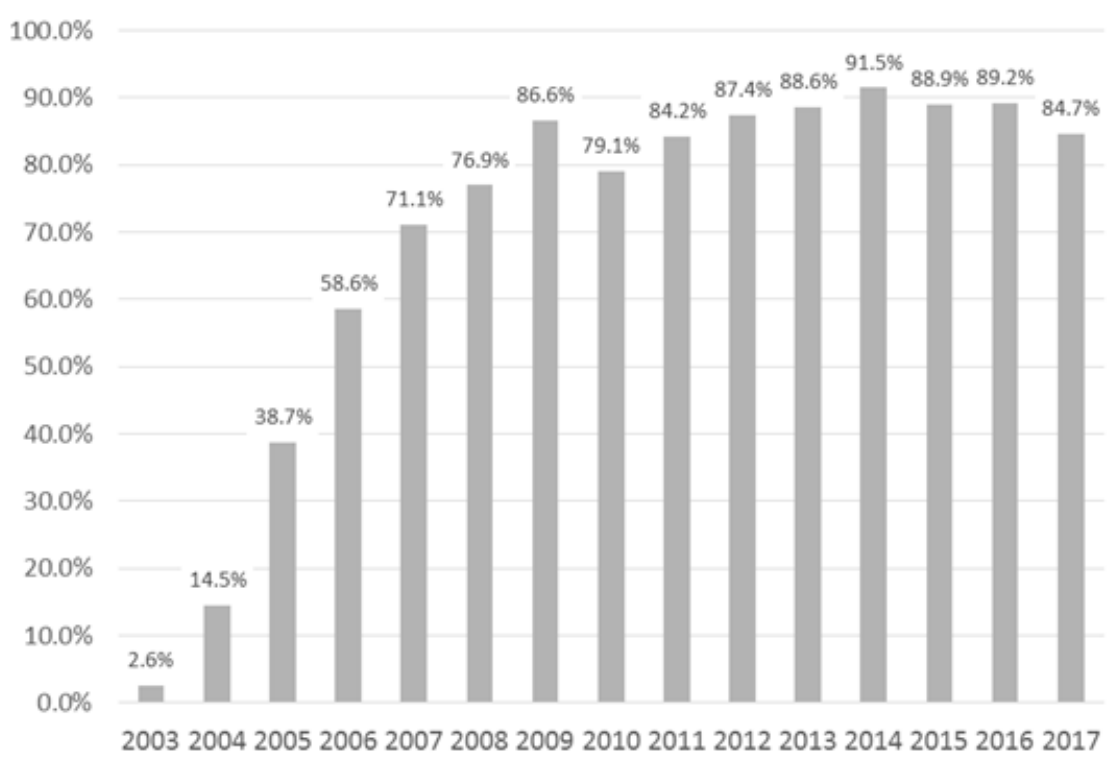

Source: Brazilian Automotive Industry Yearbook - Anfavea 2018.

\subsection{2}

\section{Labor Markets Context}

The entry of the new ethanol mills in the MS represents a positive shock in labor markets for this municipality, as a large investment in a local economy. There is a large literature that examines how local labor markets respond to demand shocks. Some of these studies use structural models to simulate the effect of labor demand shocks on employment, wages and migration (Blanchard and Katz (1992), Bartik (1991)). There is also literature that identifies a specific shock and measures its effects in the labor market. Black, McKinnish, and Sanders (2005) analyzes the effect of labor demand shocks to a specific economic sector. The labor demand shock is the increase in demand for coal, generated by the OPEC oil embargo. The embargo was a specific exogenous source of variation, what guarantees identification. They find evidence of modest employment spillovers into sectors with locally traded goods sectors, but not into sectors with nationally traded goods.

This study evaluates the impact of new mills in MS on the local labor market. Figure 2.3 shows that in the period between 2005 and 2012 years, the agriculture and service sectors lost weight in MS economy. On the same period, there was a higher in the industry's relative size. In Brazil as a whole, the relative size of agriculture also dropped, with services being stable and industry with some growth (Figure 2.4). However, the movements are much smoother than in MS. In MS, employment in industry shows some stability between 2002 and 2006, at around 18\%. In coincidence with the beginning 
Figure 2.3: Proportion of Sectors in the MS Economy

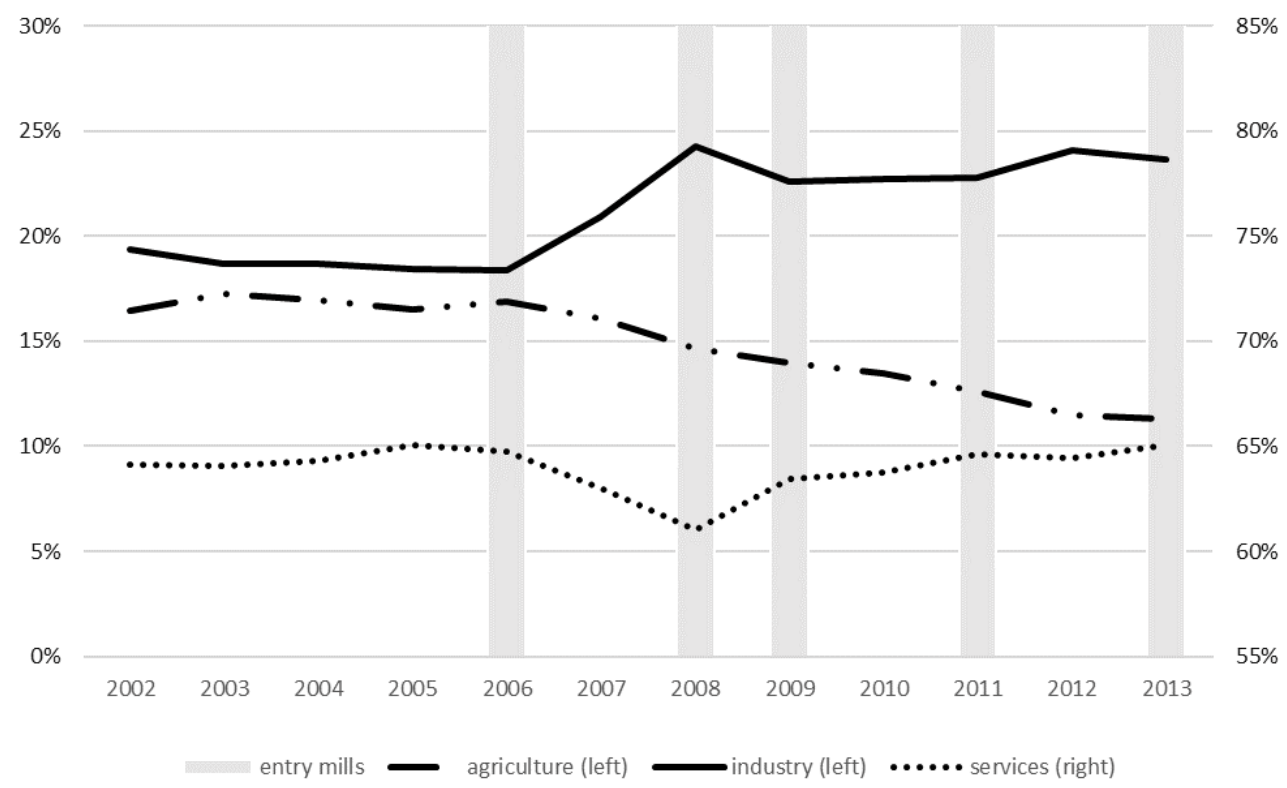

Note: The proportions of sectors are calculated analyzing the labor force associated with each sector, considering Rais. Mills information is provided by CPI-Brazil (Climate Policy Initiative - Brazil).

of the new cycle of entry of mills, this proportion starts to grow from 2006, reaching around $24 \%$ in 2008, and settling at a higher level since then. This pattern is very different from Brazil as a whole, where the industry had a stable weight, around $25 \%$, during the same period. Figure 2.5 shows a correlation between the entry of the new mill and the increase in the industry sector participation in municipalities of MS.

There is empirical evidence that the entry of the new mills affects both the mill sector itself and generates spillovers for other sectors. Assunção, Pietracci, and Souza (2016) find positive effects in several economic outcomes of the municipalities that received the mills. A typical municipality has a $30 \%$ increase in GDP, a $10 \%$ increase in population and a $40 \%$ increase in employment in the long run (three periods after the mill's implementation). Employment in the industry sector (where mills are categorized) almost quadruplicates in the same period. According to them, employment starts to increase significantly in the same year the mills begin operating, and more than doubles after three years. A similar dynamic effect occurs in the number of skilled labor contracts. Impacts on aggregate wages are observed two years before and add up to an $\mathrm{R} \$ 4$ million increase two years later. Wages seem to stabilize three years later. The impact on the number of firms is significant, starting at one year before the entry of the mill. Three years later, it has observed an accumulated increase 
Figure 2.4: Proportion of Sectors in the Brazilian Economy

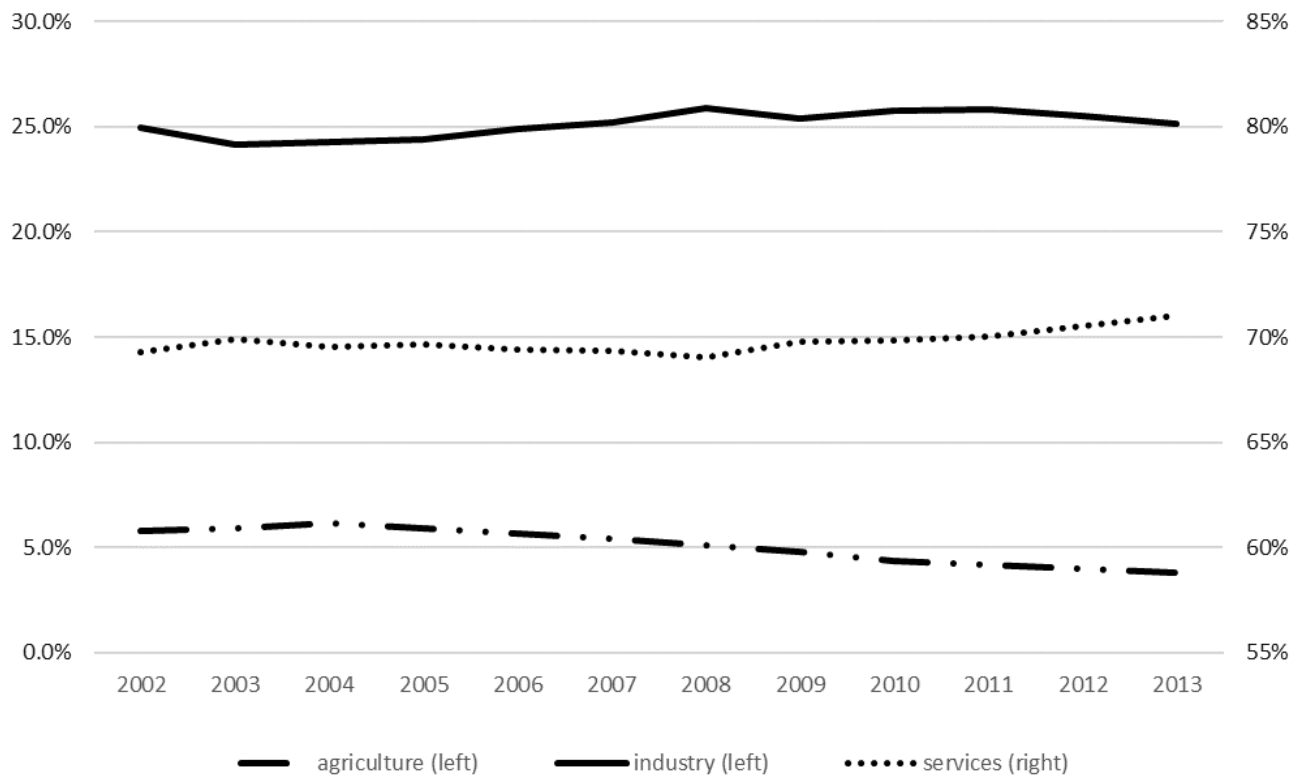

Note: The proportions of sectors are calculated analyzing the labor force associated with each sector, considering Rais.

of $82 \%$ in the number of firms.

Assunção, Pietracci and Souza 2016 show the results for the same variables, disaggregating by sector. The main results are in the industry and the service sector, with an increase in the number of workers, wages and different effects for skilled and unskilled workers. Overall effects in agriculture are small, and the paper points some reasons for that. First, there is an ambiguous effect in the agricultural sector. Second, a mill is assigned to the industry sector, even when an employee is working on sugarcane crops. Finally, it is possible that some effect is in the informal labor market, and RAIS dataset does not cover the nonformal sector.

Those results reveal that the entry of the mills is a positive shock on labor demand. This paper aims to evaluate this shock from a labor reallocation perspective. The purpose is to find which kind of movements were necessary to accommodate the local economy of affected municipalities to the new economic conditions. Regional reallocation, specially across the states of Brazil, shows an important mechanism. On the other hand, the pure reallocation of MS workers across sectors of the economy does not show such defined patterns.

\section{3}

\section{Empirical Strategy}

This paper measures the impacts of the entry of new mills into the labor markets of MS municipalities, from the reallocation perspective. It uses an 
Figure 2.5: Industry Presence in MS

2005

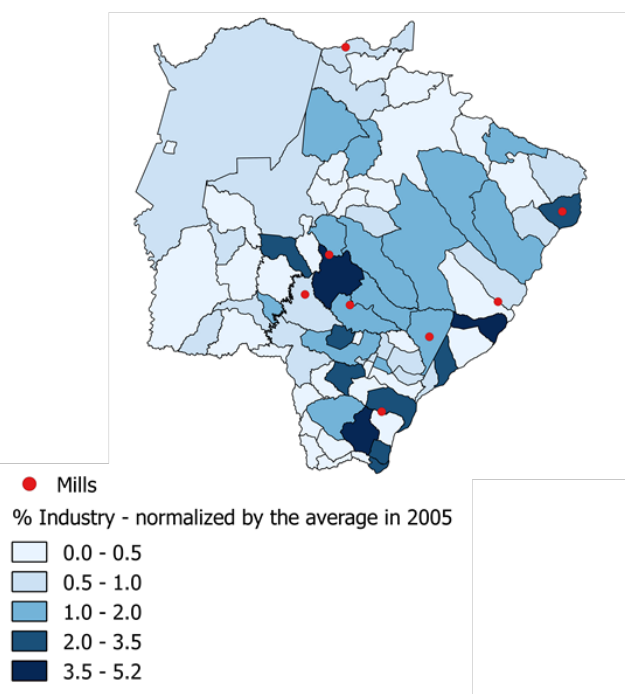

2012

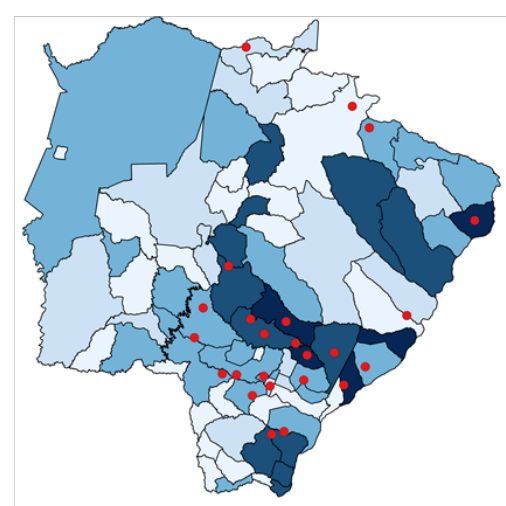

Note: The proportions of sectors are calculated analyzing the labor force associated with each sector, considering Rais. Mills information is provided by CPI-Brazil (Climate Policy Initiative - Brazil).

event study approach, which considers leads and lags effects. A priori, the duration of impacts are unknown. Before the start of the operation of the mills, there is an effort associated with their planning and construction, which also may impact the local labor market. Once the mill is ready to operate, adjustments in the labor market are not immediate and may persist for some time. These aspects justify the analysis of anticipated and delayed effects. The main equation of analysis is:

$$
y_{m t}=\alpha_{m}+\theta_{t}+\sum_{k=t-4}^{k=t+4} \beta_{k}(\text { newmill } m k)+e_{m t}
$$

In equation $2-1, y_{m t}$ is the outcome of interest to the municipality $m$ in period $t . \alpha_{m}$ and $\theta_{t}$ are municipality and year fixed effects, respectively. newmill $_{m k}$ is a dummy indicating the entry of a mill in municipality $m$ in period $k$. The $\beta$ 's are the coefficients of interest.

The outcomes of interest $\left(y_{m t}\right)$ refer to the number of people who experienced some reallocation, in a municipality $(m)$ in a period $(t)$. For example, $y_{m t}$ may be the migration of people from municipalities in Brazil to municipalities of MS who received a new mill or not. In this case, the variable is the total of individuals that in the current period $(t)$ are in the municipality $(m)$ in MS and that in the previous period $(t-1)$ were outside the MS, divided 
by the total of individuals in this municipality $(m, t)$. Section 2.4 provides a more detailed description of other outcomes.

The variable newmill $l_{m k}$ represents the demand shock generated by the new mill, that is, the treatment. For a municipality $m$, newmill $l_{m t}=1$ if a mill has started operations in period $t$. If the beginning of the operation was in the previous year $(t-1)$, newmill $l_{m t+1}=1$ : that is, in the period $t$, newmill $l_{m t+1}$ means that this municipality already had a mill running for one year, and $\beta_{t+1}$ measures the impact of that one-year lag.

$\beta_{k}$ are the effects of anticipation $(k<t)$ and the lagged effects $(k>t)$. The eight year's panel data and the timing of entry of new sugarcane mills restricts estimation to 9 parameters per regression. Thus, the leads and lags can range from $\left(\right.$ newmill $\left._{m t-4}\right)$ up to $\left(\right.$ newmill $\left._{m t+4}\right)$. Lead dummies capture anticipated effects, while lag dummies capture delayed effects. In $(t+4)$ there are only five mills to estimate parameters, and therefore the parameters are inaccurate. Despite their inclusion in the regressions as controls, interpretations should not consider their coefficients.

Temporal trends common to the municipalities, which can influence both the existence of mills $\left(\right.$ newmill $\left.l_{m k}\right)$ and the outcomes of interest $\left(y_{m t}\right)$, are controlled in the time fixed effect $\theta_{t}$. Characteristics such as the quality of life of the municipality, the availability of natural resources and the level of infrastructure can also influence both $y_{m t}$ and newmill $l_{m k}$, but the municipality fixed effect $\alpha_{m}$ controls for it. What persists in the error term $\left(e_{m t}\right)$ are characteristics that change in the municipality over time. For example, an improvement in infrastructure or a negative land price shock, which could both attract more mills and more migrants to the municipality, would be sources of problems for the estimation. The hypothesis of the absence of this type of event seems reasonable for the period studied.

The sugarcane mills investment profile suggests that the statistically significant impacts should trace back at most two years before the mill starts operation (Assunção, Pietracci, and Souza (2016)). Thus our exogeneity assumption requires that the effects of the operation of the new mill are not significant before $(t-2)$.

\section{4}

Data

This study uses data from the Relação Anual de Informações Sociais (RAIS). RAIS is a restricted-access matched employee-firm administrative dataset, with all formal job contracts in Brazil. Observations considered are the job contracts, excluding those of the public sector, between the years 2005 and 
2012. RAIS has detailed information on the employee (social security number, gender, education, occupation), on the employer (tax number, the sector of activity, establishment size, geographical location), and on the employment relationship (wage, tenure, hiring date, lay-off date and reason, etc.).

A unique social security number identifies each worker, making it possible to track each employee over the years, collecting their available information. For each year, the municipality where the individual works and the sector of activity in which of the firm are available. All individuals who have had an employment contract in MS, during any period of the sample, are tracked.

Each employee can have more than one job contract in a same year, even at the same time. As the strategy involves to track each one, it is necessary to define a main contract in each year, for each worker. The algorithm that establishes this main contract works according to the following criteria, in order of priority: the job contract with the highest average wage in the year, the job contract with the highest working hours in the year, and the job contract with the highest tenure in the year. If the main contract is still not defined, the observation is dropped. At the end of this process, each worker has only one job contract in a year, the main job contract.

By observing the main contract of the worker in each year, it is possible to analyze information about her status about the municipality in which she works, sector of activity, and occupation, for example. The variables of interest come precisely from the change of worker status every year. For example, there is a dummy indicating if the individual remained in the same city, another dummy indicating if she migrated between municipalities within MS, and another dummy indicating if she migrated from a municipality from another state. In some specifications, characteristics of the municipality of origin are also considered. Additionally, some dummies indicate if the person remained in the same sector of activity (agriculture, industry, services) and specific dummies for each reallocation between sectors.

Regression 2-1 is run at the municipality level, with each dummy aggregated and then weighted by the total workforce of the municipality. Thus, outcome variables represent reallocation in the municipality $m$ in the year $t$.

The panel of municipalities over the years is merged with information on mills. In the mills database, there are 15 different treated municipalities (out of 77) and 16 mills. Treatment is just the entry of a new mill, and so municipalities with mills that already existed in 2005 and no entry of new mills from 2005 to 2012 are in the control group. The control group has 62 municipalities (56 without mills and 6 with mills that existed before 2005). The results are generally stable in a sample without the municipalities that 
already had mills.

Table 2.7 shows some descriptive characteristics for the years 2005 (before the entry of the new mills) and 2012 (after the shock), for treated municipalities (with new mills) and municipalities untreated (without new mills). The numbers indicate that the treated municipalities already had a higher level of employment, hours worked and wages than the municipalities not treated in 2005, before the shock. This difference increases later, in 2012. The sectoral reallocation did not have a significant difference between the municipalities treated and not treated in 2005 but started to show more flows to the industry in the municipalities treated in 2012. The differences in reallocation across occupations are not significant. Regarding migratory flows, the differences are also not significant, but they point to higher inflows from outside the MS to the treated municipalities.

Table 2.7 shows only mean difference tests to describe the data. The empirical strategy uses controls, fixed effects of time and municipality and, moreover, more precisely explores the timing of the beginning of the operation of a mill in each municipality, as seen in equation 2-1. Section 2.5 presents the results of this strategy.

\section{5}

\section{Results}

This section presents the main results in figures, and the more detailed results are tables in Section 2.7. In the figures, the graphs show the estimated coefficients for periods of four years before, to four years after the initiation of the operation of the ethanol mill in the municipality, with a confidence interval of $95 \%$. Is expected that the effects concentrate in periods close to $t+0$, but there is no hypothesis about the duration of effects a priori.

\subsection{1}

\section{Characterizing the Shock in Labor Demand}

This subsection evaluates the effects of the new mills in MS on employment, worked hours and wages. The objective is to characterize the event as a positive shock in local labor markets in MS. Assunção, Pietracci, and Souza (2016) show results in this direction, but using a different database structure ${ }^{3}$.

Table 2.1 shows effects on employment, average real wages and average hours worked in municipalities ${ }^{4}$. Column 1 presents the effects on overall

\footnotetext{
${ }^{3}$ Assunção, Pietracci, and Souza (2016) consider employment as the number of contracts throughout the year. This paper considers only the main employment contract of each employee in a year. Also, Table 2.1 considers variables in log.

${ }^{4}$ Variables are in log.
} 
employment. The positive effect is significant between one year before and two years after the mill entry ${ }^{5}$. Impact of mills on average real wages (Column 2) are significant only one period after the mill's entrance and then dissipates, and effects on worked hours (Column 3) are positive and significant between one year earlier and two years after the shock (the same period in which there is employment growth).

These results suggest that the new mills affect municipalities as a positive shock in labor demand. Job growth (in terms of the number of employees and hours worked) was a more important driver than the growth of average wages. The goal of the next subsections is understanding this labor demand shock from the perspective of labor reallocation.

\subsection{2}

\section{Geographical Reallocation}

This subsection presents the first results related to reallocation. The main lessons are that the reallocation between municipalities, or migrations, were the main drivers for the settlement of the economy in a new equilibrium in the labor market.

Figure 2.6 shows that the municipalities that received mills have more migrant workers than municipalities in the control group. Considering the migrations between municipalities of MS, the first graph of Figure 2.6 shows that one municipality in the treatment group has 2.7 migrant workers more than municipalities of the control group, for every 100 workers, one year before the beginning of the mill operation. The flow of migrants remains at this level up to one year after the shock, and two years later there is no difference between the control and treatment groups. As the outcome variable considers the municipality where the employee worked in the previous year, the coefficient not significant of $\beta_{t+2}$ does not mean that the effects dissipate in the sense of return of the migrants to their municipalities of origin. A $\beta_{t+2}$ not significant means a new equilibrium, in which more workers who are currently in the municipality, originate from another municipality. That is, at some point they migrated to the municipalities of the treatment group.

The second graph in Figure 2.6 shows migrations from municipalities outside the MS to municipalities in MS. The numbers point to a more intense and concentrated flow precisely at the beginning of the mill operation. A municipality in the treatment group has 3.7 migrant workers more than municipalities of the control group, for every 100 workers, in the year that

\footnotetext{
${ }^{5}$ The impact is less persistent over time than found in Assunção, Pietracci, and Souza (2016).
} 
Figure 2.6: Migrations Flows to MS

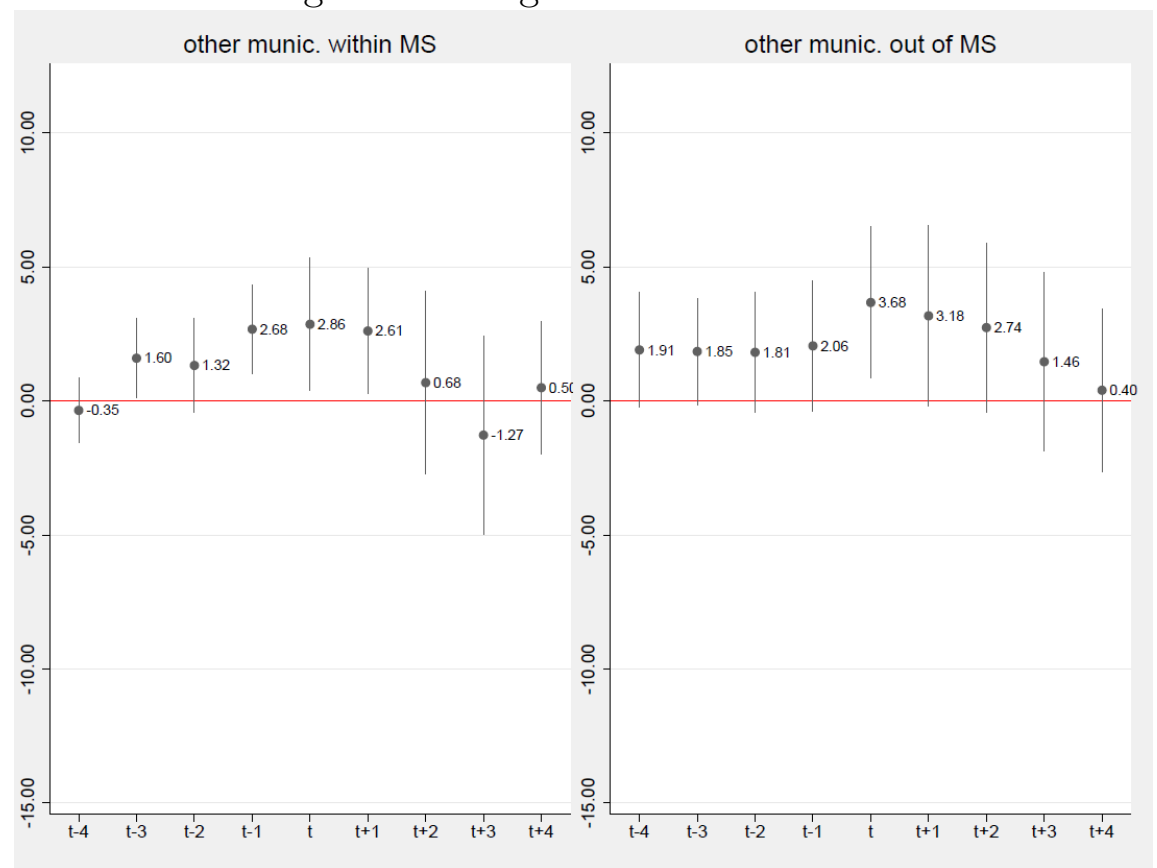

Note: Each $\beta_{k}$ reflects the impact in the number of reallocations, as a proportion of the total contracts in a municipality. Estimated coefficients for the periods between $t-4$ and $t+4$, with a confidence interval of $95 \%$. Source: RAIS.

the mill starts operation. Table 2.2 in Section 2.7 shows these results in more detail, and considering a subsample of more skilled workers ${ }^{6}$.

The next subsection presents these results for migrations from outside the MS to municipalities of the MS but considering some aspects of the migrants. These aspects are related to their qualification, both in terms of schooling and in terms of the dominant sector of their municipalities of origin.

\subsection{3}

\section{Geographical Reallocation and Profile of Migrants}

This subsection focuses on migrants that come from municipalities from outside the MS , such as those presented in Graph 2 of Figure 2.6. Complementary, the numbers in Figure 2.7 show how treated municipalities received more migrants than municipalities in the control group, considering three sectors of intensity in the municipality of origin: general agriculture, sugar cane, and industry.

The goal is to have an approximation of how much specific human capital to the ethanol industry (or related industries) the migrants have and carry to MS. In order to do this, the proportion of job contracts of each of these sectors

${ }^{6}$ The coefficients of the Figures are multiplied by 100, to facilitate visualization (thus, 1 means 1\%). The coefficients of the Tables in Section 2.7 are not normalized (thus, 0.01 means $1 \%)$. 
(agriculture, sugar cane, and industry) in the total contracts in a municipality is calculated, for each Brazilian municipality ${ }^{7}$. Consider, for example, the industrial sector. In each year, it is considered $10 \%$ of the municipalities with the highest proportion of labor contracts in the industrial sector in Brazil. This group of municipalities is then considered as intensive in the industrial sector. The same is done for the agriculture sector, and more specifically the sugar cane sector. The analyses contemplate these sectors because they are related to ethanol mills activity.

Figure 2.7 shows an influx of workers from municipalities intensive in sugar cane sector. The movements start three years earlier and persist until two years after the mill's entrance. In more preceding periods, the migration starts smaller, with less than one migrant worker for every 100 workers in the labor force. In the next two years before the start of the mill operation, flows intensify, with between 1.6 and 1.7 workers migrating each year, to every 100 workers. In the year when the mill stars the operation and the next year, flows are even more substantial, from about 3.1 migrants to every 100 workers each year, and this number moderates to 2.3 two years after the shock. These numbers represent the additional amount of migrants in the municipalities of the treatment group compared to those in the control group.

The effects for migrants from agricultural sector intensive municipalities are concentrated only in the period of the mill entry ( 1 migrant per 100 workers), and for migrants from municipalities with intense activity in the industry only in the first year afterward (1.5 migrants for every 100 workers).

Figure 2.8 shows the same results in a subsample of skilled workers ${ }^{8}$. Although the impacts show a smaller magnitude, the patterns show a more persistent flow of workers who came from industrial municipalities, with the effects starting one year before the shock and being persistent over the next periods. The coefficients indicate that in each year, something between 2 and 3 workers were this type of migrant, for every 1000 people in the workforce. When considering skilled workers from municipalities with intense sugar cane activity, migration is also more persistent. The coefficients indicate that in each year (starting two years before the shock), something between 3 and 13 workers were this type of migrant, for every 1000 people in the workforce.

Tables 2.3 and 2.4 in Section 2.7 show these results, and also results for migration inside MS.

${ }^{7}$ All contracts are considered, not only the main ones.

${ }^{8}$ People who attend at least high school. 
Figure 2.7: Migrations Flows from Brazil to MS

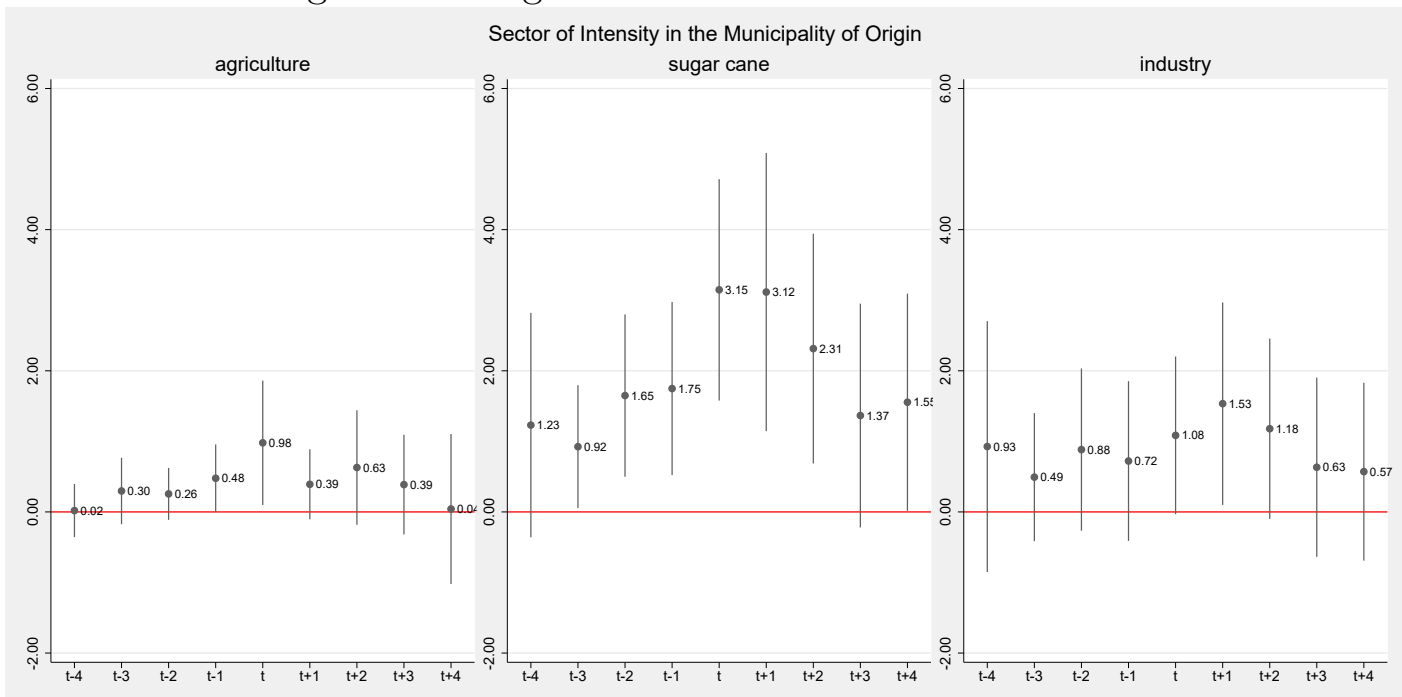

Note: Each $\beta_{k}$ reflects the impact in the number of reallocations, as a proportion of the total contracts in a municipality. Estimated coefficients for the periods between $t-4$ and $t+4$, with a confidence interval of $95 \%$. Source: RAIS.

Figure 2.8: Migrations Flows from Brazil to MS - sub sample: skilled workers

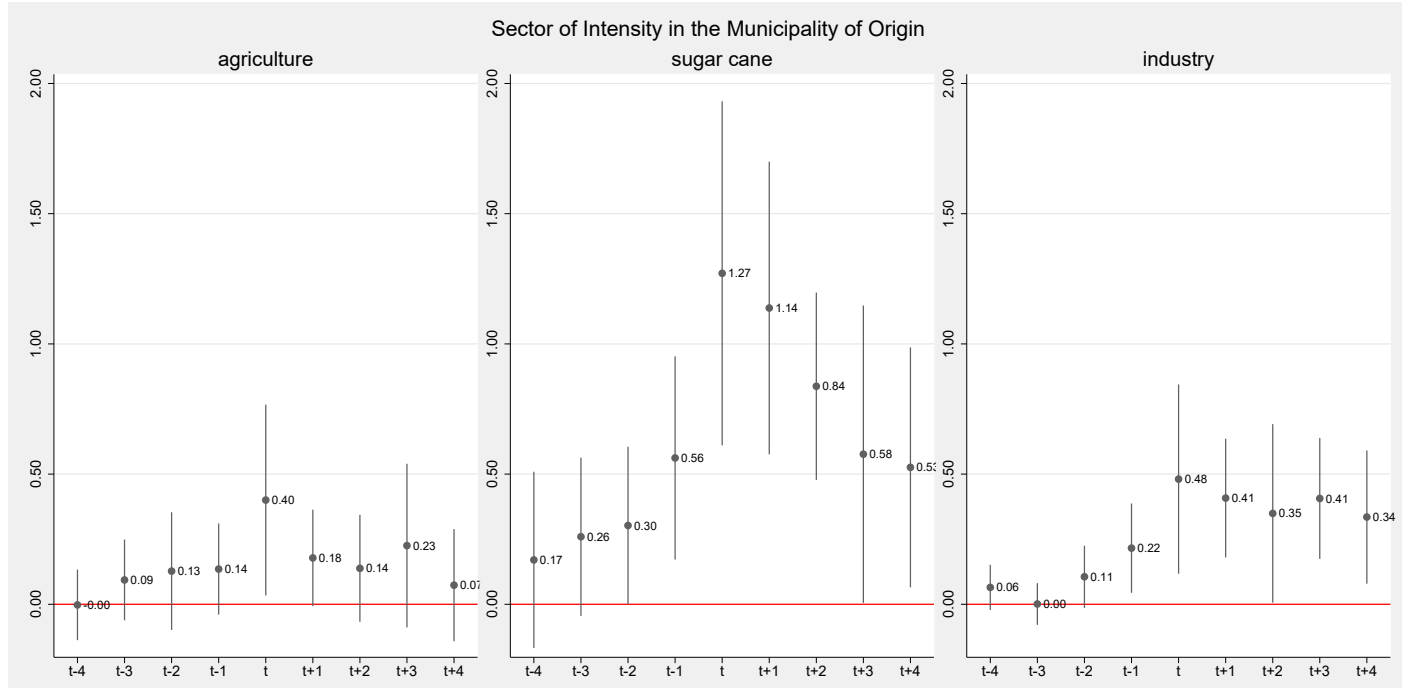

Note: Each $\beta_{k}$ reflects the impact in the number of reallocations, as a proportion of the total contracts in a municipality. Estimated coefficients for the periods between $t-4$ and $t+4$, with a confidence interval of $95 \%$. Source: RAIS.

\subsection{4}

\section{Reallocation across Occupations}

Figure 2.9 shows reallocation across kinds of occupation. The idea is to understand how positive labor shock affects reallocation from low-skilled to high-skilled occupations. These flows capture the change of worker occupation, in one year against the previous year. Figure 2.9 shows that more bluecollar workers receive promotions on municipalities in the treatment group in comparison with municipalities in the control group. For blue-collar workers, 
reallocation starts a year earlier, up to a year after the shock.

Figure 2.9: Flows to Higher Skill Occupations

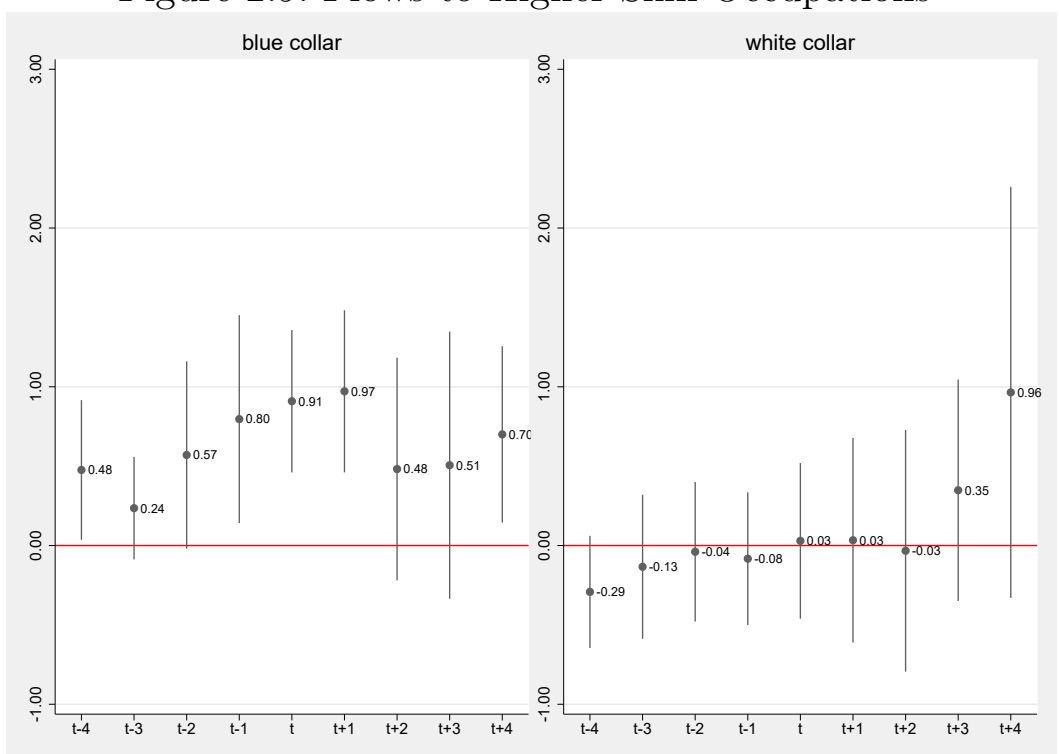

Note: Each $\beta_{k}$ reflects the impact in the number of reallocations, as a proportion of the total contracts in a municipality. Estimated coefficients for the periods between $t-4$ and $t+4$, with a confidence interval of $95 \%$. Source: RAIS.

The coefficients indicate that in each year something between 8 and 10 workers receives a promotion, for every 1000 people in the workforce. The results are not significant to white-collar workers, which make sense because blue-collar workers have activities more related to ethanol industry.

Table 2.5 in Section 2.7 shows these results with more detail.

\subsection{5}

\section{Reallocation across Sectors}

Figure 2.10 shows the results considering reallocation across sectors of the economy. Although the descriptive statistics and the previous results suggest a greater dynamism in the industrial sector, results from the perspective of reallocation do not show an evident pattern.

Consider retention (the opposite of reallocation) as the case when an individual is working in a specific sector in the current period, and this was the same sector she was in the previous period. In this analysis, the interest is in the sector of activity, and thus, a change of employer is not relevant. Figure 2.10 shows some drop in retention in agriculture, a more significant drop in retention in services, and an increase in retention in the industry. The increase in retention in the industry is quite persistent and means this sector has gained strength. However, the results of flows across sectors (reallocation), not just 
retention, are not very conclusive. Table 2.6 in Section 2.7 shows all flow across sectors.

Figure 2.10: Retention in Sectors

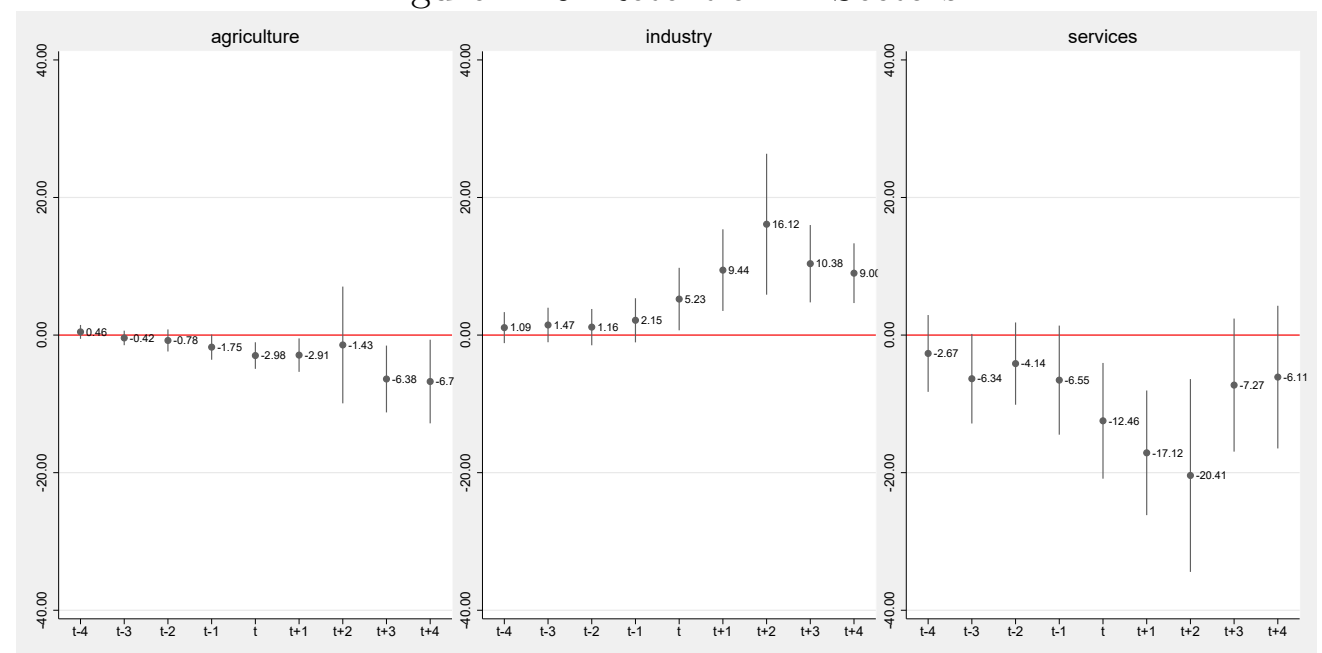

Note: Each $\beta_{k}$ reflects the impact in the number of retention in each sector, as a proportion of the total contracts in a municipality. Estimated coefficients for the periods between $t-4$ and $t+4$, with a confidence interval of $95 \%$. Source: RAIS.

\section{6}

\section{Final Considerations}

This study contributes to the literature of labor reallocation in the context of large investments in local economies. MS received a large number of mills, starting in 2006. Investments associated with a typical mill represent about $90 \%$ of the GDP of a municipality in MS. This work analyzes how this shock impacted reallocation in local labor markets.

Aggregated data shows the shock represents a positive impact on labor demand. From a perspective not so common in literature, with the tracking of worker over the years, the main results point that migration flows were a relevant tool to accommodate economy in the new labor market equilibrium. Flows of workers from other Brazilian states to municipalities in MS were a powerful mechanism to supply the new demand.

Geographical flows also meant an influx of human capital in the state. Results reveal significant patterns on the migration of skilled workers, considering their educational level and the profile of the municipality of origin. Several effects are persistent over time.

Concerning the effects in sectors of activity, the mills promoted an increase in the retention of workers in the industry sector. However, the effects on reallocation across sectors are not conclusive. 
There is a vast literature analyzing the effects of shocks on non-renewable energy sources (oil, coal and natural gas) in local economies. With the growing need for renewable energy sources, the use of ethanol and bio-energy tend to intensify, and it is crucial to understand how ethanol mills affect local economies.

In the context of the effects on the formal labor market, the results reveal a massive flow of workers going to the municipalities that received investments from ethanol mill. These workers were able to increase the stock of human capital of the affected cities, bringing the necessary tools for the development of new activities. Also, the results also point to an improvement in qualification, with workers from low-skilled occupations going to high-skill occupations. Many of the effects are persistent and are not exhausted in the period of analysis. 
Chapter 2. Labor Reallocation in Local Economies Following Large Investments in Ethanol Mills

\section{7}

\section{Tables}

Table 2.1: General Results

\begin{tabular}{lccc}
\hline & & & \\
\cline { 2 - 4 } & Employment & Wage & Worked Hours \\
& $(1)$ & $(2)$ & $(3)$ \\
\hline \hline $\mathrm{t}-4$ & 0.012 & 0.035 & 0.002 \\
& $(0.780)$ & $(0.307)$ & $(0.723)$ \\
$\mathrm{t}-3$ & 0.018 & -0.019 & 0.010 \\
& $(0.689)$ & $(0.455)$ & $(0.145)$ \\
$\mathrm{t}-2$ & 0.092 & 0.018 & 0.012 \\
& $(0.066)$ & $(0.564)$ & $(0.125)$ \\
$\mathrm{t}-1$ & $0.188^{* *}$ & 0.046 & $0.018^{*}$ \\
& $(0.006)$ & $(0.250)$ & $(0.037)$ \\
$\mathrm{t}$ & $0.243^{* *}$ & 0.038 & $0.019^{*}$ \\
& $(0.004)$ & $(0.345)$ & $(0.045)$ \\
$\mathrm{t}+1$ & $0.341^{* *}$ & $0.079^{*}$ & 0.018 \\
& $(0.001)$ & $(0.045)$ & $(0.085)$ \\
$\mathrm{t}+2$ & $0.400^{*}$ & 0.101 & $0.026^{*}$ \\
& $(0.026)$ & $(0.079)$ & $(0.019)$ \\
$\mathrm{t}+3$ & 0.032 & 0.055 & 0.016 \\
& $(0.847)$ & $(0.198)$ & $(0.172)$ \\
$\mathrm{t}+4$ & -0.009 & $0.099^{*}$ & 0.013 \\
& $(0.943)$ & $(0.022)$ & $(0.311)$ \\
\hline Observations & 462 & 462 & 462 \\
& 0.518 & 0.389 & 0.018 \\
\hline$p-v a l n s+$ & &
\end{tabular}

$p$-values in parentheses

Municipality FE, Yes, Year FE, Yes - Outcome variables in log

${ }^{*} p<0.05,{ }^{* *} p<0.01,{ }^{* * *} p<0.001$ 


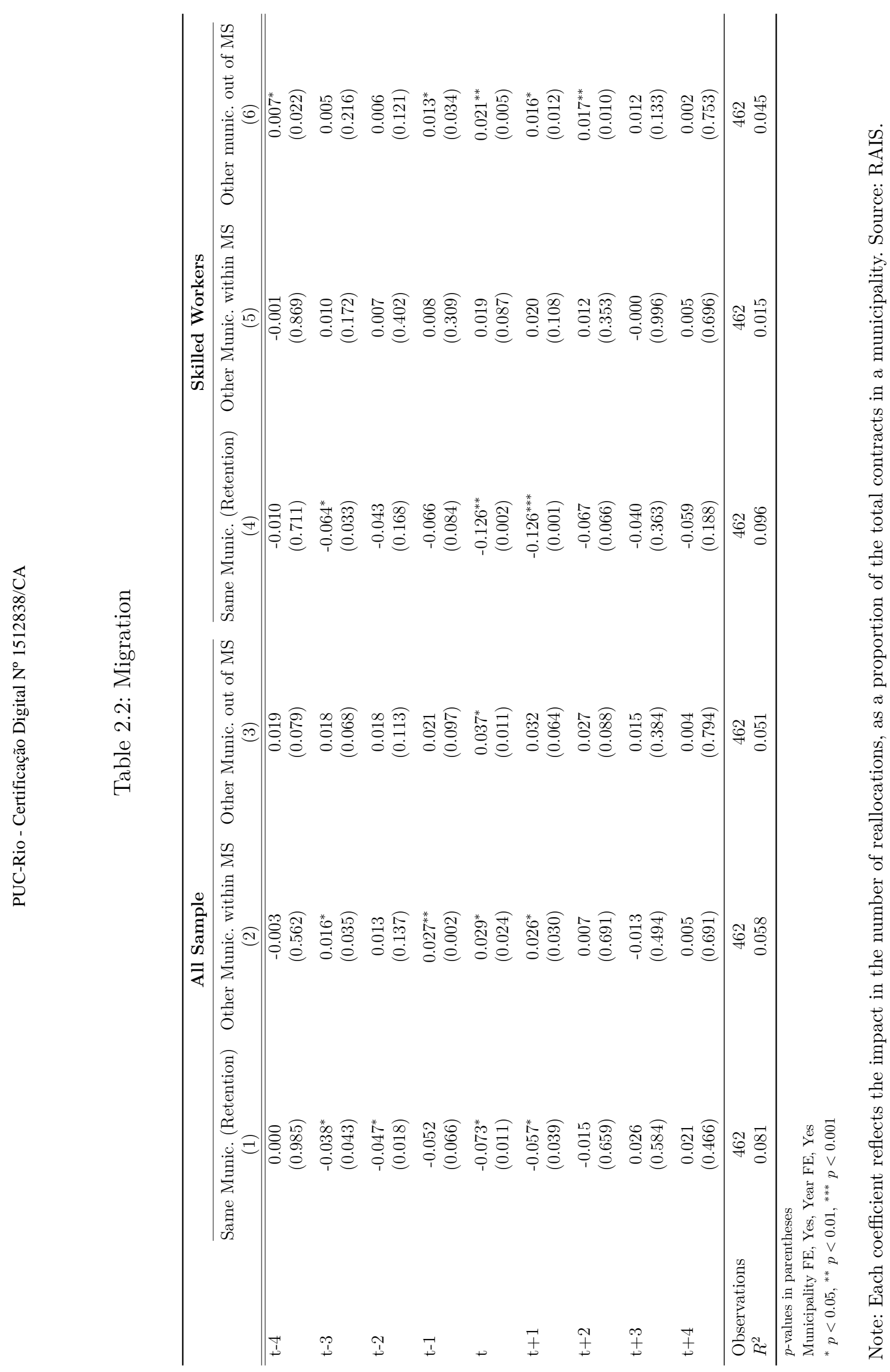




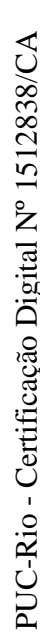

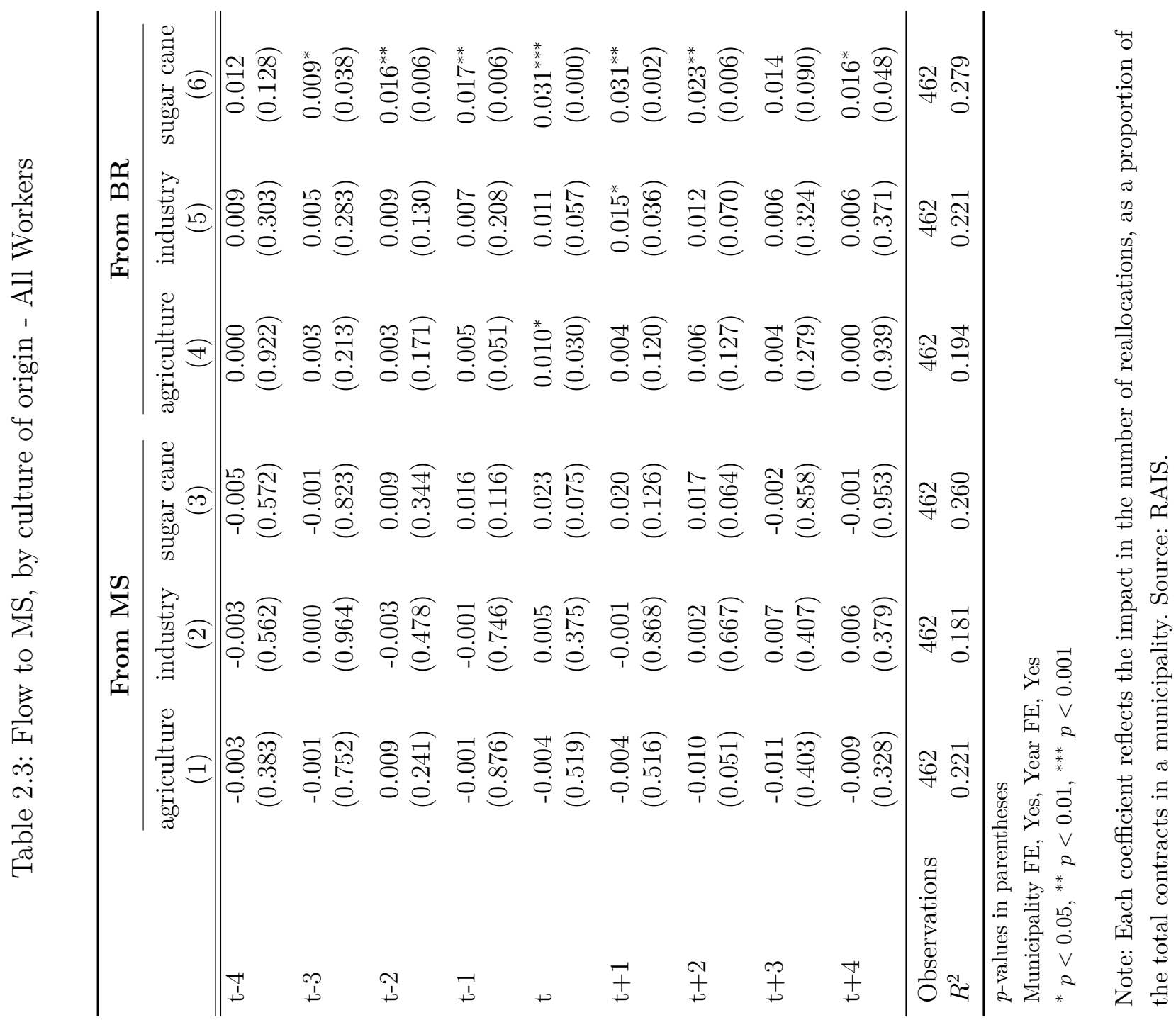




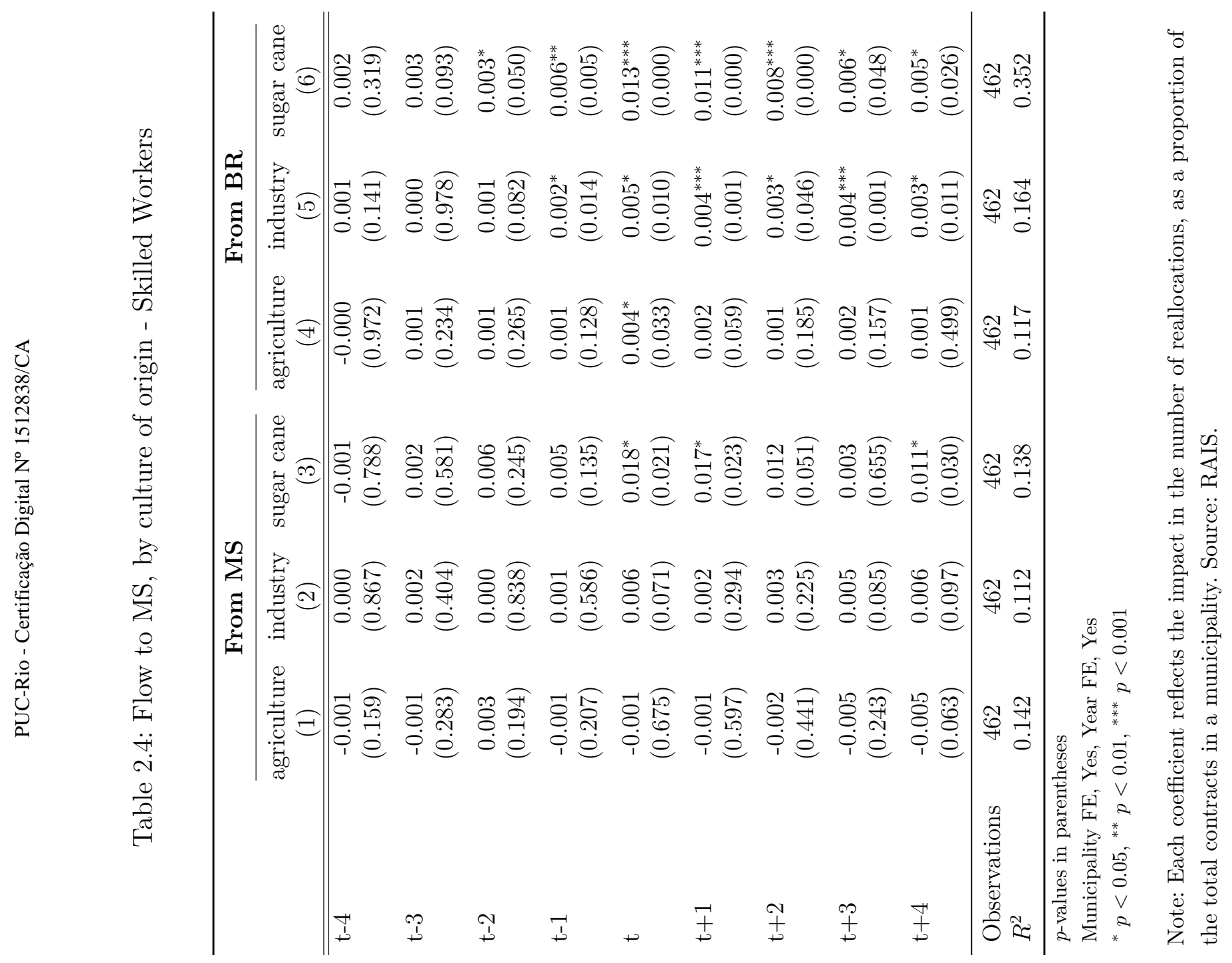




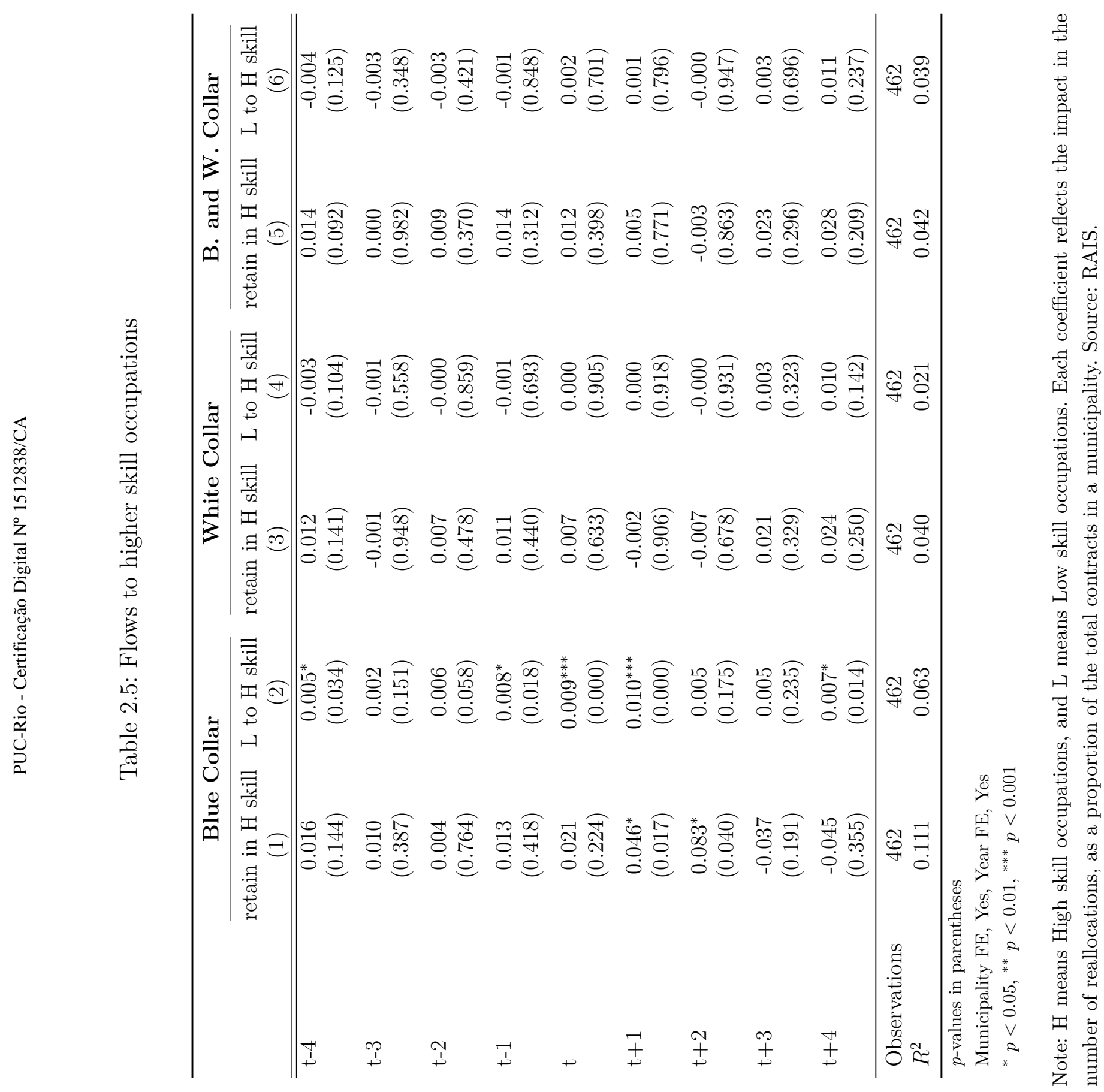




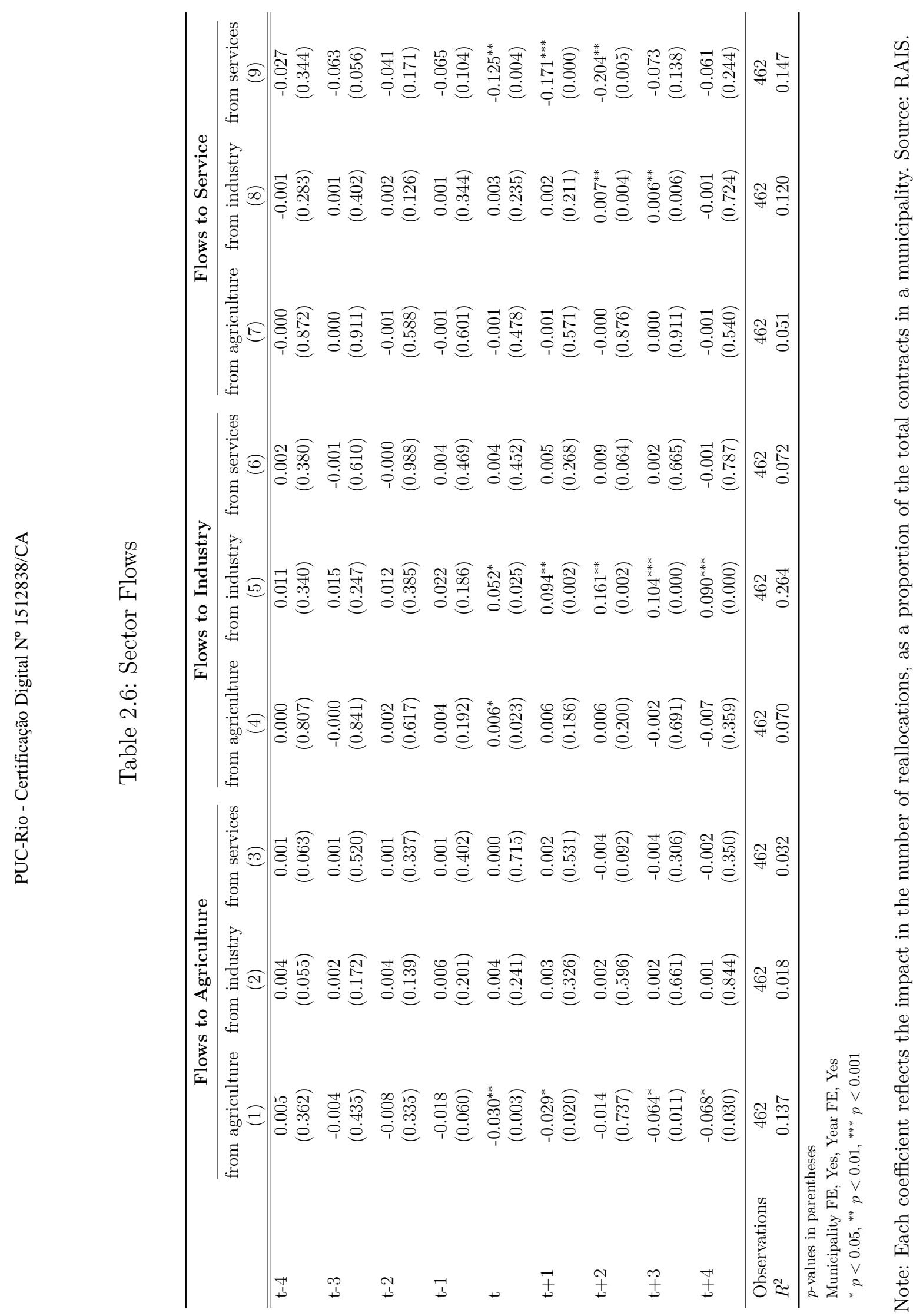




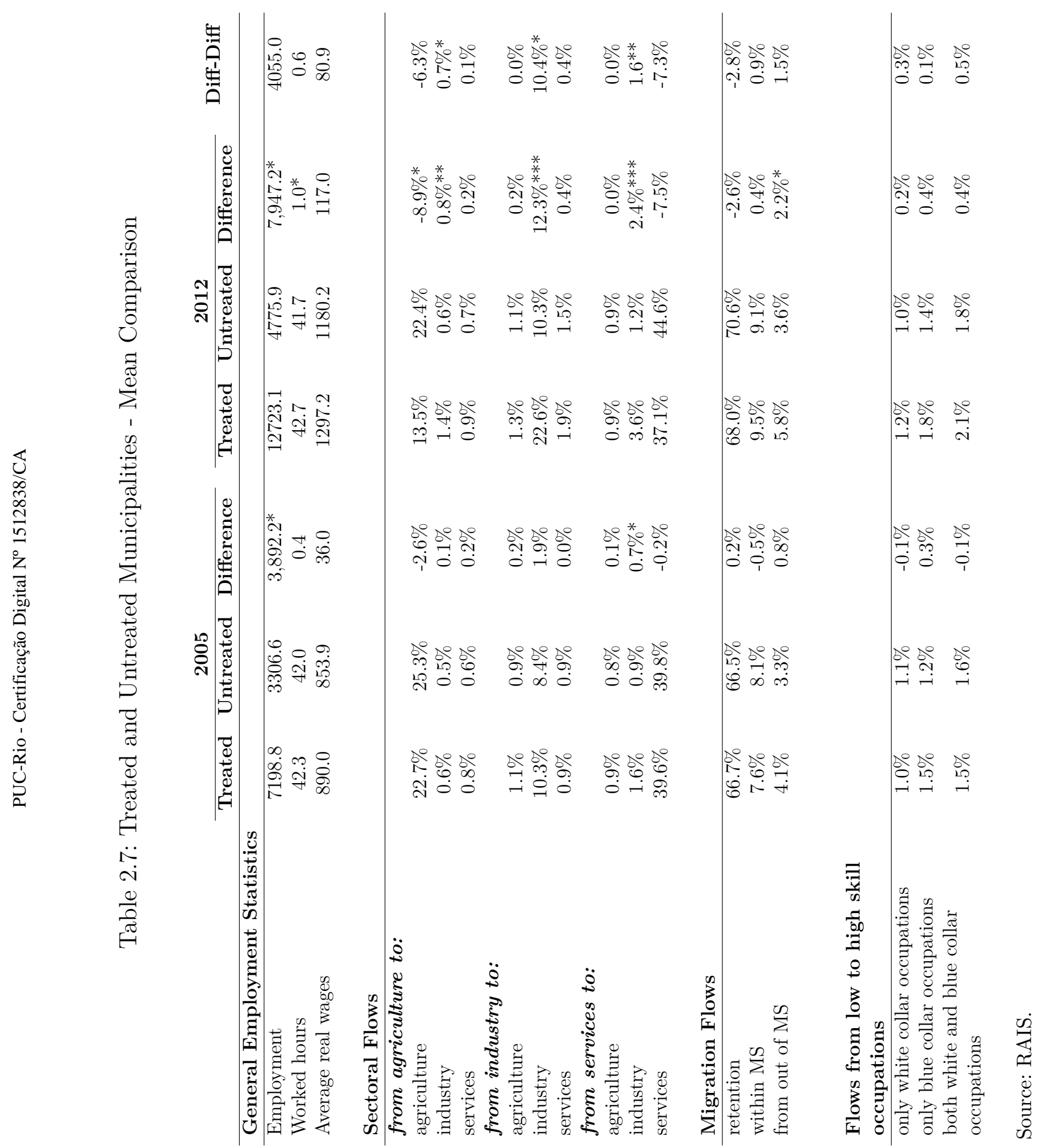




\section{3 Modernization of Agriculture in Central Brazil and Impacts
on Human Capital Investment}

3.1

Introduction

Innovations implemented during the 1970s enabled soybean cultivation in the poor soils of Central Brazil. Agriculture is a labor-intensive activity, and so this episode represented a positive shock on labor demand. Also, the innovations involved higher technology for the sector, which became more demanding of skilled labor.

A positive shock in demand for skilled labor may change the incentives of investment in human capital. Although evidence points out that agriculture attracted more skilled workers after innovations, it is not trivial if the event had some positive impact on the population's human capital investment at the margin. To attend school typically increases labor productivity, and to evaluate the effect of these innovations on the young population human capital formation is essential.

This paper contributes to the literature on human capital investment, analyzing how the modernization of soybean cultivation during the 1970s affected child and adolescent labor supply. I estimate the impact of the technological change in outcomes of interest combining the timing of the technological change with the potential gain of modernization. The empirical strategy analyzes differences in outcomes between municipalities more and less potentially affected by modernization, over time. The methodology analyze the impact on the modernization of soybean in agricultural outcomes, labor selection, and migration. This work estimates the impact of the same modernization process on outcomes of children and adolescents: the probability of working, attending school, and combining these activities. The focus is to understand how choices in investment in human capital have been encouraged (with increased demand for skilled labor) or discouraged (with increased immediate job gains).

The main results suggest that the effects of modernization of agriculture worked more as an incentive to work than as an incentive to invest in human capital, in a higher wage labor market. That is, the dominant effect was 
discouraged investment in human capital. For the adult population, there is an increase in the probability of working more than 39 hours a week, as well as an increase in real income. These results characterize the modernization as a positive shock on labor demand. The results for the younger population goes in the direction of increasing the time at work and a decrease in the investment in human capital. These effects generally remain when using restricted samples of non-migrants children and families.

Labor market variables come from the Population Census of Brazil, for the years 1970, 1980, 1991, and cover all children population. To measure the effects of the modernization of soybean in the labor market, the empirical strategy explores the variation in potential benefits of technological innovations across municipalities. The magnitude of these benefits come from data from the Food and Agricultural Organization (FAO) Global Agro-Ecological Zones (GAEZ).

The process of occupation of Central Brazil started late when compared with the coastal areas of the country. This delay in the settlement is related to infertile soils of the region, that represented a limitation factor for agricultural development and occupation for many decades. Considering that the region covers about one-fifth of the country, its development has been the target of some policies. Driven by different causes over time, governments promoted incentives to the occupation and agricultural development in Central Brazil. These incentives were largely related to improvements in technologies to overcome geographical limitations. In this context, innovations implemented during the 1970s enabled soybean cultivation in the soils from Central Brazil, which made it possible for farmers to move from extensive cattle grazing to intensive crop cultivation.

Different from livestock on grazing lands, agriculture was intensive in labor, and represent a positive shock on labor demand. Agriculture is often characterized as an unsophisticated sector, where investment in human capital may have little return (Rosenzweig (1995), Tao Yang (1997) and Laszlo (2008)). However, technological shocks may increase demand for more skilled labor both directly, in the use of new agricultural technologies, and indirectly, by the development of more complex markets (Laszlo (2008) and Lockheed, Jamison, and Lau (1980)).

The literature suggests that human capital was essential to induce soybean adoption (Strauss et al. (1991)) and that migration had a significant role for the agricultural modernization in Central Brazil (Kiihl and Calvo (2008)). Also, technological innovations induced the immigration of skilled individuals to municipalities that benefited more from it (Bragança, Assunção, 
and Ferraz (2015)). This evidence motivates the evaluation of how this shock affected the choices about the human capital formation of the population in the region.

The choice between entering the labor market and investing in human capital represents a trade-off for people and families. Entry into the labor market generates immediate benefits (increase in current income, by receiving wages), while human capital investment generates potential future gains (higher future wages). In this sense, positive shocks in skilled labor may be an incentive for more significant investment in education. This aspect should then result in people allocating more time to education and less to work. In the case of children, these choices occur at the household level, but they follow similar incentives.

On the other hand, it is crucial to consider that incentives for work may have also increased for some part of the population. Even in the event of a technological shock, it is not clear that returns to education are enough to increase incentives for study for all people. The increase in the demand for skilled labor only affects the incentives of studying of the least vulnerable part of the population. For example, there is evidence that, in some settings, landowning families have incentives to invest more in their children's education (to meet the demand for skilled labor), while the children of poorer households only fill the space left at less qualified labor (Foster and Rosenzweig (1996)). In this case, a positive shock in demand for skilled labor (in a context of technological innovations in agriculture) can increase unskilled labor as well, having positive impacts on child labor. Such an effect would be very adverse in the sense of jeopardizing the human capital formation of children and adolescents in the region.

This work contributes to the literature on human capital investment, estimating the impact of modernization on the choices between work and education of adolescents and children in the affected regions. Younger people typically have lower human capital stock, and not investing in education can have negative impacts throughout life. So, this trade-off is especially relevant for them.

It is also important to consider that the effects may be different between children and adolescents. Therefore, to consider the heterogeneity of decision, the analysis uses sub-samples of adolescents (14 to 17 years old) and children (10 to 13 years old). A positive effect on child or adolescent labor market participation rate would be an undesirable outcome since it means less investment in human capital.

The rest of the paper is organized as follows. Section 3.2 explains the 
regional and historical context of the Central Brazil, and Section 3.3 considers aspects related to the labor market for adults and child labor. Section 3.4 discusses the identification strategy. Section 3.5 presents the databases used in the paper, with descriptive statistics. Section 3.6 analyses the results and Section 3.7 concluded.

\section{2}

\section{Regional and Historical Context}

Central Brazil has a natural disadvantage in terms of the quality of its soil, which is typically poorly fertile. Historically, this characteristic has limited land occupation and agricultural development. Also, the large distance from Brazil's coast means high transportation costs to the main cities and ports, increasing the disincentive for settlement (Guimarães and Leme (2002); Klink and Moreira (2002)). After 1920, other Brazilian states increased the demand for meat, which promoted extensive cattle ranching in the region. Unlike agriculture, this activity was feasible even without fertile soil, depending only on native pastures that covered a substantial share of Central Brazil's land area. However, the cattle ranching was not intensive in labor, and in modern inputs (Klink and Moreira (2002)) and so the impact on occupation was limited, as well as the effect on agricultural development.

Central Brazil covers four large states (Goiás, Mato Grosso, Mato Grosso do Sul and Tocantins), corresponding to about one-fifth of the country's territory. After 1940, the Brazilian government fostered? occupation and agricultural development of Central Brazil (Guimarães and Leme (2002)), with the primary objective of supplying the growing food demand in the country (Klink and Moreira (2002)). The increase in the supply of food was also essential to incentives industries of tractors and fertilizers.

Encouraged by the Green Revolution ${ }^{1}$ in other developing countries, in the 1960s governments started to spend more resources in agricultural research, in order to overcome the regions' geographic limitations (Klink and Moreira (2002)). Their focus was in engineering varieties of soy crops, adapted to the tropical climate and the Cerrado biome. The reduced sunlight exposition in tropical areas and the abundance of aluminum (which is toxic to plants) were crucial concerns (Spehar (1995)). Between 1965 and 1967 the first adapted varieties were launched, enabling soybean cultivation in southern localities. This process of research and innovation was essential for the cultivation in Central Brazil. Technological developments induced settlement and cultivation

\footnotetext{
${ }^{1}$ The Green Revolution is a set of research and technology innovations happening between the 1950s and 1960s. In the period, agricultural production increased, particularly in the developing world.
} 
in northern Central Brazil by the end of the 1970s, despite the reduction in international prices. Rural population increased by an average of $3 \%$ per year, going from less than 1 million in 1940 to 2.6 million in 1970, even with a substantial urbanization movement happening in the rest of the country (Bragança, Assunção, and Ferraz (2015)). Different from livestock on grazing lands, agriculture was intensive in labor, and represented a positive shock on labor demand. This event may change the incentives for human capital formation. On the one hand, it has a potentially positive effect on incomes, which affects positively labor force participation. On the other hand, there is evidence of positive impacts on skilled work, so that it would make sense for an individual to spend more time investing in her qualification, in order to obtain higher wages in the future. Therefore, the net effect on the investment in human capital is not trivial, which motivates the empirical analysis of this study..

\section{3}

\section{The Workforce of Central Brazil}

This paper estimates the impact of modernization in soybean cultivation on human capital formation. The effects are measured in terms of the choices between work and study, for individuals under 18 years old. In this sense, it is necessary to characterize the analyzed event as a positive shock on labor demand. Figure 3.1 shows the averages of some variables of interest in two groups of municipalities in Central Brazil. These groups differ in the potential gains associated with the adoption of modern practices and adoption of soybean technologies (Soy Potential). Group 1 includes the 10\% of municipalities that would have the lowest potential gain, and group 10 represents the $10 \%$ of the municipalities that would have the highest potential gain. In a preliminary view, the figure shows how the difference between the outcomes of these municipalities changed from before to after modernization. The red line shows the variation of the gap between the two groups, over time.

Regarding labor market variables, the proportion of those who worked more than 39 hours a week was practically the same in the two groups in 1970. After the modernization period, this value decreased for the group of municipalities with low soybean potential and was stable for the group with high soy potential. Thus, there was a gap between the hours worked in the municipalities with the higher soy potential. About average wages in municipalities ${ }^{2}$, there was a small gap between the two groups of municipalities in 1970. This gap almost quadrupled after the modernization period, in 1991.

\footnotetext{
${ }^{2}$ Evaluated in real terms.
} 
Figure 3.1 presents only descriptive statistics, but it suggests that adopting more modern practices has brought an increase in demand for labor (more hours worked and higher average salaries $)^{3}$.

Figure 3.1: Descriptive Statistics: Adult Population
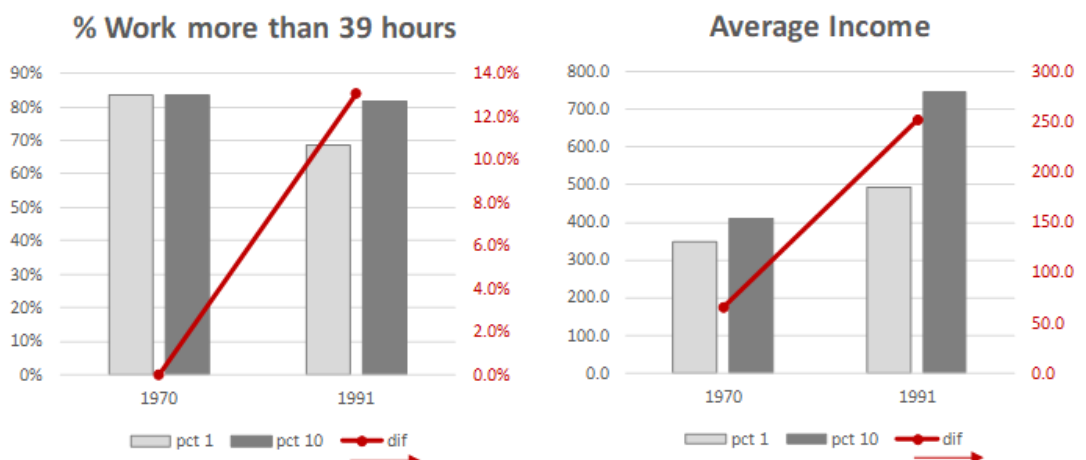

Note: Statistics from people between 20 and 50 years old, living in rural areas, in the workforce. Comparison of annual averages in municipalities. The first group (pct1) includes the $10 \%$ of municipalities that would have the lowest potential gain, and the second group (pct10) represents the $10 \%$ of the municipalities that would have the highest potential gain. Source: Census/IBGE.

A positive shock in labor demand can change some of the trade-offs that affected individuals face. The choice between entering the labor market or investing in human capital is one of the most relevant of them. Entry into the labor market generates immediate benefits (increase in current income, by receiving wages), while human capital investment generates potential future gains (higher future wages), combined with a lower current income.

Schooling improves abilities by at least two channels: by improving access to information sources (instructions manuals, for example) and by finding new information (Rosenzweig (1995)). Through these channels, schooling can increase the productivity of a worker. However, agriculture is often characterized as an unsophisticated sector, where investment in human capital may have little return. Being literate and having numeracy skills may be enough to perform basic tasks, and this may work as an incentive for premature entry into the job market, with low investment in human capital. Also, there is evidence pointing to the existence of a selection of better-educated workers in off-farm activities. The idea is that schooling does not enhance labor productivity in routine tasks and has a limited effect on subsistence farm productivity (Tao Yang (1997), Laszlo (2008)).

Still, an elementary school can have effects on farm productivity, but these effects are much more likely to be positive in modernizing than traditional

${ }^{3}$ Tables 3.2 and 3.1, in section 2.4, show detailed results with descriptive statistics. 
environments (Lockheed, Jamison, and Lau (1980) $)^{4}$ ). Technology may increase demand for more skilled labor both directly (in the use of new agricultural technologies) and indirectly (by the development of more complex markets). Therefore, the occurrence of a technological shock can increase the return to education, changing incentives of an individual facing the trade-off between work and study (Laszlo (2008)).

However, even in the event of a technological shock, it is not clear that returns to education are enough to increase incentives for studying for all population. Agricultural technological changes can increase schooling returns for wealthy households (landowners, for example), but not for other households (who continue to practice routine tasks). If those families compete in the labor market, technological shocks may increase the demand for the labor supplied by landless households, increasing opportunity costs of schooling for them (Foster and Rosenzweig (1996)).

The literature suggests that human capital was crucial to induce soybean adoption (Strauss et al. (1991)). Migration has a considerable role for the agricultural modernization in Central Brazil (Kiihl and Calvo (2008)) and technological innovations induced the immigration of skilled individuals to municipalities that benefited more from it (Bragança, Assunção, and Ferraz (2015)).

Nevertheless, the selection of more skilled workers for agriculture does not necessarily mean incentives for investment in human capital at the margin. It is possible for a more skilled worker to find better working conditions, and to devote more hours to this work, and fewer hours for additional investment in qualification.

\subsection{1}

\section{The nature of child labor}

Child labor is a phenomenon observed in many developing countries, especially among low-income families. In 1970, at the beginning of the period of analysis, children's participation rate $^{5}$ was $22.30 \%$ in the world and $20.33 \%$ in Brazil (Basu (1999)). After the shock we analyze in this study, by 1990, these rates were $14.65 \%$ and $17.78 \%$ in the world and in Brazil, respectively. These numbers show that although Brazil has reduced child labor in absolute terms, the drop was lower than in other countries.

Child labor is one of the consequences of persistent poverty (Krueger (1996), and Fallon and Tzannatos (1998)), in a context of failures in the

\footnotetext{
${ }^{4}$ They synthesize results of studies of the effect of a farmer's educational level on productivity, focusing in low-income regions.

${ }^{5}$ Children between 10 and 14 years old.
} 
credit market. In several low-income countries, child labor is higher even in the presence of large returns to education (Psacharopoulos and Patrinos (2004)). This pattern reflects inefficiency of this practice and, even if parents are altruistic, it may arise in equilibrium when capital markets are imperfect (Baland (2000) and Ranjan (2001)). Credit access restrictions affect the choices of poor households that, without assets to use, are unable to smoothing income throughout the life cycle. If low-income families cannot take loans, they may have to use child labor to get current income, not investing in child human capital.

A family that suffers a temporary income shock ideally soften its effects disposing of assets or borrowing. Low-income households, by definition, have few assets and need loans to smooth shocks throughout the life cycle. If the credit market fails, the family may use child labor. The effects of credit restriction on the choice of a family about a child's schooling are known to be negative (Jacoby (1994) and Dumas (2013)). In the context of credit restriction, adverse income shocks tend to increase child labor (Jacoby and Skoufias (1997), Guarcello, Mealli, and Rosati (2010) and Beegle, Dehejia, and Gatti (2006)).

The importance of investment in minimum human capital is enormous, and it is a consensus that there are social gains in this investment. For instance, the literature shows that school attendance affects positively health (Wolff (2008), Beegle, Dehejia, and Gatti (2009), O'Donnell, Rosati, and Van Doorslaer (2005)). Even when children can combine study and work, there is evidence that child labor negatively affects mathematics skills and the pulmonary function (Sim, Suryadarma, and Suryahadi (2017)).

There is also an adverse effect of working, that reduces the time available for studying, playing, and sleeping (Edmonds and Pavcnik (2005)). Meanwhile, even child labor having so many adverse effects, families can still accept it. Tolerance with child labor occurs because sometimes a family needs sufficient income to meet their basic needs, and even allows the child to remain in school. Indeed, Basu (1999) and Edmonds (2007) show many studies that find zero or positive effect of child labor on school enrollment and education attainment.

The way a family decides to allocate children's time between school, work, and domestic tasks depend on several factors. These factors include the relative productivity of the child comparatively with their parents in the labor market, and the degree of substitution between parent and child in domestic tasks (Grootaert and Kanbur (1995)).

In this sense, positive shocks in labor demand could have different effects if they affect more in unskilled or skilled labor. While the first type would encourage child labor, the second could be a disincentive. Evidence shows 
an inflow of skilled labor in the regions after modernization, which suggests a positive shock in demand for skilled labor. However, besides innovations in agriculture attracted people with a higher level of human capital, it is not trivial if it had some positive impact on the population's human capital investment at margin.

In the situation of increased demand for skilled labor, there are incentives for more meaningful investment in education, which may result in families allocating more time for their children to education and less to work. On the other hand, there are also incentives to invest time in work, because a more tight labor market results in higher wages. This more attractive market can affect children too.

Figure 3.2 shows the averages of the variables of interest for the two groups of municipalities in Central Brazil. In this case, the variables of interest are the status of children and adolescents, between work and study. These groups differ in the potential gain associated with the adoption of modern practices and adoption of soybean technologies (Soy Potential). Group 1 includes the $10 \%$ that would have the least potential gain, and group 10 represents the $10 \%$ of the municipalities that would have the highest potential gain. In a preliminary view, the figure shows how the difference between the outcomes of these municipalities changed from before to after modernization. The red line shows the variation of the gap between the two groups, over time. The first graph shows that the proportion of children attending school was already higher in municipalities with greater soy potential, but this difference became less intense after modernization. School attendance increased for both groups during the period.

Figure 3.2: Descriptive Statistics: Children Population $\%$ Attending School $\%$ Working
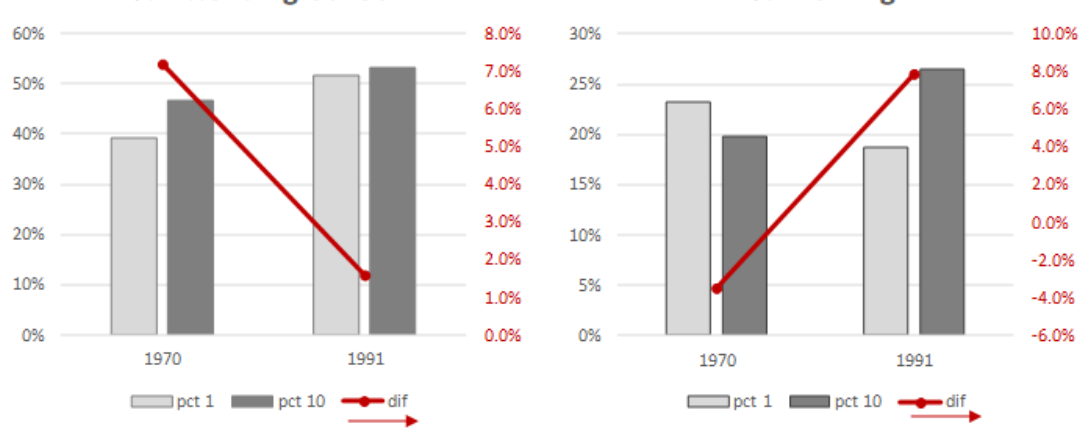

Note: Statistics from children between 10 and 17 years old, living in rural areas. Comparison of annual averages in municipalities. The first group (pct1) includes the $10 \%$ of municipalities that would have the lowest potential gain, and the second group (pct10) represents the $10 \%$ of the municipalities that would have the highest potential gain. Source: Census/IBGE. 
On the other hand, the proportion of the children population working was lower in the municipalities with high soybean potential, and became higher after the modernization period. In this case, even the absolute trends show a difference. While in municipalities with low soy potential child labor fell, in municipalities with high soy potential, child labor increased in the period ${ }^{6}$.

Figures 3.1 and 3.2 show only general trends for two groups of municipalities. These trends point to greater incentives to work, and lower incentives for investment in human capital. However, to estimate the causality of modernization, a more sophisticated empirical strategy is needed.

\section{4}

\section{Identification Strategy}

This paper measures the impacts of the technological innovations on human capital formation. The empirical strategy is close to the difference in difference approach, and explores year-specific changes between municipalities with different levels of exposure to modernization in soybean cultivation. We measure the exposure to modernization (the treatment $S P_{m}$ ) as the potential gain that a municipality would have with the modernization of its agricultural practices.

The treatment $S P_{m}$ is a continuous variable, in which higher values reflect higher gains to use more modern practices. Data from the Food and Agricultural Organization (FAO) Global Agro-Ecological Zones (GAEZ) measures the benefit that each municipality had with innovations ${ }^{7}$. Therefore, the variable $S P_{m}$ is not the amount of innovation made in each municipality, but a potential gain associated with innovation, or a level of exposure to modernization. The treatment variable $S P_{m}$ is correlated with innovation and modernization, implemented during the 1970s in the central region of Brazil, that allowed an expansion of soybean cultivation ${ }^{8}$.

In order to analyze how the modernization of soybean cultivation affected the workforce in Central Brazil, it is essential to be aware of how to identify a causal effect. It is possible that the degree of modernization in agriculture and the child labor outcomes had evolved together over the years in the municipalities, and this may occur because both of them were subject to the same influences. In this way, a regression using the level of modernization as treatment would find spurious results. On the other hand, using a variable that

\footnotetext{
${ }^{6}$ Tables 3.2 and 3.1, in section 2.4, show detailed results with descriptive statistics.

${ }^{7}$ Subsection 3.5.1 explains the construction of this variable.

${ }^{8}$ Bragança, Assunção, and Ferraz (2015) shows that municipalities more suitable for soybean cultivation experienced faster increases in the crop production.
} 
measures exposure to modern practices, from time-constant geographical and environmental features, avoids this issue.

The strategy uses a probit model:

$\operatorname{Pr}\left(Y_{i m s t}=1\right)=\operatorname{Pr}\left(\alpha_{m}+\delta_{s t}+\sum_{v=1980}^{1991} \gamma_{v}\left(S P_{m} * I_{v}\right)+\sum_{v=1980}^{1991}\left(X_{m} * I_{v}\right) \theta_{v}+\beta Z_{i m s t}+u_{i m s t}>0\right)$

$Y_{i m s t}$ is the outcome of interest for the individual $i$, in the municipality $m$, state $s$, and period $t . \alpha_{m}$ is a fixed municipality effect, $\delta_{s t}$ is a fixed effect of state and year, $X_{m} * I_{v}$ is a vector of geographical and baseline characteristics, $S P_{m}$ is the measure of soybean potential, $I_{v}$ is an indicator of year, $Z_{i m s t}$ is a vector of individual and households characteristics control and $u_{i m s t}$ is the error term. $\gamma_{v}$ is the coefficient of interest.

The variables of interest are dummies for the status of the individual. For children and adolescents, dummies assume a value equal to 1 when the individual: attends school, works, only attends school (and does not work), only works (and does not attend school), attends school and works at the same time, does not attend school and neither works ("nem-nem").

For the adult population, the impact on hours worked (probability of working more than 39 hours per week) using Equation 3-1, and the effect on real wages, using Equation 3-2, are estimated. These estimates are not the primary results of the paper but help to characterize the positive labor market shock.

$$
Y_{i m s t}=\alpha_{m}+\delta_{s t}+\sum_{v=1980}^{1991} \gamma_{v}\left(S P_{m} * I_{v}\right)+\sum_{v=1980}^{1991}\left(X_{m} * I_{v}\right) \theta_{v}+\beta Z_{i m s t}+u_{i m s t}
$$

Other factors affect outcomes of interest and may be related to treatment $S P_{m}$. For example, due to several factors, child labor has tended to fall in recent decades, just as innovations in the field have tended to increase. Common temporal trends are controlled in the fixed effect $\delta_{s t}$. In fact, this fixed time effect combined with state controls for all common temporal trends between states, which is stronger than a general fixed effect. Also, characteristics such as environmental conditions, amenities in the municipality, geographic characteristics and other factors that are constant in time and that can affect child labor and innovation in the field are in the fixed effect of municipality $\alpha_{m}$ 
and in $X_{m}$. The vector of controls $Z_{i m s t}$ contains variables at the individual and household level which, if omitted, could bias the estimation ${ }^{9}$. By hypothesis, the error term does not contain variables that may affect treatment and outcomes $^{10}$.

Finally, a source of concern is the possibility that families more likely to use child labor migrated to these municipalities, in response to the shock of innovation. In this case, the treatment itself would be causing a change in the profile of the local population. To avoid this problem, two additional subsamples are used: that of individuals living in the same municipality where they were born, and that of individuals whose head of household lives in the same municipality in which they were born. All the results are obtained for the full sample and for these two subsamples, which seek to exclude a possible bias of the migrants.

\section{5}

\section{Data}

This study uses two data sources. For the individual and county-level outcomes and control variables, the information comes from the Population Censuses of 1970, 1980 and 1991. Information on potential gains from agricultural interventions comes from Food and Agricultural Organization (FAO) Global Agro-Ecological Zones (GAEZ).

\subsection{1 \\ Data on Soybean Potential}

The treatment variable explores the potential benefits from the technological innovations in each municipality. A model with information of climatic and geographical conditions of each region generates predictions of potential yields for various cultures, from different input uses. Thus, for each region there is a measure of low level input yield (when using practice in traditional agriculture) and high level input yield (when using commercial agricultural practices, machinery and chemical). From these measurements, the gain with the adoption of technology would be the difference between the high-level input yield and the low level. This indicator is exogenous to factors that may influence child labor. This work uses this measure, which is at the municipality level, using data from the Food and Agriculture Organization (FAO) Global

\footnotetext{
${ }^{9}$ Variables of gender, household conditions (water supply, sanitary network, electric lighting). $X_{m}$ is a vector of variables at the municipality level, interacted with year dummies, such as geographic, social, and production characteristics.

${ }^{10}$ Bragança, Assunção, and Ferraz (2015) investigate whether the international commodity price may be affecting the results, showing that their estimates are robust to its inclusion.
} 
Agro-Ecological Zones (GAEZ) database ${ }^{11}$. The treatment variable, therefore, is constant for the municipality over the years.

\section{5 .2}

\section{Data on Socioeconomic Outcomes}

This study uses data from the Census Population of Brazil, for the years 1970, 1980, 1991. The data are at the individual level, and 1970 is the period before the technological innovation, 1980 is the period during innovations, and 1991 is the period after. The Census is a representative base at the municipality level, with information for individuals and households. This work consider a sample of people living in rural areas of municipalities of Central Brazil (Mato Grosso, Mato Grosso do Sul, Tocantins, and Goias).

For child labor variables, there are two subsamples: children from 10 to 13 years old, and adolescents from 14 to 17 years old. The variables of interest are dummies at the level of the individual that indicate their status in the choices between study and work. There are six outcomes of interest:

- The probability of studying: the outcome is a dummy that assumes value 1 when the child attends school, and 0 when not attending.

- The probability of working: the outcome is a dummy that assumes value 1 when the child works, and 0 when it does not work.

- The probability of only studying: the outcome is a dummy that assumes value 1 when the child attends school and does not work, and 0 when attending school and works. This regression does not consider children that do not attend school.

- The probability of just working: the outcome is a dummy that assumes value 1 when the child works and does not attend school, and 0 when working and attending school. This regression does not consider children that do not work.

- The probability of attending school and working, concomitantly: the outcome is a dummy that assumes value 1 when the child works and attends school, and 0 in the other possibilities.

\footnotetext{
${ }^{11}$ This measure was previously calculated by Bragança, Assunção, and Ferraz (2015), following the strategy of Bustos, Caprettini, and Ponticelli (2016). They superimpose the map on potential soybean yields under different input regimes and the map on municipalities. Then they calculate the average potential soybean yield under the low input and the high input regimes, for each cell in a municipality. Finally, they calculate the difference between the average soybean potential yields in municipalities, in each input level: this is the soybean potential. The indicator ranges from 0.67 tons per hectare to 3.3 tons per hectare, the average is 2.15 , and the standard deviation is 0.58 . They use contemporaneous information on technologies to measure the agricultural potential for each crop. Therefore, they assume that technological innovations did not change the comparative advantage to cultivate soybeans.
} 
- The probability of neither attending school and nor working, concomitantly: the outcome is a dummy that assumes value 1 when the child does not work and does not attend school, and 0 in other possibilities.

Descriptive statistics (Table 3.2 and Table 3.1) compare the means tendencies of the outcomes of interest, in groups of municipalities more and less impacted by the treatment. The least impacted municipalities are those in the first decile of soybean potential (pct1), and the most impacted are those in the last decile (pct10). Both groups present increased school attendance in 1991 against 1970. However, this increase was lower in the group of municipalities most affected.

Table 3.1: Descriptive Statistics: Comparison of annual averages in municipalities, in the highest and lowest decile of soybean potential

\begin{tabular}{|c|c|c|c|c|c|c|c|c|c|}
\hline & & 1970 & & & 1980 & & & 1991 & \\
\hline & pct10 & pct1 & $\operatorname{diff}$ & pct10 & pct1 & diff & pct0 & pct1 & diff \\
\hline \multicolumn{10}{|l|}{ Adults Statistics (\%) } \\
\hline Working >39 hours/week & 0.795 & 0.769 & 0.025 & 0.841 & 0.649 & $0.192^{* *}$ & 0.778 & 0.602 & $0.176^{* * *}$ \\
\hline Income & 384.343 & 336.867 & 47.476 & 994.764 & 706.875 & $287.889^{* *}$ & 720.335 & 525.782 & $194.554^{* *}$ \\
\hline \multicolumn{10}{|l|}{ Children Statistics (\%) } \\
\hline Attending school & 0.496 & 0.436 & 0.06 & 0.374 & 0.432 & -0.058 & 0.514 & 0.537 & -0.023 \\
\hline Working & 0.201 & 0.250 & $-0.049^{*}$ & 0.259 & 0.215 & 0.044 & 0.229 & 0.208 & 0.021 \\
\hline Just attending school & 0.475 & 0.409 & 0.066 & 0.336 & 0.385 & -0.049 & 0.453 & 0.495 & -0.042 \\
\hline Just working & 0.180 & 0.223 & $-0.043^{*}$ & 0.221 & 0.168 & $0.054^{*}$ & 0.169 & 0.167 & 0.002 \\
\hline \multirow{2}{*}{$\begin{array}{l}\text { Attending school and working } \\
\text { Neither attending school nor } \\
\text { working }\end{array}$} & 0.021 & 0.026 & -0.006 & 0.038 & 0.048 & -0.009 & 0.060 & 0.041 & 0.019 \\
\hline & 0.324 & 0.341 & -0.017 & 0.405 & 0.400 & 0.005 & 0.318 & 0.297 & 0.021 \\
\hline $\begin{array}{l}\text { Robust standard errors in par } \\
*^{* *} \mathrm{p}<0.01,{ }^{* *} \mathrm{p}<0.05,{ }^{*} \mathrm{p}<0\end{array}$ & entheses & & & & & & & & \\
\hline
\end{tabular}

Note: Comparison of annual averages in municipalities. The first group (pct10) includes the $10 \%$ of municipalities that would have the highest potential gain, and the second group (pct10) represents the $10 \%$ of the municipalities that would have the lowest potential gain. Source: Census/IBGE.

Labor market data for the adult population also come from the Census and covers people between the ages of 20 and 50, who either work or seek work (i.e., are in the economically active population) and live in rural areas. Table 3.2 and Table 3.1 also show statistics for the adult workforce. These descriptive statistics suggest a positive impact on the labor demand in the municipalities most affected by the innovations in soybean.

Original Census data presents differences in variables and some classifications from one period to another. DataZoom provides a data compatibility package that was useful to this work ${ }^{12}$. Furthermore, during the period 19701991, many municipalities were created, and others have had their borders

\footnotetext{
${ }^{12}$ http://www.econ.puc-rio.br/datazoom
} 
changed. The sample considers the definition of minimum comparable areas of the Brazilian Institute of Applied Economic Research (IPEA) that make spatial units consistent over time, also provided by DataZoom.

Table 3.2: Descriptive Statistics: comparison of annual averages in municipalities

\begin{tabular}{lllllll}
\hline & $\mathbf{1 9 7 0}$ & $\mathbf{1 9 8 0}$ & $\mathbf{1 9 9 1}$ & \multicolumn{3}{c}{ Diff Diff } \\
\hline & & & & $\mathbf{1 9 8 0} / \mathbf{1 9 7 0}$ & $\mathbf{1 9 9 1 / 1 9 8 0}$ & $\mathbf{1 9 9 1 / \mathbf { 1 9 7 0 }}$ \\
Adults Statistics & & & & & & \\
\hline Working >39 hours/week & 0.800 & 0.742 & 0.690 & $-0.058^{* *}$ & $-0.053^{* *}$ & $-0.111^{* * *}$ \\
Income & 375.88 & 886.23 & 606.99 & $510.347^{* * *}$ & $-279.236^{* * *}$ & $231.111^{* * *}$ \\
& & & & & & \\
Children Statistics & & & & & & \\
\hline Attending school & 0.478 & 0.433 & 0.553 & $0.067^{* * *}$ & $0.088^{* * *}$ & $0.155^{* * *}$ \\
Working & 0.219 & 0.229 & 0.221 & $0.015^{* * *}$ & $-0.007^{*}$ & $0.007^{* * *}$ \\
Just attending school & 0.459 & 0.391 & 0.496 & $-0.058^{* *}$ & $-0.053^{* *}$ & $-0.111^{* * *}$ \\
Just working & 0.200 & 0.187 & 0.164 & $510.347^{* * *}$ & $-279.236^{* * *}$ & $231.111^{* * *}$ \\
Attending school and working & 0.019 & 0.042 & 0.057 & $-0.045^{* *}$ & $0.120^{* * *}$ & $0.075^{* * *}$ \\
Neither attending school nor & 0.322 & 0.380 & 0.283 & 0.010 & -0.01 & 0.00 \\
working & & & & & & \\
& & & & & & \\
\hline
\end{tabular}

Robust standard errors in parentheses

$* * * \mathrm{p}<0.01,{ }^{* *} \mathrm{p}<0.05, * \mathrm{p}<0.1$

Note: Comparison of annual averages in municipalities. Source: Census/IBGE.

\section{6}

Results

Tables 3.5 to 3.4 show the impact of technological innovations on the outcomes of the adult and child population. The coefficients of interest present the most immediate impacts of the shock (Soy Potential 1980) and the more long-term impacts (Soy Potential 1991). Columns 1 and 7 show the basic specification with only municipality fixed effects and and state-year fixed effects. Columns 2 and 8 add controls of individual characteristics, columns 3 and 9 add family characteristics, and columns 4 and 10 add both individual and family characteristics.

Dealing with migration is especially relevant to the analyses of adolescents and children, and columns 5, 6, 11 and 12 restrict the sample to nonmigrants. The intention is to understand the effects on the population originally living in the affected region, excluding the change of composition coming from migrations. Two strategies are used to select non-migrants. In columns 5 and 11 , the sample considers non-migrants those who live in the same municipality of birth. In columns 6 and 12, the sample considers as nonmigrants 
those who live in families whose head was born in the same municipality in which they live.

\subsection{1}

\section{Effects on child labor market}

Tables 3.3 and 3.4 report estimates of the impact of technological innovations on child labor (10 to 13 years old) and adolescents (14 to 17 years old), using equation (1). The coefficients of interest present the most immediate impacts of the shock we are evaluating (Soy Potential 1980) and the more long-term impacts (Soy Potential 1991).

Panel A shows the impacts of the modernization shock on the decision to attend school. In general, we see null or negative impacts. For children aged between 10 and 13, the impacts are negative, but they are no longer statistically significant when restricting the sample to children from nonmigrant households (column 6). The magnitude of the impact indicates that an increase of one standard deviation in soybean potential corresponds to a decrease of 3.2 percentage points in the probability of a child attending school from 1970 to 1980, and a decrease of 4.2 percentage points from 1970 to 1991. These results are not significant for children of parents who were born in the same municipality.

For adolescents between 14 and 17 years old, the impacts are negative and significant in all specifications. It is interesting to note that long-term effects show higher magnitudes than short-term effects. The magnitude of the impact indicates that an increase of one standard deviation in soybean potential corresponds to a decrease of 3.9-5.3 percentage points in the probability of an adolescent attending school from 1970 to 1980, and a decrease of 4.4-5.8 percentage points from 1970 to 1991.

Panel B exhibits the effects on the decision to work for children and adolescents. In general, there are positive impacts on long-term work in both groups. The impacts are even more significant in the restricted sample of children of non-migrant families (columns 6 and 12). The magnitude of the impact indicates that an increase of one standard deviation in soybean potential corresponds to an increase of 6.2-6.9 percentage points in the probability of a child working from 1970 to 1991, and an increase of 4.1-7.0 percentage points in the probability of a young person working from 1970 to 1991.

Panel C shows, only for children who study, the effects on the probability of only studying. The results are not significant in any specification or group of age. This result is compatible with the lack of incentives for investment in human capital. 
Panel D shows that the effects on the probability of only working (and not studying) are positive and significant. For adolescents between 14 and 17 years old, the impacts are concentrated in the period closest to the shock and are not persistent in the long run. The magnitude of the impact indicates that an increase of one standard deviation in soybean potential corresponds to an increase of 5.7-7.9 percentage points in the probability of a young person only working from 1970 to 1980.

However, for 10-13 years old children, the timing is inconclusive. In the specifications of columns 1 to 4, the impacts are significant in the short and the long term. When the sample is restricted to non-migrants, the temporal horizon of the effect is inconclusive. In the nonmigrant-children sample (column $5)$, there are significant effects in the long run. In the sample of non-migrant families (column 6), the results are more relevant in the short term. In any case, the results point to a higher probability of full dedication to work for working children.

Panel E reports estimates of the impact of technological innovations on the probability of a child to study and work at the same time. The outcome of interest is an indicator equal to one if the child both study and work. The effects are not significant for children between 10 and 13 years old. For adolescents (between 14 and 17 years old) there is a negative effect in the short run (1980). The magnitude of the impact indicates that an increase of one standard deviation in soybean potential corresponds to a decrease of between 3.8 and 5.7 percentage points in the probability of a young person attending school and working from 1970 to 1980. From the results in other panels, it is associated with the decision of working children (Panel D). Thus, the overall results point to children spending more time at work and less time on their education.

Finally, Panel F shows that the shock has no significant impact on getting children out of school and the labor market at the same time.

All results suggest that immediate income gains in a tighter labor market seem to be decisive on the choice of children and adolescents to spend more time on work and less time in education. The results present adverse effects on the human capital formation of children and adolescents, which has the potential to jeopardize their future performance in the labor market. The heterogeneity of some results for the total sample and the non-migrant subsamples also indicate a change in population composition. 


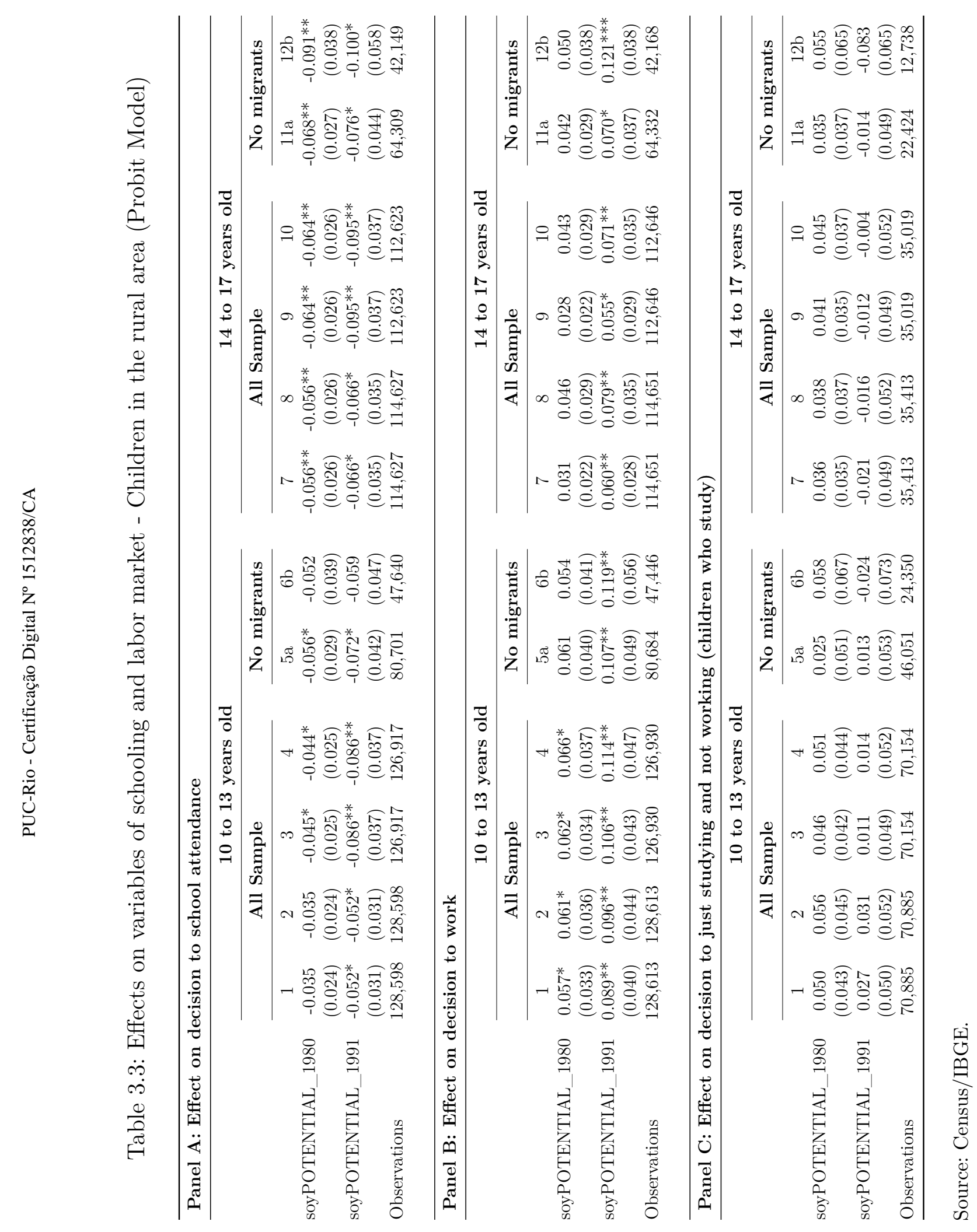




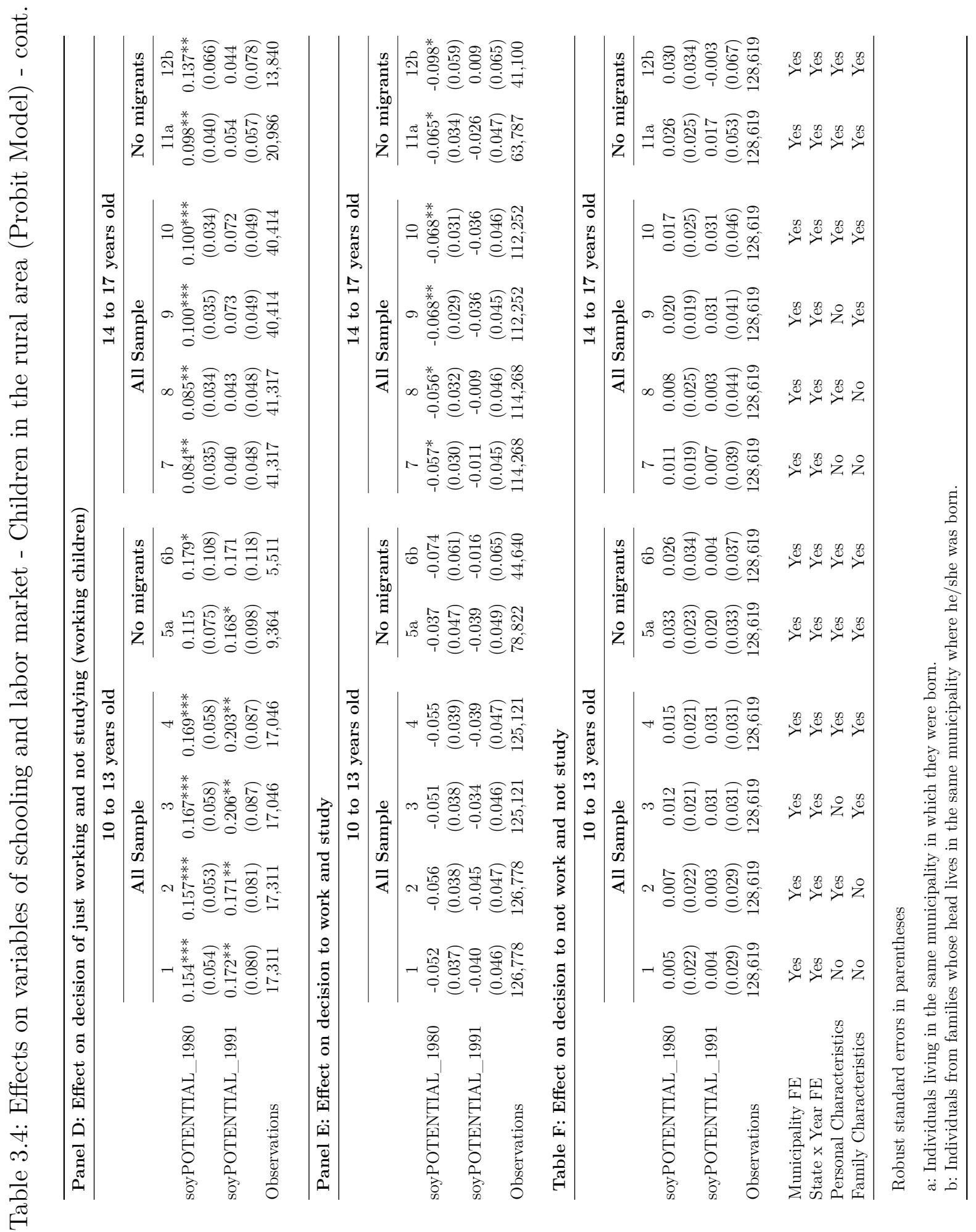




\subsection{2}

\section{Effects on labor market - Adults}

Though not the focus of this study, the results for the adult workforce are presented in Table 3.5. The objective is just to characterize the innovation in soybean as a positive shock in the labor market. Panel A shows the effect on the probability of working more than 39 hours per week. In all specifications, the results show an increase in this probability in the short term (1980). Longterm effects are not significant when considering the sample of nonmigrants. Panel B shows the impacts on real income. All specifications exhibit positive impacts, especially in the short run, but also persistent in the long run. The results remain significant when selecting only non-migrants suggesting that technological innovations increased workers' income and working hours per week. This is evidence that the event constituted a positive shock on the labor market.

Table 3.5: Effects on variables of schooling and labor market - Adults in the workforce, between 20 and 50 years old and living in the rural area

\begin{tabular}{|c|c|c|c|c|c|c|}
\hline & \multicolumn{4}{|c|}{ All Sample } & \multicolumn{2}{|c|}{ No migrants } \\
\hline \multicolumn{7}{|c|}{ Panel A: Effect of work more than 39 hours per week (probit) } \\
\hline \multirow{3}{*}{ soyPOTENTIAL_1980 } & 1 & 2 & 3 & 4 & $5 a$ & $6 \mathrm{~b}$ \\
\hline & $0.139 * *$ & $0.157^{* * *}$ & $0.131^{* * *}$ & $0.154^{* * *}$ & $0.149^{* *}$ & $0.132^{* *}$ \\
\hline & $(0.054)$ & $(0.055)$ & $(0.050)$ & $(0.050)$ & $(0.063)$ & $(0.067)$ \\
\hline \multirow[t]{2}{*}{ SOyPOTENTIAL_1991 } & $0.122^{* *}$ & $0.168^{* * *}$ & $0.111^{* *}$ & $0.160^{* * *}$ & $0.105^{*}$ & 0.051 \\
\hline & $(0.052)$ & $(0.050)$ & $(0.048)$ & $(0.046)$ & $(0.057)$ & $(0.056)$ \\
\hline Observations & 46,318 & 46,318 & 42,856 & 42,856 & 13,203 & 13,075 \\
\hline \multicolumn{7}{|c|}{ Panel B: Effect on overall deflated income (log) } \\
\hline \multirow{3}{*}{ soyPOTENTIAL_1980 } & 1 & 2 & 3 & 4 & $5 \mathrm{a}$ & $6 \mathrm{~b}$ \\
\hline & $0.169^{* * *}$ & $0.169^{* * *}$ & $0.150^{* * *}$ & $0.149^{* * *}$ & $0.123^{* *}$ & $0.129^{* *}$ \\
\hline & $(0.049)$ & $(0.049)$ & $(0.046)$ & $(0.046)$ & $(0.061)$ & $(0.065)$ \\
\hline \multirow[t]{2}{*}{ SOyPOTENTIAL_1991 } & $0.145^{* * *}$ & $0.146^{* * *}$ & $0.090 * * *$ & $0.086^{* * *}$ & $0.097^{* * *}$ & $0.090 * *$ \\
\hline & $(0.034)$ & $(0.034)$ & $(0.032)$ & $(0.031)$ & $(0.037)$ & $(0.038)$ \\
\hline Observations & 263,729 & 263,729 & 254,073 & 254,073 & 97,892 & 99,025 \\
\hline R-squared & 0.033 & 0.045 & 0.051 & 0.067 & 0.059 & 0.064 \\
\hline \multirow{4}{*}{$\begin{array}{l}\text { Municipality FE } \\
\text { State x Year FE } \\
\text { Personal Characteristics } \\
\text { Family Characteristics }\end{array}$} & Yes & Yes & Yes & Yes & Yes & Yes \\
\hline & Yes & Yes & Yes & Yes & Yes & Yes \\
\hline & No & Yes & No & Yes & Yes & Yes \\
\hline & No & No & Yes & Yes & Yes & Yes \\
\hline \multicolumn{7}{|c|}{$\begin{array}{l}\text { Robust standard errors in parentheses } \\
* * * \mathrm{p}<0.01, * * \mathrm{p}<0.05, * \mathrm{p}<0.1 \\
\text { a: Individuals living in the same municipality in which they were born. } \\
\text { b: Individuals from families whose head lives in the same municipality where he/she was born. }\end{array}$} \\
\hline
\end{tabular}

Source: Census/IBGE. 


\section{7}

\section{Final Considerations}

Technological advances during the 1970s enabled soybean cultivation in Central Brazil and worked as a positive shock in the labor market. In this sense, human capital had a crucial role in the development of the sector, which was more modern and technological than previous activities. Thus, the tradeoff between entering the labor market and investing in human capital could change with the new circumstances.

This paper contributes to the literature on human capital formation, analyzing how the modernization of soybean cultivation affected outcomes of the child and adolescent labor. In the same way as entry into the labor market generates higher immediate benefits (with higher wages), returns to human capital investment may higher too. The paper initially estimates positive effects on the probability of working more than 39 hours per week and positive impacts on income, for the adult population. These results suggest that innovations worked as a shock in labor demand, and motivate the evaluation of impacts in investment in human capital by the younger population.

The empirical strategy combines the timing of the technological change with the potential gain of modernization, in order to estimate impacts on the decision between work and study for children and adolescents. The analysis focuses on two sub-samples, investigating the effects on child labor (10 to 13 years old) and adolescent labor (14 to 17 years old).

For children between 10 and 13 years old, the impacts of modernization are negative on attending school, but they are no longer significant when restricting the sample to children from non-migrant households. For adolescents between 14 and 17 years old, impacts are persistently negative and significant in all specifications. The effects on the decision to work for children and adolescents are positive on long-term work in both groups. These results suggest incentives for children and adolescents to spend less time on study and more time at work.

Looking only at working children, the effects on the probability of only work (and not study) are positive for adolescents (14 to 17 years old), but impacts are concentrated in the period closest to the shock and are not persistent in the long run.

In summary, the main results suggest that the effects of technological innovations go in the direction of an increase in work and a drop in investment in education, in a labor market with higher wages. These effects generally remain when the sample is restricted to people who live in the same place of birth (or people from families whose chief was born in the same municipality 
where lives), avoiding migration effects. It can be argued that there is a composition effect, with the possible entry into the labor market of people most likely to work for a given level of wages. However, the results for children and adolescents consider all sample (and not just those who are part of the workforce).

These results are adverse because when children or adolescents spend more time on work and less studying, a less qualified and potentially less productive population may be expected in the future. It is possible to think that investing in education at higher levels in a less sophisticated environment does not bring a return. In this case, a more significant investment in education would not be efficient, and the optimal response would be to enter the labor market in order to obtain the highest current wages. However, at basic levels of education, this hypothesis is not reasonable, and the mechanism behind these impacts seems to come from credit market failures. In the existence of credit restrictions, families may choose not to invest in education, even in a scenario of higher expected return. 


\section{4}

\section{Bibliography}

Allcott, H. and D. Keniston (2017). "Dutch disease or agglomeration? The local economic effects of natural resource booms in modern America." In: The Review of Economic Studies 85.2, pp. 695-731.

Amadeo, E. and J. M. Camargo (1996). "Instituições e o mercado de trabalho no Brasil." In: Flexibilidade do mercado de trabalho no Brasil. Rio de Janeiro: $F G V$, pp. 47-94.

Artuc, E., S. Chaudhuri, and J. McLaren (2010). "Trade shocks and labor adjustment: A structural empirical approach." In: American Economic Review 100.3, pp. 1008-45.

Assunção, J., B. Pietracci, and P. Souza (2016). "Fueling Development: Sugarcane Expansion Impacts in Brazil." In: INPUT-Iniciativa para o Uso da Terra 55.

Assunção, J., D. Szerman, and F. Costa (2016). "Efeitos locais de hidrelétricas no Brasil." In: INPUT. Incentiva para o Uso da Terra. http://www. inputbrasil. org/wp-content/uploads/2017/01/CPI_Estudo_Efeitos-Locaisde-hidreletricas_no_Brasil. pdf.

Autor, D., D. Dorn, and G.H. Hanson (2015). "Untangling trade and technology: Evidence from local labour markets." In: The Economic Journal 125.584, pp. 621-646.

Autor, D.H. (2003). "Outsourcing at Will: The Contribution of Unjust Dismissal Doctrine to the Growth of Employment Outsourcing." In: Journal of Labor Economics 21.1.

Autor, D.H., D. Dorn, G.H. Hanson, and J. Song (2014). "Trade adjustment: Worker-level evidence." In: The Quarterly Journal of Economics 129.4, pp. 1799-1860.

Baland J.and Robinson, J.A. (2000). "Is child labor inefficient?" In: journal of Political Economy 108.4, pp. 663-679.

Barros, R.P., C.H. Corseuil, and M. Foguel (2000). "Os incentivos adversos e a focalização dos programas de proteção ao trabalhador no Brasil." In: Planejamento e Políticas Públicas 22.

Bartik, T. J. (1991). "Who benefits from state and local economic development policies?" In: 
Basu, K. (1999). "Child labor: cause, consequence, and cure, with remarks on international labor standards." In: Journal of Economic literature 37.3, pp. 1083-1119.

Beegle, K., R. Dehejia, and R. Gatti (2009). "Why should we care about child labor? The education, labor market, and health consequences of child labor." In: Journal of Human Resources 44.4, pp. 871-889.

Beegle, K., R.H. Dehejia, and R. Gatti (2006). "Child labor and agricultural shocks." In: Journal of Development economics 81.1, pp. 80-96.

Benjamin, D. and F. Meza (2007). "Total Factor Productivity and Labor Reallocation: the Case of the Korean 1997 Crisis." In: Universidad Carlos III de Madrid.

Bentolila, S. and G. Bertola (1990). "Firing Costs and Labor Demand: How Bad is Eurosclerosis?" In: The Review of Economic Studies 57.3.

Bertola, G. (1991). "Labor Turnover and Average Labor Demand." In: NBER Working Papers Series 3866.

Black, D., T. McKinnish, and S. Sanders (2005). "The economic impact of the coal boom and bust." In: The Economic Journal 115.503, pp. 449-476.

Blanchard, O. and L.F. Katz (1992). "Regional Evolutions." In: Brookings Papers on Economic Activity 1.

- (1997). "What we know and don't know about the natural rate of unemployment." In: Journal of Economic Perspectives 11.1.

Boeri, T. and J.F. Jimeno (2005). "The effects of employment protection: Learning from variable enforcement." In: European Economic Review 49.8 .

Bound, J. and H.J. Holzer (2000). "Demand shifts, population adjustments, and labor market outcomes during the 1980s." In: Journal of labor Economics 18.1, pp. 20-54.

Bragança, A., J. Assunção, and C. Ferraz (2015). Technological change and labor selection in agriculture: Evidence from the brazilian soybean revolution. Tech. rep. Working Paper.

Bustos, P. (2005). "Rising wage inequality in the Argentinean manufacturing sector: the impact of trade and foreign investment on technology and skill upgrading." In: Unpub. Paper, Harvard University.

Bustos, P., B. Caprettini, and J. Ponticelli (2016). "Agricultural productivity and structural transformation: Evidence from Brazil." In: American Economic Review 106.6, pp. 1320-65.

Cahuc, P., S. Carcillo, and A. Zylberberg (2014). Labor Economics, Second Edition. MIT Press. ISBN: 9780262027700. 
Carvalho, C., R. Corbi, and R. Narita (2018). "Unintended consequences of unemployment insurance: Evidence from stricter eligibility criteria in Brazil." In: Economics Letters 162, pp. 157-161.

Chodorow-Reich, G. and J. Wieland (2016). Secular labor reallocation and business cycles. Tech. rep. National Bureau of Economic Research.

Corseuil, C. H., E. P. Ribeiro, et al. (2002). "Job and worker Flows in Brazil." In: Labor market dynamics in Brazil. Final Report, 2nd draft, Part I, Inter-American Development Bank Research Network, 11th round, FipeUSP.

Corseuil, C.H. and L. Servo (2006). "Criação, destruição e realocação de empregos no Brasil." In: IPEA.

Dix-Carneiro, R. and B.K. Kovak (2015). Trade reform and regional dynamics: Evidence from 25 years of Brazilian matched employer-employee data. The World Bank.

Doornik, B., D. Schoenherr, and J. Skrastins (2017). "Unemployment Insurance, Strategic Unemployment, and Firm ${ }_{w}$ orkerCollusion." In:

Dumas, C. (2013). "Market imperfections and child labor." In: World development 42, pp. 127-142.

Edmonds, E.V. (2007). "Child labor." In: Handbook of development economics 4, pp. 3607-3709.

Edmonds, E.V. and N. Pavcnik (2005). "Child labor in the global economy." In: Journal of Economic Perspectives 19.1, pp. 199-220.

Fallon, P. and Z. Tzannatos (1998). Child Labor. World Bank.

Fetzer, T. (2014). "Fracking growth." In: CEP Discussion Papers dp1278. Centre for Economic Performance, LSE.

Feyrer, J., E. T. Mansur, and B. Sacerdote (2017). "Geographic dispersion of economic shocks: Evidence from the fracking revolution." In: American Economic Review 107.4, pp. 1313-34.

Figueiredo, C. and N. Francis (2018). "State-dependent Adjustment Cost and Labor Dynamics in Recessions: Evidence using FGTS Policy in Brazil." In: Available at SSRN 3272449.

Foster, A.D. and M.R. Rosenzweig (1996). "Technical change and humancapital returns and investments: evidence from the green revolution." In: The American economic review, pp. 931-953.

Fraisse, H., F. Kramarz, and C. Prost (2014). "Labor Disputes and Job Flows." In: Direction des Études et Synthèses Économiques.

Gianfreda, G. and G. Vallanti (2017). "Institutions and firms adjustments: measuring the impact of courts delays on job flows and productivity." In: The Journal of Law and Economics 60.1. 
Gonzaga, G. (1998). "Rotatividade e qualidade do emprego no Brasil." In: Revista de economia politica 18.1, pp. 120-140.

- (2003). "Labor Turnover and Labor Legislation in Brazil." In: Economía 4.1 .

Greenstone, M. and E. Moretti (2003). Bidding for industrial plants: Does winning a million dollar plant increase welfare? Tech. rep. National Bureau of Economic Research.

Grootaert, C. and R. Kanbur (1995). "Child labor: A review ', Policy Research Working Paper No 1454, World Bank, Washington DC." In:

Guarcello, L., F. Mealli, and F. C. Rosati (2010). "Household vulnerability and child labor: the effect of shocks, credit rationing, and insurance." In: Journal of population economics 23.1, pp. 169-198.

Guimarães, E. N. and H. de C. Leme (2002). "Caracterização histórica e configuração espacial da estrutura produtiva do Centro-Oeste." In: NEPO/UNICAMP. Redistribuição da população e meio ambiente: São Paulo e Centro-Oeste 1, pp. 25-65.

Heckman, J.J. and C. Pagés (2004). "Law and Employment: Lessons from Latin American and the Caribbean." In: University of Chicago Press.

Hijzen, A., L. Mondauto, and S. Scarpetta (2013). "The Perverse Effects of JobSecurity Provisions on Job Security in Italy: Results from a Regression Discontinuity Design." In: IZA: Discussion Papers Series 7594.

Jacobsen, G.D. and D.P. Parker (2014). "The economic aftermath of resource booms: evidence from boomtowns in the American West." In: The Economic Journal 126.593, pp. 1092-1128.

Jacoby, H.G. (1994). "Borrowing constraints and progress through school: evidence from Peru." In: The Review of Economics and Statistics, pp. 151160.

Jacoby, H.G. and E. Skoufias (1997). "Risk, financial markets, and human capital in a developing country." In: The Review of Economic Studies 64.3, pp. 311-335.

Kiihl, R.A. and E.S. Calvo (2008). "A soja no Brasil: mais de 100 anos de história, quatro décadas de sucesso." In: Albuquerque, Ana Christina Sagebin; Silva, Aliomar Gabriel da. Agricultura tropical: quatro décadas de inovações tecnológicas, institucionais e polıticas. Brasılia: Embrapa, pp. 189-276.

Klink, C.A. and A.G. Moreira (2002). "Past and current human occupation, and land use." In: The Cerrados of Brasil: Ecology and Natural History of a Neotropical Savanna, pp. 69-90. 
Krueger, A.B. (1996). Observations on international labor standards and trade. Tech. rep. National Bureau of Economic Research.

Kugler, A. and G. Pica (2008). "Effects of employment protection on worker and job flows: Evidence from the 1990 Italian reform." In: Labor Economics 15.1 .

Kugler, A. and G. Saint-Paul (2004). "How Do Firing Costs Affect Worker Flows in a World with Adverse Selection?" In: Journal of Labor Economics 22.3 .

Kugler, A.D. (1999). "The Impact of Firing Costs on Turnover and Unemployment: Evidence from the Colombian Labour Market Reform." In: International Tax and Public Finance 6.3.

Laszlo, S. (2008). "Education, labor supply, and market development in rural Peru." In: World Development 36.11, pp. 2421-2439.

Lazear, E. (1990). "Job security provisions and employment." In: Quarterly Journal of Economics 105.3.

Leonardi, M. and G. Pica (2013). "Who pays for it? The heterogeneous wage effects of employment protection legislation." In: The Economic Journal 123.

Lockheed, M.E., T. Jamison, and L.J. Lau (1980). "Farmer education and farm efficiency: A survey." In: Economic development and cultural change 29.1, pp. $37-76$.

Macedo, R. (1985). "Diferenciais de salários entre empresas privadas e estatais no Brasil." In: Revista Brasileira de Economia 39.4, pp. 437-448.

Malcomson, J. (1999). "Individual employment contracts." In: The Handbook of Labor Economics 3.

Marchand, J. (2012). "Local labor market impacts of energy boom-bust-boom in Western Canada." In: Journal of Urban Economics 71.1, pp. 165-174.

Marinescu, I. (2009). "Job Security Legislation and Job Duration: Evidence from the United Kingdom." In: Journal of Labor Economics 27.3.

Menezes-Filho, N. and R. Fernandes (2004). "The costs of displacement in Brazil." In: XXVI Encontro Brasileiro de Ecomometria, pp. 8-10.

Menezes-Filho, N. and M.A. Muendler (2011). Labor reallocation in response to trade reform. Tech. rep. National Bureau of Economic Research.

Michaels, G. (2010). "The long term consequences of resource-based specialisation." In: The Economic Journal 121.551, pp. 31-57.

O'Donnell, O., F.C. Rosati, and E. Van Doorslaer (2005). "Health effects of child work: Evidence from rural Vietnam." In: Journal of Population Economics 18.3, pp. 437-467. 
Pereira, M.C. et al. (2007). "A Expansão da Cadeia Sucroalcooleira em Mato Grosso do Sul." In: XLV Congresso da Sociedade Brasileira de Economia, Administração e Sociologia Rual.

Pinto, R. de C.C. (2015). "Three essays on labor market institutions and labor turnover in Brazil." In: Thesis presented to the Programa de Pós-graduação em Economia of PUC-Rio.

Pissarides, K. (2010). "Why Do Firms Offer 'Employment Protection?" In: Economica 77.308 .

Psacharopoulos, G. and H.A. Patrinos (2004). "Returns to investment in education: a further update." In: Education economics 12.2, pp. 111134 .

Ranjan, P. (2001). "Credit constraints and the phenomenon of child labor." In: Journal of development economics 64.1, pp. 81-102.

Rosenzweig, M.R. (1995). "Why are there returns to schooling?" In: The American Economic Review 85.2, pp. 153-158.

Saks, R. and A. Wozniak (2011). "Labor reallocation over the business cycle: New evidence from internal migration." In: Journal of Labor Economics 29.4, pp. 697-739.

Sim, A., D. Suryadarma, and A. Suryahadi (2017). "The Consequences of Child Market Work on the Growth of Human Capital." In: World Development 91, pp. 144-155.

Spehar, C.R. (1995). "Impact of strategic genes in soybean on agricultural development in the Brazilian tropical savannahs." In: Field Crops Research 41.3, pp. 141-146.

Strauss, J. et al. (1991). "Role of education and extension in the adoption of technology: a study of upland rice and soybean farmers in Central-West Brazil." In: Agricultural Economics 5.4, pp. 341-359.

Tao Yang, D. (1997). "Education and off-farm work." In: Economic development and cultural change 45.3, pp. 613-632.

Walker, W. R. (2011). "Environmental regulation and labor reallocation: Evidence from the Clean Air Act." In: American Economic Review 101.3, pp. $442-47$.

Weber, J. G. (2014). "A decade of natural gas development: The makings of a resource curse?" In: Resource and Energy Economics 37, pp. 168-183.

Wolff, F.C. et al. (2008). "Evidence on the impact of child labor on child health in Indonesia, 1993-2000." In: Economics \& Human Biology 6.1, pp. 143169. 